\title{
Zur Biogeographie des Südwestatlantik mit besonderer Berücksichtigung der Seeanemonen (Coelenterata: Actiniaria)*
}

\author{
Karin Riemann-Zürneck ${ }^{* *}$ \\ Biologische Anstalt Helgoland; Notkestr. 31, D-2000 Hamburg 52 \\ und \\ Alfred-Wegener-Institut für Polar- und Meeresforschung; Am Handelshafen 12, \\ D-2850 Bremerhaven, Bundesrepublik Deutschland * *
}

\begin{abstract}
On the biogeography of the southwest Atlantic with special reference to the sea anemones (Coelenterata: Actiniaria). Extensive sampling of benthos by F.R.V. "Walther Herwig" $(1966,1970 / 71,1978)$ covering the continental shelf of Argentina yielded some 1000 sea anemone specimens (19 species). The distribution patterns of the sublittoral and archibenthal species are analysed and compared with the rather scanty and controversial hydrographical information available. Species with discontinuous distribution along the continental shelf edge are believed to indicate discontinuous yet relatively stable oceanographic conditions within the depth concerned. The archibenthal "Challenger Terrace", located immediately near and beneath the subtropical convergence, harbours a peculiar faunal assemblage of partly subantarctic/antarctic character and partly consisting of species which seem to be typical for permanent hydrographic fronts. In addition, the study includes a new taxonomic combination: Bolocera tuediae subsp. kerguelensis (Studer, 1879) nov. comb.
\end{abstract}

\section{EINLEITUNG}

Das südwestatlantische Schelfgebiet zwischen Uruguay und Feuerland wurde seit der historischen Reise der "Challenger" (1872-1876) mehrfach von Forschungsschiffen bereist, ohne daß jedoch aus diesem etwa eine Million Quadratkilometer großen Seegebiet bedeutsame größere Aufsammlungen von Seeanemonen bekanntgeworden wären. Zumeist befanden sich die Schiffe auf der Durchreise zu anderen Untersuchungsgebieten, oder sie berührten den Südwestatlantik nur bei der Abgrenzung benachbarter Regionen, so daß die im Südwestatlantik gesammelten Aktinien Gelegenheitsfunde blieben (Studer, 1879; McMurrich, 1893, 1904; Carlgren, 1899, 1927, 1939, 1959; Stephenson, 1918; Pax, 1922, 1923, 1926). Das bisher wohl umfangreichste InvertebratenMaterial überhaupt wurde im Südwestatlantik von den englischen Forschungsschiffen "William Scoresby" und "Discovery" 1926 bis 1932 gesammelt (vgl. Hart, 1946; pp. 233,

- Ergebnisse der Forschungsreisen des FFS "Walther Herwig" nach Südamerika Nr. 66

- Mitglied der Taxonomischen Arbeitsgruppe

-. Anschrift der Autorin: Am Handelshafen 12, D-2850 Bremerhaven

(c) Biologische Anstalt Helgoland, Hamburg 
$235 \mathrm{ff}$ ); nach Auskunft von P. Cornelius (British Museum) existieren von den nicht bearbeiteten Aktinien nur noch 3 Proben.

So blieb, was die Seeanemonen anbetrifft, das 1876 gesammelte und 1882 und 1888 von R. Hertwig beschriebene "Challenger" Material das wissenschaftlich ergiebigste dieser Region. Die Bearbeitung der Challenger-Aktinien stellt den Beginn der anatomisch-histologisch ausgerichteten Taxonomie der Aktinien dar (vgl. Riemann-Zürneck, $1973 ;$ p. 275). Auf tiergeographische Aspekte wurde in dieser, wie auch in späteren Aktinien-Bearbeitungen aus dieser Region kaum eingegangen; wichtig aber ist die von Hertwig (1888; p. 26) ausgesprochene Vermutung, daß eine am Schelfhang vor der La Plata-Mündung gefundene Seeanemone möglicherweise identisch sei mit einer etwa $2000 \mathrm{~km}$ entfernt vor Südchile gefundenen Art. Diese Annahme wurde durch Funde von "Walther Herwig" nicht nur bestätigt, sondern es wurde auch deutlich, daß dem ersten Fundort (Challenger-Station 320: Archibenthal in $1097 \mathrm{~m}$ Tiefe außerhalb der Mündung des La Plata) eine ganz besondere tiergeographische Bedeutung zukommt, da viele der damals dort gesammelten Invertebraten später in antarktischen Regionen wiedergefunden wurden (Echinodermen, Mollusken, Polychaeten, Cephalopoden, Siphonophoren, Stylasterinen und Scleractinien).

Daß im Südwestatlantik als dem kältesten Sektor der Subantarktis antarktische Faunenelemente vorhanden seien, wurde von vielen Taxonomen festgestellt $(\mathrm{z}$. B. Lohmann \& Hentschel, 1939; Hastings, 1943; Bartsch, 1982); viel weniger beachtet wurden dagegen die unzweifelhaft ebenfalls vorhandenen Warmwasser-Elemente der Fauna, auf die vor allem Planktologen und Ichthyologen (z. B. Balech, 1968; Bé, 1969; E. Boltovskoy, 1971; Ehrich, 1980) aufmerksam machten. In einigen Gebieten scheinen sich die Berichte zu widersprechen, denn dort wurden sowohl kälteliebende wie wärmeliebende Meeresorganismen gefunden (Nordargentinien, Falklands, Drakestraße).

In den Jahren 1966, 1968, 1970/71 und 1978 sammelte das Fischereiforschungsschiff "Walther Herwig" an einem dichten Probennetz Benthosorganismen mit der Absicht, die demersale Fischfauna qualitativ und quantitativ zu verschiedenen Jahreszeiten zu erfassen. Als Beifang wurden hierbei etwa 1000 Seeanemonen an 345 Stationen im Südwestatlantik aus dem Tiefenbereich zwischen 90 und $1220 \mathrm{~m}$ gesammelt, wovon die Winter-Expedition 1966 (6. Juni bis 3. August) und die Sommer-Expedition 1970/71 (30. Dezember bis 27. Februar) das für die taxonomische und tiergeographische Bearbeitung wertvollste Material lieferten. Fünfzehn der insgesamt 19 dort gefundenen Seeanemonen-Arten wurden bisher taxonomisch bearbeitet (Riemann-Zürneck, 1973, $1975 \mathrm{a}$, $1975 \mathrm{~b}, 1978,1980)$. Aus dem südlichsten Teil des Untersuchungsgebietes stand außerdem Material von amerikanischen Forschungsschiffen zur Verfügung.

Die Seeanemonen sind als auffälliges und häufiges Faunenelement gut geeignet für eine tiergeographische Analyse des Sublitorals und Archibenthals dieser ausgedehnten Region. Die sessile Lebensweise und das für Invertebraten hohe Lebensalter von GroßAktinien ( 50 bis 210 Jahre; Ottaway, 1980), verleihen ihnen darüber hinaus die Funktion von Langzeit-Monitoren. Für einige sublitorale Arten ist bekannt, daß ihre Verbreitung eng mit den herrschenden Temperatur-Verhältnissen korreliert ist (Sassaman \& Mangum, 1970).

Bisher waren auf der Aktinien-Fauna basierende, tiergeographische Bearbeitungen wenig erfolgreich, obwohl in mehreren Arbeiten über Charakter und Beziehungen subantarktischer und antarktischer Seeanemonen spekuliert wurde (McMurrich, 1893; 


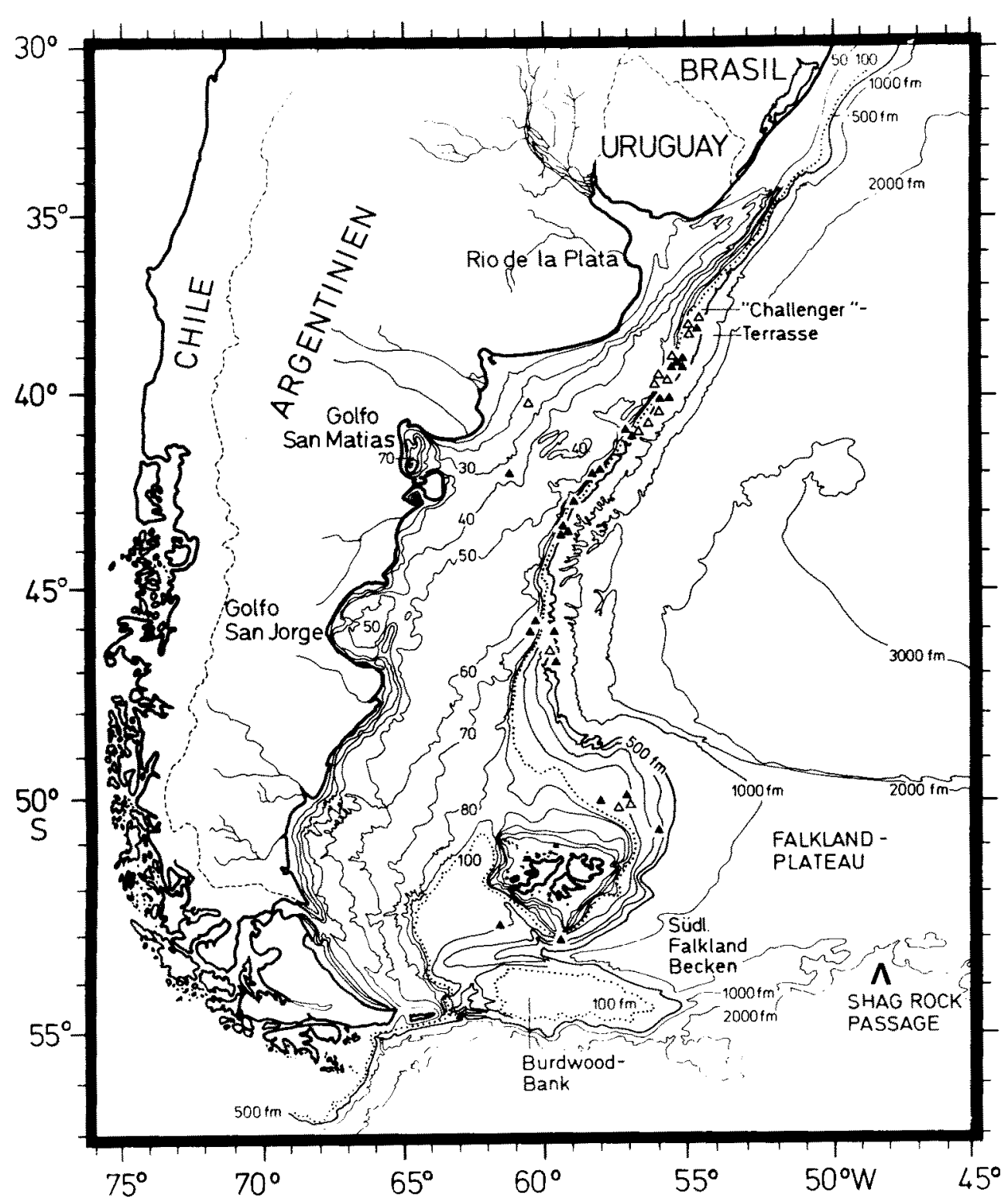

Abb. 1. A Fundorte der Seeanemone Isosicyonis alba. Die Art kommt ausschließlich auf dem Gehãuse der lebenden Schnecke Provocator corderoi vor. $\triangle$ Fundorte der Schnecke Provocator corderoi ohne Seeanemonen (nach Kaiser, 1977a). Beide Arten werden als Indikator-Organismen für subantarktische Lebensbedingungen im Benthal angesehen; sie kommen auch an der Westküste der antarktischen Halbinsel vor 
Carlgren, 1899; Pax, 1923, 1926; Carlgren, 1927, 1928). Die Kontroversen von Pax und Carlgren zeigen, wie problematisch die Verwendung dieser taxonomisch noch nicht konsolidierten Tiergruppe für tiergeographische Zwecke war. Häufig ließ die geringe Qualität und Quantität des Materials eine befriedigende taxonomische und tiergeographische Bearbeitung nicht zu. Biogeographische Fehlinterpretationen resultierten aus dem Vergleich von sich nicht entsprechenden Tiefenzonen, ein Fehler, der oft ebenfalls durch das zur Verfügung stehende beschränkte Material bedingt war.

Noch immer sind unsere Kenntnisse der subantarktisch-südamerikanischen wie auch der antarktischen Aktinien für eine Gesamtanalyse nicht ausreichend, jedoch erlaubt das von F.F.S. "Walther Herwig" und von amerikanischen Forschungsschiffen gesammelte Material (Dunn, 1983, 1984) die Diskussion der Verbreitungsbilder einiger für diese Region typischer Seeanemonen. Neben einigen fast überall angetroffenen Arten gruppieren sich andere in unterschiedlich langen und breiten Streifen entlang den Isobathen nahe der Schelfkante. Einige seltenere Arten wurden allerdings nur in weit auseinanderliegenden Gebieten gefunden, was jedoch mit der insgesamt geringeren Sammelaktivität an und unterhalb der Schelfkante erklärt werden könnte.

Anlaß zu einer genaueren Analyse einiger Verbreitungsmuster war Isosicyonis alba (Studer, 1879), eine den Actiniiden zugeordnete Seeanemone (vgl. Riemann-Zürneck, 1980 ; p. 28), von der insgesamt 45 Exemplare gesammelt werden konnten. Biologisch zeichnet sich die Art dadurch aus, daß sie offenbar obligatorisch an eine lebende Gehäuseschnecke, Provocator corderoi gebunden ist, die auch ohne Aktinie vorkommt (Kaiser, 1977 a). Wenn man die 16 Fundorte der Schnecke und die 24 Fundorte beider Partner in eine Karte einzeichnet, so erkennt man, daß sie sich in 5 disjunkten Gebieten entlang der Schelfkante gruppieren (Abb. 1), mit fundortfreien Abschnitten von 100 bis $500 \mathrm{~km}$ Breite.

Ahnliche Verbreitungsmuster wurden auch bei anderen südwestatlantischen Benthostieren festgestellt (Hedgpeth, 1969; Moyano, 1982b; Cairns, 1982, 1983). Noch erstaunlicher als die analoge Verbreitung benthischer Tiere, die auch durch Schwerpunkte bei der Probennahme entstehen kann, ist die ebenfalls zu beobachtende Ähnlichkeit der Verbreitungsmuster einiger pelagischer Organismen; (Fische: Ehrich, 1980; Hart, 1946; die Siphonophore Rhodalia miranda Haeckel, 1888 nach eigenen Ergebnissen; Hydromeduse: Thiel, 1935; Cephalopoden: Schöne, 1974; Dinoflagellaten: Balech, 1968; Foraminiferen: Echols \& Kennett, 1973; Heron-Allen \& Earland, 1932). Selbst einige Seevögel scheinen diesem Muster zu folgen (Hedgpeth, 1969; Shuntov et al., 1982).

Dieses offenbar reale Bild der disjunkten Verbreitung vieler mariner Organismen im Südwestatlantik steht im Widerspruch zu der herrschenden Ansicht (z. B. Boltovskoy, 1959), daß der äußere argentinische Schelf in ganzer Länge vom sogenannten "Falkland-Strom" begleitet wird. Dieser Strom soll vom Kap-Horn-Strom in der DrakePassage fast rechtwinklig abzweigen und sich zwischen Feuerland und den FalklandInseln nach Norden wenden. Nach dieser Beschreibung müßten zumindest planktisch lebende Organismen gleichmäßiger verteilt sein und sich nicht wie das Benthos auf bestimmte Abschnitte des Schelfs und der Schelfkante beschränken.

In der vorliegenden tiergeographischen Analyse des südwestatlantischen Sublitorals und Archibenthals soll daher versucht werden, mit Hilfe der Verbreitungsmuster von Aktinien und anderen Benthostieren Indizien für bisher nicht oder nur wenig 
bekannte ozeanographische Bedingungen und Vorgänge an der argentinischen Schelfkante zu sammeln. Wie schon weiter oben festgestellt, empfehlen sich Aktinien durch ihre sessile Lebensweise und ihr vergleichsweise hohes Lebensalter als Indikator-Arten für stationäre und langfristig wirksame ozeanographische Vorgänge. Da viele Seeanemonen auch über freie, pelagisch oder demersal lebende Entwicklungsstadien verfügen, können auch Rückschlüsse auf Verbreitungsmechanismen gezogen werden.

\section{PHYSIOGRAPHIE DES SÜDWESTATLANTIK}

Bis in die jüngste Zeit hinein galt der gesamte argentinische Schelf als topographisch und hydrographisch besonders eintönig; auch moderne Publikationen (Ekman, 1967; Briggs, 1974; D. Boltovskoy, 1981) vermitteln noch immer das Bild eines riesigen Gebietes mit sanft undulierenden Isobathen, dessen einzige Besonderheit der von Kap Horn nach Norden ziehende "Falkland-Strom" ist. Die Ansichten über diesen seit Klähn (1911) häufig erwähnten Strom divergieren indessen so stark (E. Boltovskoy, 1959; D. Boltovskoy, 1981; Gordon \& Goldberg, 1970; Lonardi \& Ewing, 1971; Krepper \& Rivas, 1979; Legeckis \& Gordon, 1982), daß auch er inzwischen nicht mehr als wohlbekanntes physiographisches Merkmal der Region angesehen werden kann.

Nur ganz wenige biogeographisch arbeitende Autoren weisen darauf hin, daß einige der an der argentinischen Schelfkante vorkommenden Arten und Lebensgemeinschaften so diskontinuierlich verbreitet sind, daß dies nicht mit den "einfachen hydrographischen Verhältnissen" eines von Süd nach Nord die Schelfkante begleitenden Stromes erklärt werden könne (Rayner, 1935; Hart, 1946; Lorenz, 1979). Allerdings waren die Benthos-Aufsammlungen an und unter der argentinischen Schelfkante bisher so gering, daß erst durch das Material der "Walther-Herwig"-Reisen solche Verbreitungsbilder bei Benthostieren dieser Tiefenzone verläßlich bestätigt werden konnten.

Leider gibt es keine Kompilation der hydrographischen Daten im Benthal des äußeren Schelfs und oberen Kontinentalhanges, die es dem Biologen erlauben, sich ein Bild von den dort herrschenden Lebensbedingungen zu machen. Eine Kompilation und Revision der hydrographischen Kenntnisse erscheint um so dringlicher, als die inzwischen bekanntgewordenen topographischen Verhältnisse am argentinischen Schelfhang (Lonardi \& Ewing, 1971) bisher unbekannte Wasserbewegungen vermuten lassen, die in Wechselbeziehung zu den dort vorgefundenen Canyon-Systemen stehen.

Die beiden folgenden hydrographischen Kapitel, die dem tiergeographischen Teil dieser Arbeit vorangestellt sind, sollen einen Uberblick über die hydrographischen Bedingungen in den hier interessierenden Lebensräumen geben. Besondere Beachtung finden dabei Gebiete mit Temperatur-Anomalien, deren Temperaturen zeitweise oder immer von der durch geographische Breite und Wassertiefe bestimmten Norm abweichen. Wie Shuntov et al. (1982) betonen, sind Temperatur-Anomalien für die Verbreitung mariner Tiere wichtiger als die absoluten Temperaturen. Die zugrunde gelegten bathymetrischen Karten, auf denen die Tiefenlinien in englischen Faden eingezeichnet sind, wurden Lonardi \& Ewing (1971) entnommen. Obwohl es den betreffenden Ausschnitt auch in Meter-Angaben gibt (GEBCO-Chart No. 5.12 von 1978 und GEBCOChart 5.16 von 1981), wird im folgenden die detailreichere Original-Karte wiedergegeben. 


\section{Topographie und Sedimentverteilung}

(a) Schelf (Abb. 1). Der argentinische Schelf ist einer der ausgedehntesten und flachsten der Erde. Seine Breite variiert zwischen einigen Kilometern südlich der Staaten-Insel und 1250 Kilometern bei $51^{\circ} \mathrm{S}$, wo er die Falkland-Inseln einschließt; seine Gesamtfläche beträgt etwa 1 Million Quadratkilometer (Lonardi \& Ewing, 1971). Charakteristisch für die gesamte Region ist die Anwesenheit gewaltiger Sand- und Schlickmassen (Mathews, 1934). Sowohl auf dem Schelf wie auch entlang des Kontinentalsokkels wird ein Sedimenttransport von Süden nach Norden angenommen (Ewing \& Lonardi, 1971).

Die Schlickgebiete am Ausfluß des La Plata und innerhalb des Golfo San Jorge sind von gröberem Material wie Kies und Schill begrenzt. Grobes Sediment, Schill und Korallen-Bruchstücke finden sich auch bei $60^{\circ} \mathrm{W}$ auf der Burdwood-Bank, im Nordosten der Staaten-Insel, um die Falkland-Inseln, am südlichen Auslaß der Magellan-Straße, an der Schelfkante bei $47^{\circ} 30^{\prime} \mathrm{S}$ und eingestreut in die nördlichen Sand- und Schlickgebiete (Mathews, 1934; Servicio de Hidrografia Naval, 1974).

Eine Besonderheit der Schelftopographie ist, daß sich im Süden die Isobathen nahe der Küste drängen, im Norden dagegen an der Schelfkante: Die 50-Faden-Linie $(91,5 \mathrm{~m})$ löst sich bei etwa $47^{\circ} \mathrm{S}$ von der Küste, überquert den Schelf diagonal und erreicht bei $43^{\circ} \mathrm{S}$ die Schelfkante, von der sie sich nur mit 2 Einbuchtungen wieder löst. Die Schelfkante liegt demnach im Norden bei $100 \mathrm{~m}$ Tiefe, im Süden und um die FalklandInseln jedoch zwischen 200 und $500 \mathrm{~m}$ Tiefe. Im Süden der Falklands, nur durch das tiefe "Südliche Falkland-Becken" (Falkland Southern Trough) getrennt, liegt die Burdwood-Bank mit etwa 25000 Quadratkilometern Meeresboden von weniger als $200 \mathrm{~m}$ Tiefe. Südlich von Feuerland erweitert sich der Schelf noch einmal, wobei die Schelfkante bei $180 \mathrm{~m}$ Tiefe liegt.

Von den an der Küste gelegenen Golfen und Buchten (Bahia Blanca, Golfo San Matias, Golfo Nuevo, Golfo San Jorge und Bahia Grande) sind die drei mittleren tiefer als der sie einschließende Schelf, Golfo San Matias und Golfo Nuevo um $70 \mathrm{~m}$, Golfo San Jorge um $20 \mathrm{~m}$.

Das Relief des gesamten Schelfs ist sehr gering; die mittlere Tiefe steigt von $130 \mathrm{~m}$ im Süden auf 35 bis $40 \mathrm{~m}$ im Norden an. Einige sanfte, 10 bis $20 \mathrm{~m}$ hohe Sedimentrücken liegen bei $42^{\circ} \mathrm{S}$ in der Mitte zwischen den beiden Einbuchtungen der 50-FadenIsobathe.

(b) Kont in e n t a la b h a ng (Abb. 2). Im Gegensatz zu den geringen topographischen Gradienten des Schelfs steht der argentinische Kontinentalabhang, der von etwa 70 Canyons zerschnitten ist, wovon zwei, der "Ameghino Transverse Canyon" und der "Almirante Brown Transverse Canyon", parallel zu den Isobathen verlaufen. Die stärkste Erosion findet sich zwischen $42^{\circ}$ und $46^{\circ}$ Süd, wo die etwa 30 Canyons des Ameghino-Canyon-Systems liegen. Der "Ameghino" selbst wurde erst im Jahre 1960 entdeckt; seine Wände sind mit $700 \mathrm{~m}$ doppelt so hoch wie die irgendeines anderen bekannten Canyon (Lonardi \& Ewing, 1971).

Neben dem Ameghino-Canyon-System gibt es noch drei andere Canyon-Systeme (Lonardi \& Ewing, 1971; Fig. 7); unter tiergeographischen Aspekten sind dabei die folgenden Fakten von Bedeutung:

Das Rio-de-la-Plata-Canyon-System umfaßt 12 Canyons auf einem Abschnitt von 80 Seemeilen, flankiert von Zonen, die auffallend frei von Erosion sind. Den südlichen 


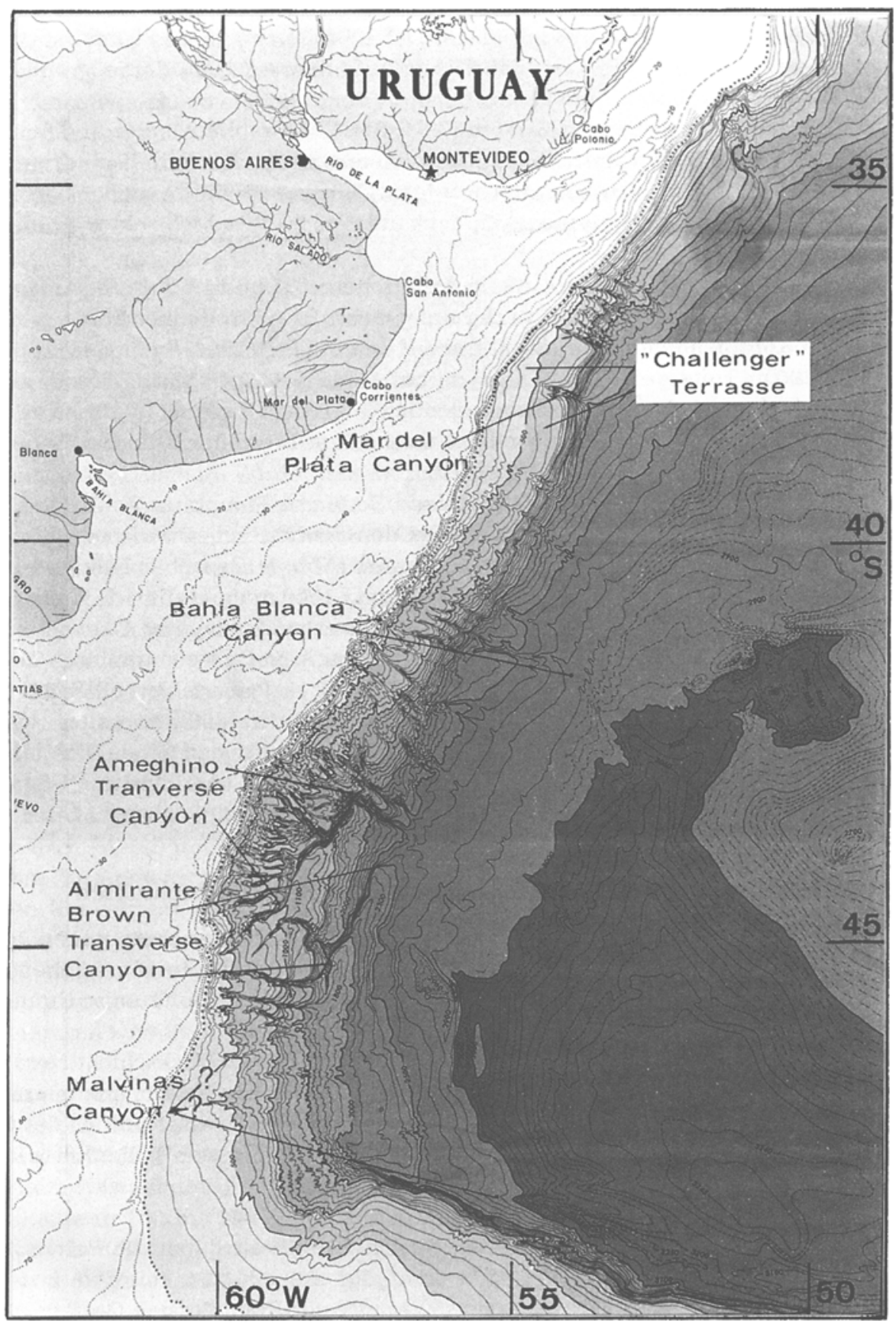

Abb. 2. Topographie des argentinischen Kontinentalabhanges (nach Ewing \& Lonardi, 1971; Tiefe in englischen Faden; 1 fathom $=1,829 \mathrm{~m}$ ) 
Anschluß bildet die "Terrasse", eine Stufe im Kontinentalabhang, die besonders deutlich zwischen $37^{\circ}$ und $39^{\circ}$ Süd ausgebildet ist, eine Breite von 35 bis $70 \mathrm{~km}$ hat und die Tiefenzone von 800 bis $1300 \mathrm{~m}$ umfaßt. Diese Stufe nenne ich im tiergeographischen Teil "Challenger-Terrasse" (Abb. 2).

Das Colorado-Negro-Canyon-System $\left(39^{\circ} \mathrm{S}\right.$ bis $\left.42^{\circ} \mathrm{S}\right)$ schließt unter anderem den Bahia-Blanca-Canyon ein, der nicht nur besonders weit in den Schelf eindringt (bei etwa $41^{\circ} \mathrm{S}$ ), sondern der auch einer der wenigen Canyons ist, die in großen Tiefen am Kontinentalsockel und im Tiefseebecken noch als topographische Struktur zu identifizieren sind.

Das Patagonia-Canyon-System, das sich zwischen $46^{\circ} \mathrm{S}$ und $49^{\circ} \mathrm{S}$ an das AmeghinoSystem anschließt, ist noch relativ wenig untersucht. Es gibt offenbar keine größeren Canyons am Kontinentalabhang, jedoch sei auf den bei Lonardi \& Ewing $(1971 ;$ p. 103 , Fig. 8) in $2200 \mathrm{~m}$ Tiefe gefundenen Canyon bei $46^{\circ} 45^{\prime} \mathrm{S}$ hingewiesen, der vermutlich mit dem tiefer am Kontinentalsockel liegenden Malvinas-Canyon identisch ist. Der Kontinentalabhang des Patagonia-Systems zeigt kaum Erosionsspuren, im Gegensatz zum Kontinentalsockel, der stark erodiert ist.

Das "Südliche Falkland-Becken" (Falkland Southern Trough) ist ein in West-OstRichtung verlaufendes Tiefwasserbecken, das den Scotia-Rücken zwischen Südgeorgien und Staaten-Insel vom Falkland-Plateau trennt (Abb. 1). Zwischen Falkland-Inseln und Burdwood-Bank bei $60^{\circ} \mathrm{W}$ hat es eine Tiefe von $1000 \mathrm{~m}$ und teilt sich in eine nach Westen auslaufende Bucht und in einen nach Nordwesten gerichteten Canyon.

Der Scotia-Rücken hat an 3 Stellen hydrographisch und tiergeographisch bedeutsame Durchlässe: Die wichtigste Lücke ist die "Shag-Rock-Passage" bei $53^{\circ} \mathrm{S}$ und $48^{\circ} \mathrm{W}$ (bis $3000 \mathrm{~m}$ tief und etwa $300 \mathrm{~km}$ breit). Eine ebenfalls etwa $300 \mathrm{~km}$ breite, aber nur $1600 \mathrm{~m}$ tiefe Lücke befindet sich östlich der Burdwood-Bank, und schließlich ist noch der etwa $150 \mathrm{~km}$ breite Durchlaß zwischen Staaten-Insel und Burdwood-Bank zu nennen, in dem jedoch nur ein schmaler Canyon Tiefen um $400 \mathrm{~m}$ erreicht (Abb. 3).

\section{Hydrographie des Schelfs und der oberen Wasserschichten}

Die Gezeiten erreichen in den küstennahen Meeresbuchten Amplituden bis zu 9 Metern mit Gezeitenströmen, die auch das Sublitoral beeinflussen können. Geschwindigkeiten bis 5 Knoten wurden beobachtet; die Hauptausbreitungsrichtung der Gezeitenwelle ist Süd (Brandhorst \& Castello, 1971).

Im übrigen ist die vorherrschende Bewegungsrichtung der Deckschicht Nord oder Nordost (E. Boltovskoy, 1968), entsprechend den in diesen Breiten dominierenden Westwinden; dies gilt auch für die relativ salzarmen Küstengewässer südlich des Golfo San Jorge. Stationäre wie auch ephemer auftretende Auftriebszonen an der Küste lassen Querzirkulationen unter der Oberflächenschicht vermuten (Brandhorst \& Castello, 1971).

Das Oberwasser der Magellan-Straße, dessen Salzgehalt durch die Beimischung kontinentalen Wassers unter $32,5 \%$ sinkt, vereinigt sich offenbar mit dem zwischen Feuerland und Staaten-Insel eindringenden Stromband (Brandhorst \& Castello, 1971; Fig. 16), dessen nicht so stark herabgesetzter Salzgehalt $(33,5 \%)$ auf Wasser aus den pazifischen Kanälè Feuerlands hindeutet. Das so entstandene Salzgehalts-Minimum, das im Süden nur die Oberflächenschicht betrifft, ist ein sehr beständiges und typisches 
Merkmal der argentinischen Küstengewässer (Brandhorst \& Castello, 1971; Lusquinos \& Valdez, 1971; Krepper \& Rivas, 1979). Es läßt sich im Winter bis in die La-Plata-Region verfolgen. Die Stabilität dieses Salzgehalts-Minimums über so weite Strecken hinweg setzt einen ausreichend starken und stabilen Strom voraus. Brandhorst \& Castello (1971) nennen diesen Strom "Patagonischer Strom" und zeigen, daß er sich im Süden zunächst nahe der Küste entlang der 40-Meter-Linie hält, am südlichen Rand des Golfo San Jorge die Küste mit der 50-Meter-Linie verläßt, wo er im Sommer an der Ausbildung einer kräftigen Sprungschicht zwischen $45^{\circ} \mathrm{S}$ und $41^{\circ} \mathrm{S}$ beteiligt ist (vgl. Stehman \& Lenz, 1972).

Diese Sprungschicht begrenzt im Südsommer das warme Oberflächen- und Küstenwasser nördlich des 45. Breitengrades gegen das ganzjährig kühle, das dem äußeren Schelf aufliegt und das hohe Anteile subantarktischen Wassers führt. So betrug die Temperatur-Differenz zwischen Oberflächen- und Bodenwasser im Frühsommer beispielsweise $9^{\circ} \mathrm{C}$ ("Walther-Herwig"-Reise 36, Januar 1971).

Das warme Wasser kann im Sommer an der Oberfläche küstenparallel bis $48^{\circ} \mathrm{S}$ vordringen, und auch im Winter ist sein Einfluß in den Golfen wahrnehmbar, wo an der Oberfläche $10^{\circ} \mathrm{C}$ nicht unterschritten werden (Stehman \& Lenz, 1972; p. 194) und am Boden die Temperaturen zwischen $8,9^{\circ} \mathrm{C}$ (Golfo San Jorge) und $11^{\circ} \mathrm{C}$ (Golfo San Matias) liegen nach Messungen an den Stationen 371 und 381 der "Walther Herwig" 1966. Die ganzjährig hohen Temperaturen verdankt dieser Wasserkörper dem Brasilstrom, der, aus äquatorialen Regionen kommend vor Uruguay auf entgegengesetzt sich bewegende kalte Wassermassen trifft, wobei ein oberflächlicher Ast im Südsommer die nordargentinische Küstenregion in der beschriebenen Weise beeinflußt, während sich die Hauptmasse des Brasilstromes nach Osten wendet (Balech, 1964; p. 109; Brandhorst \& Castello, 1971; p. 21; Legeckis \& Gordon, 1982; p. 285).

Insgesamt ist dieser küstenparallele Streifen zwischen Mar del Plata $\left(38^{\circ} \mathrm{S}\right)$ und Golfo San Jorge $\left(48^{\circ} \mathrm{S}\right)$ den stärksten hydrographischen Veränderungen ausgesetzt, die aperiodisch (Wind) und periodisch (Gezeiten, Jahreszeiten) auftreten können.

Den Zusammenschluß der beiden so verschiedenen Wassermassen an der "Subtropischen Konvergenz" darf man sich nach Deacon (1963; p. 261) und Lenz (1975; p. 6) nicht als eine relativ stabile Linie vorstellen, sondern als ein ziemlich weiträumiges Gebiet, dessen Grenzen jahreszeitlich variieren und über das sich scharfe Fronten hinwegbewegen. Die Grenzen dieses Gebietes lassen sich aus Karten der Oberflächentemperaturen zu verschiedenen Jahreszeiten ablesen (Gordon \& Molinelli, 1982; Plates 7 bis 10 ).

An der argentinischen Schelfkante ist demgegenüber die subtropische Konvergenz sehr wohl als Linie oder Front ausgebildet, die das ganze Jahr über ziemlich stationär ist (Lusquinos, 1966; Fig. 4 und 5; Brandhorst \& Castello, 1971; Hubold, 1980b; p. 39).

Allem Anschein nach ebenfalls ganzjährig stabil sind die Temperaturen nahe der Schelfkante in 100 bis $200 \mathrm{~m}$ Tiefe in einem Streifen zwischen subtropischer Konvergenz und dem Norden der Falkland-Inseln (Daten von 'Walther Herwig" 1966, 1970/71, 1978 und Kaiyu Maru 1969/70), Möglicherweise werden diese stabilen und für den südlichen Teil auch relativ hohen Temperaturen verursacht von einem südwärts gerichteten Unterstrom, dessen Ursprung Deacon (zuletzt 1982; p. 6) nördlich der subtropischen Konvergenz an der dortigen Windgrenze vermutet.

Die Region südöstlich der subtropischen Konvergenz hat eine negative Anomalie 
der Oberflächentemperaturen von $-3^{\circ} \mathrm{C}$. Eisberge erreichen hier noch gelegentlich den 37. Breitengrad (Schott, 1942). Das Auftreten von extrem tiefen Temperaturen nahe der subtropischen Konvergenz ließ Hentschel (1936; p. 276) diese Region als nördliche Verlagerung der Polarfront ansehen. Korrekter ist wohl die Beschreibung von Schemainda (1980; p. 116), der dieses Gebiet, in dem "Wassermassen subtropischen und subantarktischen Ursprungs in meridionalen Streifen nebeneinanderliegen," als eine Verschiebung des gesamten ozeanischen Aufbaus aus der normalerweise zonalen Richtung der Grenzzone ansieht (siehe auch Shuntov et al., 1982; p. 345).

Das Kaltwassergebiet südöstlich des La-Plata-Deltas ist ein Phänomen, das schon die Handelsschiffahrt im vergangenen Jahrhundert kannte (Klähn, 1911). Klähn zitiert Krümmel (1882), der diese Erscheinung als einen "Teil des Falkland-Stromes ansieht, welcher entlang des ganzen südamerikanischen Küstensaumes ... bis zur Westkante des Brasilstromes dahinzieht". Klähn fährt fort (p. 651): "Das Gebiet des besonders kalten Falklandstromwassers liegt also von $35^{\circ}$ bis $40^{\circ}$ südlicher Breite zu beiden Seiten der Meerestiefenlinie von $200 \mathrm{~m}$. Südlich von $40^{\circ} \mathrm{S}$ sind die niedrigsten Wassertemperaturen mehr außerhalb dieser Linie zu suchen ... Erwähnt muß noch werden, ... daß stellenweise abnorm tiefe Temperaturen gemessen werden, während weiter südlich wärmeres Wasser vorherrscht. Es ist demnach ausgeschlossen, daß solche abnormen Temperaturverhältnisse nur in einer Nordströmung ihre Erklärung finden."

Trotz der Differenzierung eines "Gebietes des besonders kalten Falklandstromwassers" schlossen sich Klähn und viele spätere Autoren der Auffassung Krümmels an, daß die Oberflächenströmung auf dem argentinischen Schelf und das im Nordosten an der Schelfkante liegende Kaltwassergebiet gemeinsam den "Falkland-Strom" bilden. Divergierend blieben jedoch die Ansichten, an welcher Stelle der "Falkland-Strom" vom Kap-Horn-Strom abzweigt und ob die Falkland-Inseln von einem westlichen und/ oder einem östlichen Zweig des Stromes umgeben sind (vgl. E. Boltovskoy, 1959; D. Boltovskoy, 1981; Zyryanov \& Severov, 1979; Maslennikow \& Parfenovich, 1979).

Es mehren sich in jüngerer Zeit Meinungen, daß die windgetriebene Oberflächenströmung auf dem äußeren Schelf in keinem Zusammenhang mit dem ganzjährig vorhandenen Kaltwasserkörper nahe der subtropischen Konvergenz steht, denn dieser Wasserkörper besitzt die Charakteristika des "Subantarktischen Zwischenwassers": Temperatur 3 bis $4{ }^{\circ} \mathrm{C}$; Salzgehalt 34,1 bis $34,3 \%$; Sauerstoffgehalt über $6 \mathrm{ml} / 1$ (Gordon \& Goldberg, 1970; Brandhorst \& Castello, 1971; Lenz, 1975; Abb. 5; Semenov \& Berman, 1977; Schemainda, 1980; Hubold, 1980a, b; Gordon, 1981; Molinelli, 1981). Einige der genannten Autoren nennen das "Subantarktische Zwischenwasser" auch "Antarktisches Zwischenwasser" oder nur "Zwischenwasser".

So stellt sich als zentrales Problem bei den biologischen und auch bei den ozeanographischen Untersuchungen im Südwestatlantik die Definition des "Falkland-Stromes", über dessen Ursprung, Verlauf und Indikatoren unklare oder sich widersprechende Ansichten bestehen. Den unbefriedigenden Stand unseres Wissens drücken Gordon \& Goldberg $(1970 ;$ p. 4) so aus: "It appears that the origin of the Falkland Current is quite complicated and its water may be derived from different geographical locations as depths increases." Da "die ozeanographischen Bedingungen aller Meeresgewässer Argentiniens sehr eng mit der Malvinen-(= Falkland-)Strömung verbunden sind" (Boltovskoy, 1959; p. 79), sind ganz besonders der Ursprung, das Verhalten und das Schicksal des "Subantarktischen Zwischenwassers" im Südatlantik zu klären. 
Außer der Front südöstlich der La-Plata-Mündung (Subtropische Konvergenz) findet sich nordöstlich der Falkland-Inseln noch ein weiteres Gebiet mit relativ scharfen Gradienten (Brandhorst \& Castello, 1971; p. 24). Die Autoren sehen dieses Gebiet ebenfalls als Teil der subtropischen Konvergenz an; das von ihnen genannte Gebiet $\left(47^{\circ} 45^{\prime} \mathrm{S}\right.$ bis $49^{\circ} \mathrm{S}$ und $52^{\circ} \mathrm{W}$ bis $\left.54^{\circ} \mathrm{W}\right)$ wird von mäandrierenden oder abgeschnürten Ausläufern des Brasilstromes erreicht (Deacon, 1933; p. 188, 215; Deacon; 1982; p. 5; Legeckis \& Gordon, 1982; Reid et al., 1977). Andere Autoren (vgl. E. Boltovskoy, 1978) vermuten an dieser Front jedoch auch die Beteiligung von Wasser mit antarktischen Charakteristika.

Die Hydrographie der bodennahen Wasserschichten auf dem südlichen argentinischen Schelf, der auch die Falkland-Inseln und die Burdwood-Bank einschließt, wird von Bellisio \& Lopez (1973; carta No. 4) sowie von Krepper \& Rivas (1979) beschrieben; zum Vergleich können die ebenfalls im Sommer gemessenen Oberflächentemperaturen von "Walther Herwig" 1970/71 herangezogen werden, wie sie Lenz in Kapp (1980; Fig. 5) darstellt.

Unter der Küste befindet sich ein gutdurchmischtes, relativ salzarmes Wasserband, das im Sommer sowohl an der Oberfläche wie auch am Boden eine Temperatur von etwa $10^{\circ} \mathrm{C}$ hat. Tiefe Temperaturen unter der Küste herrschen offenbar ständig an der Südspitze Feuerlands, an der Ausmündung der Magellan-Straße und zumindest zeitweise im westlichen Teil des Südlichen Falkland-Beckens.

Unter der etwa $100 \mathrm{~m}$ dicken Deckschicht, die im Winter in der offenen See eine Temperatur von 4,5 bis $5^{\circ} \mathrm{C}$ hat, befindet sich ganzjährig eine 4,5 bis $6^{\circ} \mathrm{C}$ "warme" Schicht, die nach "Walther-Herwig"-Daten im Spätherbst und Winter (WH 1966 und WH 1978) sogar noch etwas wärmer war als im Sommer (WH 1970/71 und Daten von Kaiyu Maru 1969/70). Von diesem in 100 bis $350 \mathrm{~m}$ Tiefe liegenden Wasser werden die Burdwood-Bank sowie der Südwesten und Südosten des Schelfes um die FalklandInseln beeinflußt. Charakter und Richtung des Wassers wie auch der Jahresgang der Temperatur zeigen, daß es sich hier offenbar um das relativ warme Wasser handelt, das aus dem Pazifik in die Drake-Passage eindringt (siehe unten). Dieser im tieferen Sublitoral und oberen Archibenthal liegende Wasserkörper mit Temperaturen von 4 bis $6^{\circ} \mathrm{C}$ im Süd-Winter ist in unmittelbarer Nähe der Polarfront bemerkenswert.

Eine weitere den Südwestatlantik berührende Front ist die Polarfront (= antarktische Konvergenz), die östlich der Falkland-Inseln ihre bekannte S-förmige Schleife hat (vgl. Hedgpeth, 1969; Fig. 10; Deacon, 1982; Fig. 1). Besonders in diesem S-förmigen Abschnitt ist die Front so variabel, daß sie richtiger Polarfront-Zone genannt werden sollte (Gordon et al., 1977 ; p. 311).

Das Oberflächen- und Küstenwasser Feuerlands bildet mit seinem geringen Salzgehalt eine weitere Front (E. Boltovskoy, 1971; Text Fig. 1: entnommen Atlas Antarktiki, 1966; Gordon \& Molinelli, 1982; Plates 13, 24 und 26); es entspricht dem Wasser, das man auf der pazifischen Seite an der Oberfläche des südchilenischen Archipels findet. Gordon \& Goldberg (1970) sind der Ansicht, "this indicates that the southern tip of South America is surrounded by a rather narrow current flowing parallel to the coast in a counter-clockwise direction". Die 'Temperatur-Anomalie der Oberfläche bei Feuerland ist positiv $\left(+3^{\circ} \mathrm{C}\right)$ mit geringen jahreszeitlichen Schwankungen (Dietrich \& Ulrich, 1968; Brandhorst \& Castello, 1971).

Die südchilenische Küstenregion ist nicht nur durch eine Vielzahl von Kanälen, 
Inseln und Fjorden ausgezeichnet, sondern auch durch hydrographische und biologische Besonderheiten, die El-Sayed $(1970 ;$ p. 142) an subtropische Wasserkörper zwischen Neuseeland und Tasmanien erinnern. Hinweise darauf, daß es einen solchen Wassertransport über den Südpazifik tatsächlich gibt, liefern McGinnis (1974) und Deacon (1977); zur Aufrechterhaltung der subtropischen Charakteristika des vor Südchile liegenden Wasserkörpers trägt möglicherweise auch der warme Unterstrom (Gunther-Strom, siehe unten) bei, der in dieser subpolaren Region in $200 \mathrm{~m}$ Tiefe noch Temperaturen von $10^{\circ} \mathrm{C}$ bewirkt (Brattström \& Johanssen, 1983).

Nördlich und südlich dieses "warmen" Archipels trifft der Zirkumpolarstrom auf die Küste (Brattström \& Johanssen, 1983), im Norden bei Chiloe als Humboldt- oder PeruStrom (vgl. auch Silva \& Neshyba, 1977; Sebens \& Paine, 1979), der die Küste Chiles begleitet (nach Brattström \& Johanssen, 1983; Fig. 6, pp. 319-321, zum Teil als Unterstrom) und sie an der Grenze zu Peru verläßt, wo seine Ausläufer schließlich noch die am Äquator liegenden Galapagosinseln beeinflussen (Sverdrup et al., 1942). Im Süden, etwa in Höhe der Magellan-Straße, berührt der Kap-Horn-Strom die Spitze des südamerikanischen Kontinentes.

Wie Brattström \& Johanssen (1983; p. 297) darstellen, sind die hydrographischen Verhältnisse entlang der chilenischen Küste nur geringen jahreszeitlichen Veränderungen unterworfen. Auch die meridionalen Unterschiede zwischen Nord- und Südchile sind gering; diese Stabilität der abiotischen Parameter gilt offenbar noch mehr für die unter der Deckschicht liegenden Wasserkörper.

\section{Hydrographie der bodennahen Wasserschichten}

Wir betrachten die Unter- und Tiefenströme vor der südamerikanischen Küste in west-östlicher Richtung. Zuerst ist der von Gunther (1936) entdeckte "Peru-ChileUnterstrom" (Gunther-Unterstrom) zu nennen (Taft, 1963; Wooster \& Gilmartin, 1961; Sverdrup et al., 1942; Brattström \& Johanssen, 1983), dessen Ausläufer vielleicht auch in den Südwestatlantik gelangen. Dieser Unterstrom nimmt offenbar seinen Ausgang bei $15^{\circ}$ Süd in 100 bis $200 \mathrm{~m}$ Tiefe, 100 Seemeilen von der peruanischen Küste entfernt. Von dort nähert er sich, nach Süden vorstoßend, der chilenischen Küste, an der er seine Kernschicht in Tiefen um $500 \mathrm{~m}$ hat.

Wie stark der Gunther-Unterstrom ist und wieviel Wasser er polwärts führt, ist nicht bekannt, aber die ganzjährig hohen Temperaturen im Sublitoral und Archibenthal Südchiles (Brattström \& Johanssen, 1983; Table 5) sprechen für eine starke Strömung. Nach diesen Autoren (pp. 299-300) soll Auftrieb entlang der chilenischen Küste sowohl aus dem Humboldt-Strom als auch aus dem Gunther-Unterstrom stattfinden.

Sehr wahrscheinlich ist der Gunther-Unterstrom auch an der relativ warmen und salzreichen Schicht in $500 \mathrm{~m}$ Tiefe im nördlichen Teil der Drake-Straße beteiligt (vgl. Buscaglia, 1971), in der Clowes (1933) sowie Leipper \& Capurro (1964) besonders hohe Stromgeschwindigkeiten ( $32 \mathrm{bzw} .41,6 \mathrm{~cm} / \mathrm{sec}$ ) gemessen haben. Dieses Wasserband scheint das ganze Jahr über 4 bis $5^{\circ} \mathrm{C}$ warm zu sein (Georgi, 1979); die von "Walther Herwig" gemessenen Temperaturen lassen sogar vermuten, daß das warme Wasser im Spätherbst bis in Tiefen von fast $1000 \mathrm{~m}$ reicht (WH 1978, St. 590: 4,6 ${ }^{\circ} \mathrm{C}$ in $950 \mathrm{~m}$ ).

Das moderne Konzept des Zirkumpolarstromes ist das eines Stromes mit verschiedenen variierenden Bändern stärkeren und schwächeren Fließens (Deacon, 1982; Sievers 
\& Nowlin, 1984). Wie sich das Band des salzreichen, warmen, sauerstoffarmen, aber nährstoffreichen Wassers nach Passieren der Drake-Passage verhält, ist Gegenstand kontroverser Meinungen. Nach Gordon (1966), Gordon et al. (1977), Gordon \& Goldberg (1970) und Georgi (1979) verfolgen die Wassermassen im nördlichen Teil der DrakeStraße unterhalb von $200 \mathrm{~m}$ Tiefe eine östliche Richtung (im Gegensatz zu der nördlichen bis nordöstlichen Richtung der Oberflächenschicht); sie fließen entlang des ScotiaRückens, den sie offenbar erst bei $48^{\circ}$ West durch die Shag-Rock-Passage mit nördlicher Richtung überqueren. Dieser schnelle und tiefreichende Strom muß eine Menge pazifischen Wassers in den Atlantik transportieren (Gordon, 1966; Zenk, 1981). Georgi (1979) nimmt an, daß dieses Wasser nach etwa 4 Monaten bei 40 bis $45^{\circ}$ Süd vor den argentinischen Schelf gelangt.

Die Shag-Rock-Passage, die bei $53^{\circ}$ Süd, $48^{\circ}$ West liegt, erreicht Tiefen von $3000 \mathrm{~m}$ (Abb. 3) und war in jüngerer Zeit Gegenstand ozeanographischer Untersuchungen (Zenk, 1981; Wittstock \& Zenk, 1983). Strommessungen 35 und 80 m über dem Boden

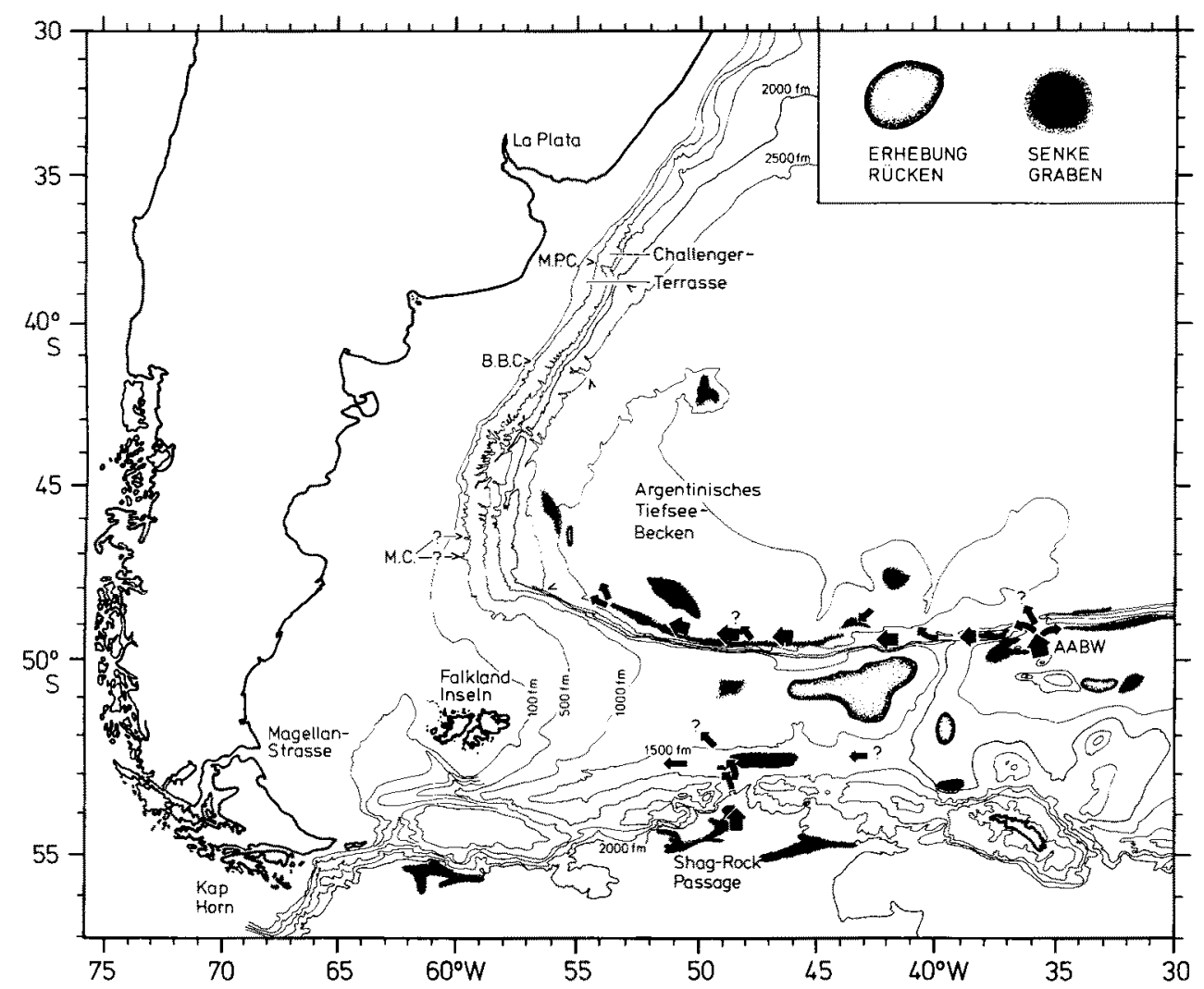

Abb. 3. Physiographie des Südwestatlantik (nach Ewing \& Lonardi, 1971, mit Ergänzungen). Die Pfeile deuten die im Text beschriebenen Tiefenströme im Südwestatlantik an. Abkürzungen: AABW - Antarktisches Bodenwasser; B.B.C. - Bahia-Blanca-Canyon; M.C. - Malvinas-Canyon (die Position des Canyon-Hauptes ist nicht bekannt); M.P.C. - Mar-del-Plata-Canyon 
ergaben nach Zenk (1981) Durchschnittswerte wie in der Drake-Passage $(30$ bis $35 \mathrm{~cm} /$ sec), jedoch mit weit höheren Spitzenwerten (bei $65 \mathrm{~cm} / \mathrm{sec}$ brach der Propeller des Meßgerätes ab). Der von Zenk festgestellte jahreszeitlich intermittierende bodennahe Strom enthält besonders im Winter Wasser mit antarktischen Charakteristika $\left(0,36-0,58^{\circ} \mathrm{C}\right)$. Das einströmende Wasser hat in der Passage eine Richtung nach WestNordwest, wobei zunehmende Stromstärke mit tieferen Temperaturen und einer verstärkt westlichen Richtung einherzugehen scheinen. Dies läßt vermuten, daß die tieleren, besonders kalten und schnellen Schichten dem Südlichen Falkland-Becken folgen, während die oberen Wasserschichten (200 bis $2000 \mathrm{~m}$ ) offenbar das Falkland-Plateau mit West-Nordwest-Richtung überqueren.

Noch nicht geklärt ist, ob der durch die Shag-Rock-Passage bei $48^{\circ}$ West aus der Scotia-See in den Südwestatlantik eindringende Strom im Zusammenhang steht mit der Bildung und/oder Ausbreitung des "Subantarktischen Zwischenwassers", wie von Molinelli (1978) angenommen. Nach klassischer Lehrmeinung (Wüst \& Defant, 1936) entsteht das "Subantarktische Zwischenwasser" aus antarktischem und subantarktischem Oberflächenwasser, das an der antarktischen Konvergenz in die Tiefe sinkt, ohne die in jüngerer Zeit angenommene Beteiligung tieferer Wasserschichten, die sich entlang isopyknischer Oberflächen vermischen (Gordon et al., 1977; Molinelli, 1981).

Allerdings wurde von einer Reihe von Ozeanographen schon früher angenommen, daß, ausgehend von der S-förmigen Schleife der Polarfront zwischen Südgeorgien und den Falklands, das Absteigen des Subantarktischen Zwischenwassers "Stromcharakter" hat (Brennecke, 1921, zitiert von Drygalski, 1927; p. 498; Deacon, 1933; p. 209; Defant, 1936; p. 438; 1961; p. 678; Wüst, 1965; p. 89; Pizarro, 1967; Dietrich et al., 1975; p. 450). Der aus der Scotia-See eindringende Strom, der offenbar alle Schichten des Zirkumpolarstromes einbezieht, wurde meines Wissens erstmals von Gordon (1966) erwähnt.

Nördlich des Falkland-Plateaus bewegt sich an dessen tiefseeischem Fuß in $6000 \mathrm{~m}$ Tiefe der gewaltige Strom des Antarktischen Bodenwassers (AABW), der von Le Pichon et al. (1971) als $200 \mathrm{~km}$ breit und 3,5 km mächtig beschrieben wird mit Geschwindigkeiten von $18 \mathrm{bis} 25 \mathrm{~cm} / \mathrm{sec}$ (etwa $20 \mathrm{~km}$ pro Tag). Wie Mantyla \& Reid (1983) betonen, ist die Bezeichnung "Antarktisches Bodenwasser' in doppelter Hinsicht irreführend, denn dieser Wasserkörper ist zum größeren Teil ( $(5 / 8)$ zirkumpolaren (und nicht antarktischen) Ursprungs, und zum anderen handelt es sich bei dem antarktischen Anteil nicht um Bodenwasser, sondern um Tiefenwasser aus dem Weddellmeer.

Das Antarktische Bodenwasser tritt bei $36^{\circ}$ West in den Südatlantik ein, wobei es sich sowohl nach Osten wie auch nach Westen ausbreitet. Der westliche Teil folgt der "Falkland Fracture Zone"; Lonardi \& Ewing (1971; Fig. 1) vermuten, daß sich von diesem Strom die unterste und damit besonders "antarktische" Schicht bei $48^{\circ} \mathrm{W}$ trennt und eine nordwestliche Richtung durch den tiefsten Teil des argentinischen Tiefseebekkens einschlägt (Abb. 3).

Der andere Teil des AABW läuft offenbar auf den argentinischen Kontinentalsockel auf, was Lonardi \& Ewing (1971) indirekt aus dessen erodierter Oberfläche erschließen. $\mathrm{Ob}$ dieser Wasserkörper auch den oberen Abschnitt des Schelfhanges berührt oder beeinflußt oder ob er teilweise oder in seiner Gesamtheit nach Norden umbiegt, ist unbekannt. Fest steht jedoch (Wüst, 1957; Tafel 16), daß ein Wasserkörper mit den Charakteristika des $\mathrm{AABW}$ bei $41^{\circ} \mathrm{S}$ am argentinischen Schelfhang mächtig entwickelt ist und durch die Kräfte der Erdrotation emporgedrückt wird. Ob es sich bei diesem 
Wasser um das in der Tiefsee bei $48^{\circ} \mathrm{W}$ und $49^{\circ} \mathrm{S}$ abgezweigte AABW handelt oder um jenes, das vielleicht dem Kontinentalsockel folgt, ist nicht bekannt.

Die hier interessierende Tiefenzone zwischen Schelfkante und $1220 \mathrm{~m}$ wird vom AABW wohl kaum erreicht, wohl aber - zumindest zeitweise - die 2000-Meter-Linie (Le Pichon et al., 1971; Zyryanov \& Severov, 1979), wie auch indirekt durch die Funde antarktischer Diatomeen-Schalen belegt ist (Burckle \& Stanton, 1975). Die von diesen beiden Autoren gefundenen Verbreitungsmuster zweier antarktischer Diatomeen-Arten erlauben außerdem die Vermutung, daß möglicherweise auch noch weiter östlich $A A B W$ in das argentinische Tiefseebecken eindringt.

Einen Einfluß des AABW auf das Archibenthal des Südwestatlantik kann man an einigen topographisch oder dynamisch exponierten Stellen annehmen: So könnten Randströme von den gewaltigen Canyons aufgefangen und auf den Schelf geleitet werden (Owen, 1981; p. 210; Deacon, 1982; p. 8). Dynamische Ursachen für Auftriebswasser vor Argentinien werden seit 100 Jahren (Krümmel, 1882, wie von Klähn zitiert) diskutiert. In jüngerer Zeit scheint allgemein ein System zyklonaler Wirbel, in das auch tiefere Schichten des Südwestatlantik einbezogen sind, akzeptiert zu werden (Lenz, 1975; Reid et al., 1977; Zyryanov \& Severov, 1979; Schemainda, 1980; Piola \& Georgi, 1982; Hollister \& McCave, 1984). Je nach Drehrichtung und Zusammenwirken dieser Wirbel kann es zum Anheben, Absinken, Verlangsamen oder Beschleunigen der beteiligten wie auch der angrenzenden Wasserkörper kommen. Besonders in den Arbeiten von Zyryanov \& Severov (1979) sowie Hollister \& McCave (1984) wird ein Einfluß solcher Wirbel auch auf die Bewegungen der tiefsten Schichten angenommen.

Diese Wirbel mit ihren Auf- und Abgleitfronten sind offenbar stationär, auch wenn sie gewissen jahreszeitlichen Veränderungen unterworfen sind, wie von Zyryanov \& Severov (1979) beschrieben (vgl. auch Lenz, 1975; Hubold, 1980a, b). Einige mir zugängliche T-, S- und Silikat-Daten (Gordon \& Molinelli, 1982; "Walther Herwig", 1970/71 und 1978; "Capitan Canepa": vgl. Aragno, 1968) bestätigen, daß es offenbar zu allen Jahreszeiten Orte in $1000 \mathrm{~m}$ Tiefe gibt, die einen gewissen Einfluß des AABW vermuten lassen (vgl. auch Pizarro, 1967; p. 77).

Es scheint so, daß der nördliche Abschnitt zwischen $37^{\circ}$ und $42^{\circ} \mathrm{S}$ ("ChallengerTerrasse") im Winter vollkommen unter dem Einfluß solcher Bedingungen steht, während im Sommer der Einfluß eher punktförmig scheint (vgl, Zyryanov \& Severov, 1979; p. 522). Weiter südlich finden sich Stationen mit entsprechenden Bedingungen zwischen $46^{\circ}$ und $47^{\circ} \mathrm{S}$ (Haupt des Malvinas-Canyon), bei den Falkland-Inseln (etwa $52^{\circ} \mathrm{S}$ ) und an einigen Stellen in der Drake-Straße $\left(56^{\circ} \mathrm{S}\right)$. Ob es sich dabei um stationäre Bedingungen handelt, die möglicherweise einer sessilen subantarktischen oder gar antarktischen Fauna Lebensbedingungen bieten, soll im tiergeographischen Teil diskutiert werden.

Betrachten wir noch einmal zusammenfassend die ozeanographischen Verhältnisse im argentinischen Archibenthal, so ist besonders die Tatsache hervorzuheben, daß südlich von etwa $41^{\circ}$ Süd bisher keine den oberen Kontinentalabhang berührende, nordwärts gerichtete Strömung nachgewiesen wurde (Ewing et al., 1971; p. 61; Piola \& Georgi, 1982; p. 691). Der von mir als "Falkland-Strom sensu stricto" angesehene Wasserkörper, der an einigen Stellen und Abschnitten die Lebensbedingungen im argentinischen Archibenthal und Sublitoral beeinflußt, nähert sich demnach offenbar aus ozeanischen Regionen. Die abiotischen Charakteristika weisen ihn als "Subantark- 
tisches Zwischenwasser" aus, das an einigen Stellen den Einfluß von "Antarktischem Bodenwasser" vermuten läßt. Beide Wasserkörper gehören im freien Ozean tieferen Schichten an und führen nach jüngeren Untersuchungen beträchtliche Anteile zirkumpolaren Tiefenwassers neben Wassermassen antarktischen Ursprungs, die sich von Schelf- und Tiefenwasser des Weddellmeeres herleiten.

\section{TIERGEOGRAPHIE DES SUDWESTATLANTIK}

Bei tiergeographischen Untersuchungen im Südatlantik sieht man sich mit ungewöhnlichen terminologischen Schwierigkeiten konfrontiert (Hayden \& Dolan, 1976; p. 80; Kusakin, 1967), Ekman (1967; p. 213) stellt fest, daß die biogeographischen Regionen der Südhalbkugel nicht analog jenen der nördlichen benannt sind und daß darüber hinaus einige ebenfalls unbefriedigende Termini der Ozeanographen benutzt werden, eine Situation, die auch von den Ozeanographen beklagt wird (Deacon, 1982; pp. 12-13). Zusätzliche Verwirrung stiftet die abweichende Unterteilung (Zyryanov \& Severov, 1979 ; p. 520; Shuntov et al., 1982) und Benennung (Semonov, 1977) der tiergeographischen Regionen durch russische Autoren (vgl. auch Hedgpeth, 1969; p. 1). Aber auch die klassischen Begriffe wie "patagonisch" und "magellanisch" werden mit unterschiedlichen Bedeutungen verwendet (siehe Briggs, 1974; pp. 143 und 161; Brattström \& Johanssen, 1983; p. 329, Fig. 18; Coelho, 1980; Fig. 1).

In seiner "Revision der marinen Zoogeographie Südbrasiliens" gibt Palacio einen Überblick über die historischen Arbeiten entlang der gesamten südamerikanischen Küste (1982; dort sind in Fig. 5 südlich des 30. Breitengrades die geographischen Breiten falsch eingezeichnet). Er nennt d'Orbigny (1835-43) als den ersten Autor, der tiergeographische Regionen entlang der südamerikanischen Küste unterscheidet. Den grundsätzlichen Faunenwechsel vor der La-Plata-Mündung und eine eigenständige Region "Platense" beschreibt Dana (1853). Hoyle (1886) differenziert in seiner Bearbeitung der "Challenger"-Cephalopoden erstmals zwischen einer litoralen und einer ozeanischen Region. Burton (1932) setzt die Verbreitung der von "Discovery" gesammelten Schwämme in Beziehung zu den herrschenden Strömungen, und Balech (1954; vgl. auch Briggs, 1974; pp. 161, 163) unterscheidet je nach Einfluß von kaltem oder warmem Wasser mehrere Distrikte innerhalb größerer Provinzen.

Zahlreiche Autoren geben eine tiergeographische Gliederung des Südwestatlantik, wie sie sich aus der Bearbeitung der jeweiligen Tiergruppe ergab: Boltovskoy (z. B. 1964: Foraminiferen); Cairns (1982, 1983: Stylasterinen und Scleractinien); Stuardo (1964: Mollusken); Boschi (1964a, b, 1979: Dekapoden); Scelzo (1973: Dekapoden); Kusakin (1967: Isopoden); Tommasi (1965: Ophiuriden); Madsen (1956) und Bernasconi (1964: Echinodermen); Moyano (1982a, b: Bryozoen). Nur wenige Autoren differenzieren dabei zwischen Schelfarten und Arten, die tieferen oder kälteren Lebensräumen angehören. Lediglich Kusakin (1967) und Moyano (1982a, b) erkennen und diskutieren die weiträumige Verbreitung vieler Arten.

Die von Semenov (1978) gegebene Kompilation der Verbreitungsmuster von 1474 Benthos-Arten gibt - besonders durch die Figuren 1 bis 4 - wertvolle Hinweise zu Verbreitungsgrenzen und regionalen Beziehungen, obwohl nur Schelfbewohner berücksichtigt werden. Semenov diskutiert weder die Vertikalverteilung der Arten noch ihre mögliche Herkunft, seine Fig. 1 zeigt jedoch einige im Südwestatlantik offenbar 
nur vereinzelt an der Schelfkante gefundene Arten, für die eine weiträumige Verbreitung in subantarktisch-antarktischen Lebensräumen angedeutet wird (s. Kapitel 4).

Semenovs Arbeit zeigt aber auch, daß für die Beurteilung des tiergeographischen Status seltener Arten die Kenntnis ihrer weiteren Verbreitung wichtig ist (vgl. Brattström \& Johanssen, 1983; p. 316; Kusakin, 1967). Eine Analyse des südwestatlantischen Benthos ohne die Berücksichtigung der benachbarten Regionen könnte sonst zu der voreiligen Schlußfolgerung führen, daß die Region durch einen hohen Anteil an Endemismen gekennzeichnet sei. Zu dieser Einschätzung kann man auch gelangen, wenn kein Vergleich mit dem Benthos anderer Tiefenzonen möglich ist, denn in der Antarktis und Subantarktis kann wegen der Auf- und Abwärtsbewegungen von Wassermassen die entsprechende Region eine andere Tiefenzone sein oder eine verschieden große Vertikalausdehnung haben.

Angaben über endemische Arten sind abhängig von Anzahl, Dichte und Art der Probennahme und von den gezogenen tiergeographischen Grenzen (Monniot \& Monniot, 1983). Was die südwestatlantischen Lebensräume anbetrifft, so müssen nach meiner Ansicht unter diesem Aspekt die von Ekman (1967; p. 216) und Briggs (1974; pp. 163-164) genannten und von Brattström \& Johanssen (1983; p. 331) diskutierten hohen Prozentzahlen endemischer Arten mit großem Vorbehalt betrachtet werden.

Bei Seeanemonen ist die Nennung endemischer Arten zur Kennzeichnung tiergeographischer Einheiten auch deswegen problematisch, weil die Beurteilung des Artund Unterart-Status in dieser Tiergruppe nach wie vor schwierig ist, besonders bei Arten mit großer Variabilität. Kriterium für die hier vorgeschlagene Gliederung des südwestatlantischen Sublitorals ist daher die Uppigkeit der Seeanemonen-Fauna mit Hinsicht auf Diversität, Anzahl und Größe der gesammelten Tiere (Johnson \& Brinton, 1963; p. 385 ; s. Boltovskoy, 1964; p. 96; Bernasconi, 1964; p. 48; Knox, 1977; p. 70).

In der hierarchischen Gliederung stelle ich die in mehrfacher Hinsicht eigenständige Provinz "La Plata" gleichberechtigt neben die Provinz "Patagonien" und die im Norden anschließende "Tropische" (westindische, karibische) Provinz. Der letztgenannten Provinz gehören die beiden zuerst zu beschreibenden Subprovinzen "São Paulo" und "Tropisches Warmwasser-Archibenthal" an.

\section{Tropische Provinz}

Das vom F.F.S. "Walther Herwig" gesammelte Material enthält nur ganz wenige Aktinien aus dem nördlich der La-Plata-Mündung gelegenen uruguayischen und brasilianischen Küstenstreifen. Zur Gesamtverbreitung der gefundenen Arten kann daher keine Aussage gemacht werden.

\section{Subprovinz São Paulo}

Referenz-Arten: Carcinactis dolosa Riemann-Zürneck (1975a; p. 80); Calliactis androgyna Riemann-Zürneck (1975b; p. 388).

C. dolosa wurde in 25 Exemplaren an 2 Stationen (St. 55: $31^{\circ} 2^{\prime} \mathrm{S}, 50^{\circ} 36^{\prime} \mathrm{W}, 40 \mathrm{~m}$; St. $76: 26^{\circ} 47^{\prime} \mathrm{S}, 47^{\circ} 52^{\prime} \mathrm{W}, 40 \mathrm{~m}$ ) im Jahre 1968 an der brasilianischen Küste gesammelt. Offenbar vergesellschaftet mit $C$. dolosa fand sich an St. 55 ein Exemplar von Calliactis androgyna; die Vergesellschaftung dieser beiden ähnlichen, aber verschiedenen Familien angehörenden Aktinien-Arten hat interessante ökologische und tiergeographisch- 
phylogenetische Aspekte: Die nächsten Verwandten beider Arten, nämlich Calliactis polypus (Forskål, 1775) und Verrillactis paguri (Verrill, 1869) sind im Indopazifik in ähnlicher Weise assoziiert (England, 1971; Riemann-Zürneck, 1975b).

Die beiden brasilianischen Seeanemonen gehören der tiergeographischen Subprovinz São Paulo an (im portugiesischen Sprachgebrauch "Paulista"; vgl. Palacio, 1982; Fig. 5), einem Gebiet, das entweder (wie von Palacio) als Übergangszone zwischen tropischer und warmtemperierter Schelffauna angesehen werden kann oder (wie hier) als letzte Subprovinz der tropischen (westindischen, karibischen) Provinz. Palacio gibt die Grenzen der Subprovinz mit $22^{\circ} \mathrm{S}$ und $33^{\circ} \mathrm{S}$ an; in diesem Schelfabschnitt haben offenbar alle tropischen Litoral- und Flachwassertiere ihre südlichste Verbreitungsgrenze, die je nach ökologischem Anspruch und dem Verhalten des tropischen Wassers auf verschiedener geographischer Breite, aber auch in verschiedenen Tiefen liegen kann.

Wie für viele andere Tiergruppen (Briggs, 1974; Palacio, 1982) konnte auch für die Seeanemonen ein hoher Anteil karibischer Arten in der Subprovinz São Paulo nachgewiesen werden (Corrêa, 1964; Corrêa \& Schlenz, 1976; Dube, 1974, 1975, 1976a, 1976b, 1977, 1978; Belem, 1980; Belem \& Preslercravo, 1973; Belem \& Monteiro, 1977; Schlenz \& Belem, 1982). Wie bei anderen Taxa gibt es jedoch Unterschiede auf Art- und Gattungsniveau: Von 24 bei Dube (1974; Tab. 1) genannten Arten sind zehn andernorts bisher nicht bekannt. Die Frage nach dem Anteil an endemischen Arten muß dennoch unbeantwortet bleiben, da einige Seeanemonen identisch oder nahe verwandt sind mit weit entfernt im Indopazifik lebenden Arten (vgl. Corrêa \& Schlenz, 1976: Paracondylactis hertwigi sowie die beiden hier diskutierten Arten). Ob es sich hierbei um die Vertreter einer alten zirkumtropischen Fauna handelt (Vanucci, 1964) oder ob in dieser Subprovinz Arten indopazifischen Ursprungs nach der Atlantik-Überquerung Fuß fassen, wie von Burton (1932) für Schwämme, von Klappenbach (1965; p. 350) für Muscheln und von Joly (1965) für die marine Flora angenommen, soll hier nicht weiter diskutiert werden.

Für die Aktinien liegt die Grenze der tropischen Flachwasserarten vermutlich mehr an der südlichen als an der nördlichen Grenze der Subprovinz. Dennoch ist zu vermuten, daß dies nicht für das Eulitoral gilt, das den für diese Region typischen großen Schwan* kungen der Lufttemperatur ausgesetzt ist. Eine veränderte Zusammensetzung des Benthos ist auch dort zu erwarten, wo-besonders im Winter (Hubold, 1980b; p. 41; Palacio, 1982) - die letzten Ausläufer des kalten "Falkland-Stromes" als Unterstrom bis zum Cabo Frio ( $23^{\circ}$ Süd) ziehen (vgl. die Seeanemone Antholoba achates und die Siphonophore Rhodalia miranda).

\section{Subprovinz Tropisches Warmwasser-Archibenthal}

Referenz-Arten: Actinauge longicornis (Verrill, 1882); Riemann-Zürneck, 1973; p. 284; Phelliactis callicyclus Riemann-Zürneck, 1973; p. 313.

Actinauge longicornis gehört der besonderen Lebensgemeinschaft des tropischen und subtropischen Archibenthals an, wie es von Krefft (1968; p. 36) und Briggs (1974; p. 366, p. 372) für die Fischfauna beschrieben wird. Briggs (p. 372): "As far as the fishes are concerned, the fauna of each tropical region seems to be highly distinctive, more so than the shelf fauna." Was die Aktinien angeht, so kann diese Aussage für die bisher untersuchten Warmwasser-Archibenthale (fast ausschließlich Atlantik) nicht bestätigt 
werden, wohl aber die Feststellung Kreffts, daß die archibenthalen Faunen verschiedener Warmwasserregionen Ähnlichkeiten zeigen. So findet man Vertreter der Gattung Actinauge überall in den Randgebieten der Warmwassersphäre in schlickigen Gebieten des Archibenthals (vgl, die Fundortangaben bei Carlgren, 1949; p. 94).

Die Fundorte von Actinauge longicornis im Archibenthal außerhalb des La Plata (Abb. 7) bestätigen die Feststellung der Ozeanographen, daß der dort auf der Schelfkante aufliegende und bis etwa $1000 \mathrm{~m}$ Tiefe reichende Brasilstrom bei $38^{\circ} \mathrm{S}$ den Kontinentalabhang verläßt und sich nach Osten wendet (Wüst \& Defant, 1936; Atlas, Tafeln 49-51; Buscaglia, 1971; Lenz, 1975; Legeckis \& Gordon, 1982; Gordon \& Molinelli, 1982; Pl. 15). Bemerkenswert ist die Exaktheit, mit der sowohl A. longicornis wie auch die später zu besprechende Isotealia antarctica die Grenze des warmen Tiefenwassers nachzeichnen (Abb. 7).

Die Subprovinz reicht bis an die südliche Grenze der Provinz "La Plata" und erstreckt sich möglicherweise in Tiefen zwischen 600 und $1200 \mathrm{~m}$ noch weiter nach Süden in die Provinz "Patagonien" hinein.

Aus den "Walther-Herwig"'-Daten läßt sich ablesen, daß das Hauptvorkommen von A. longicornis horizontal und vertikal begrenzt wird von der $6-{ }^{\circ} \mathrm{C}$-Isotherme, wodurch sich diese Seeanemone als relativ eurytherme Art des Warmwasser-Archibenthals zu erkennen gibt. Die durchgehende Küstenlinie zwischen ihren nord- und südatlantischen Fundorten macht ihr Vorkommen im dazwischenliegenden tropischen Archibenthal wahrscheinlich. Bisher allerdings ist die archibenthale Aktinienfauna Brasiliens unbekannt; andererseits erscheint es auch möglich, daß die Art nur hydrographisch-ökologische Grenzgebiete besiedelt (vgl. Hormathia pectinata und Amphianthus aff. lacteus).

Ein einziges Exemplar von A. longicornis wurde $1000 \mathrm{~km}$ südlich der subtropischen Konvergenz gefunden (WH 1978, St. 657: 47 $1,5^{\prime} \mathrm{S}, 59^{\circ} 57,5^{\prime} \mathrm{W}, 750-770 \mathrm{~m}$ ). Dieser Einzelfund wäre nicht mehr als eine Kuriosität, wenn nicht eine andere archibenthale Seeanemone, Phelliactis callicyclus, neben ihren Fundorten bei $38^{\circ} \mathrm{S}$ und $39^{\circ} \mathrm{S}$ (siehe Riemann-Zürneck, 1973 ; p. 313) sowie bei $41^{\circ} 24^{\prime} \mathrm{S}$ (WH 1978, St. 505) auch noch einen viel weiter südlich liegenden Fundort hätte (WH 1978, St. 637: 49 $3^{\prime} \mathrm{S}_{1} 55^{\circ} 59,7^{\prime} \mathrm{W}$, $970 \mathrm{~m}$ ). Dieser im Archibenthal des Falkland-Plateaus liegende Fundort zeichnet sich durch ungewöhnliche T/S-Daten aus $\left(4,69^{\circ} \mathrm{C}\right.$ und $34,35 \% \mathrm{~S}$ im Spätherbst), die relativ warmes und salzreiches Wasser anzeigen (Molinelli, 1981; p. 287).

Wenn man sich nun fragt, ob diese nur im Tiefwasser (620 bis $1220 \mathrm{~m}$ ) gefundene Phelliactis-Art möglicherweise ein Indikator für etwas erhöhte T/S-Werte in dieser Tiefenzone sein könnte, so erscheint schon diese Frage ungewöhnlich, da man die Vertreter der archibenthalen Fauna gewöhnlich als Kaltwassertiere, vielleicht sogar als stenotherme Kaltwassertiere einschätzt. Betrachtet man jedoch die Verbreitungsmuster aller neunzehn gegenwärtig bekannten Phelliactis-(und Paraphelliactis-)Arten (Carlgren, 1949; p. 94, pp. 96-97; Riemann-Zürneck, 1973; Doumenc, 1975, 1984; Dunn, 1982), so scheinen sie häufig mit gewissen Warmwassereinflüssen korreliert zu sein, auch wenn ihre Fundort-Temperaturen nur selten über $4{ }^{\circ} \mathrm{C}$ liegen dürften (FundortTemperaturen meist unbekannt). Selbst die bei Grönland vorkommende Phelliactis robusta folgt offenbar den leicht erhöhten Tiefen-Temperaturen in dieser Region (siehe Ekman, 1967; p. 106).

Woher kommt nun diese zumindest zeitweise Intrusion wärmeren und salzreicheren Wassers, die durch die hydrographischen Daten der WH-Station 637 und indirekt durch 


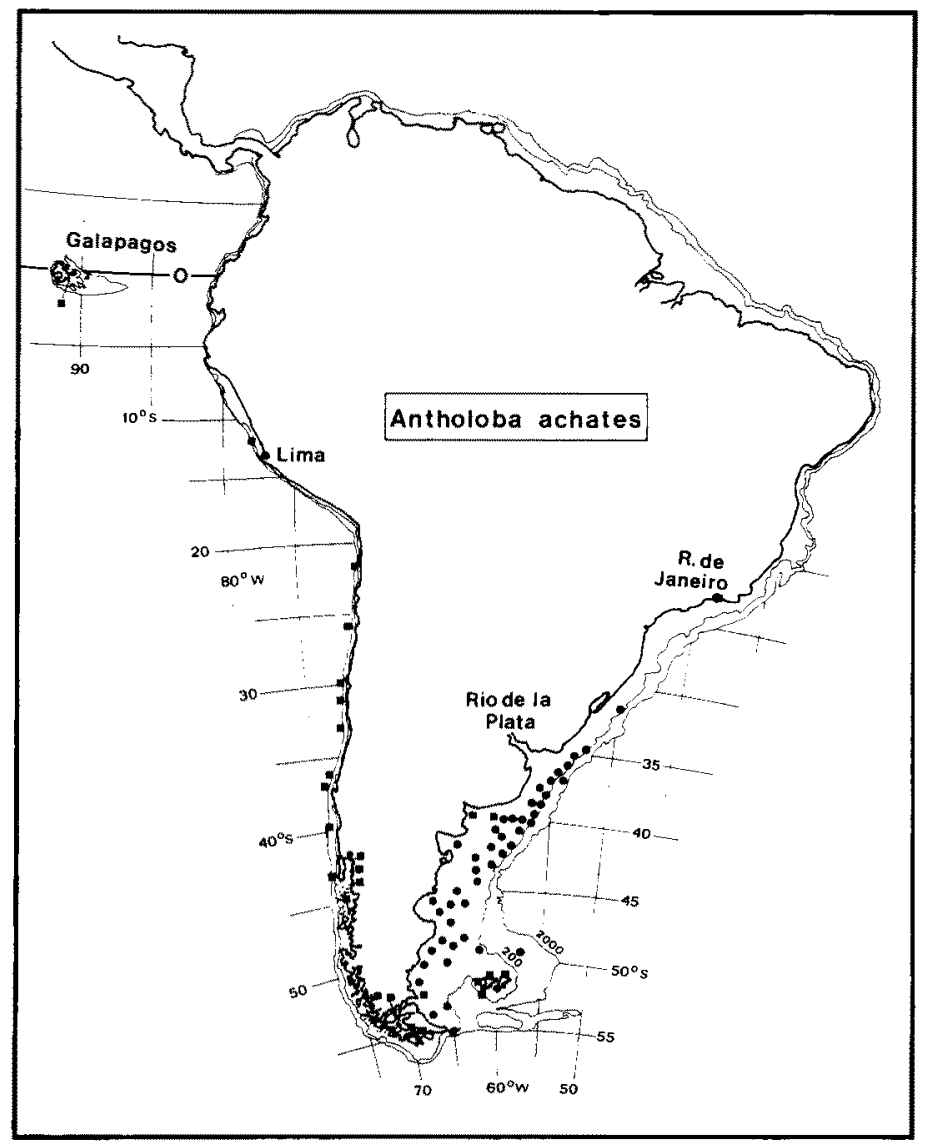

Abb. 4. Verbreitung der sublitoralen Seeanemone Antholoba achates. $\bullet$ "Walther-Herwig"-Fundorte; Fundorte anderer Autoren. A. achates ist die einzige hier behandelte Seeanemone, die keine der sublitoralen tiergeographischen Grenzen Südamerikas beachtet (Tiefenangaben in Metern)

die Fundorte von Actinauge und Phelliactis angezeigt wird? Bekannt ist, daß sich im Gebiet zwischen $38^{\circ}$ und $36^{\circ}$ Süd und zwischen $50^{\circ}$ und $55^{\circ}$ West von Frühjahr bis Herbst an der Oberfläche Eddies vom stark mäandrierenden Brasilstrom abtrennen (Legeckis \& Gordon, 1982; Bersch \& Becker, 1984), die einen Durchmesser von 70 bis $350 \mathrm{~km}$ haben und sich mit Geschwindigkeiten zwischen 4 und $35 \mathrm{~km}$ pro Tag nach Süden bewegen (Legeckis \& Gordon, 1982). Etwa zwanzig solcher Wirbel wurden zwischen September (Winter) 1975 und April 1976 (Herbst) gebildet; über das weitere Schicksal dieser "warm core eddies" ist nichts bekannt, jedoch gibt es Hinweise, daß sie die Nordflanke des Falkland-Plateaus erreichen (Klähn, 1911; Gordon, persönliche Mitteilung, 1982), wo sie offenbar auch eine leichte Erhöhung der Oberflächen-Temperaturen verursachen (Deacon, 1933; p. 215 ; 1982). Das zumindest zeitweise Erscheinen von Warmwasser-Organismen in dieser Region nordöstlich der Falkland-Inseln beschreiben Barth et al. (1965), Balech (1968: Dinoflagellaten), Bé (1969: Foraminiferen), Krüger (1939: Feuerwalzen) und Hart (1946; p. 242: Fische). 
Berichte von hydrographischen oder biologischen Warmwasser-Indikatoren im Archibenthal dieser Region sind dagegen selten. Hydrographische Hinweise geben die T- und S-Karten aus $800 \mathrm{~m}$ Tiefe bei Wüst \& Defant (1936), die Abbildungen 4 und 5 bei Buscaglia (1971) und die Abbildungen 7 und 10 bei Schemainda (1980). Dell (1964; p. 261) stellte die südlichsten Fundorte wärmeliebender Mollusken im Nordosten der Falklands fest, Cairns (1982) fand dort 2 subfossile Exemplare einer WarmwasserKoralle und Bückmann (1974; p. 23) "in einem tieferen Fang über dem Kontinentalabhang" Warmwasser-Oikopleuren. Solche Beobachtungen sprechen dafür, daß es einen regelmäßig wiederkehrenden, vielleicht sogar einen permanenten Einfluß von etwas wärmerem und salzreicherem Wasser auch in diesen Tiefen gibt. Möglicherweise ist die Zahl der die nördliche Flanke des Falkland-Plateaus erreichenden Warmwasserlinsen sogar viel größer als an der Oberfläche wahrnehmbar, denn es werden auch Wasserkörper in der Vertikalen abgeschnürt (Nehring \& Brosin, 1968; p. 13; Legeckis \& Gordon, 1982; pp. 391, 397, 398), oder das Brasilstromwasser nimmt, wie von Brandhorst \& Castello (1971; p. 21) beschrieben, besonders in seinem küstennahen Ast durch Abkühlung ein tieferes Niveau ein. Solche T- und S-Erhöhungen unter der Deckschicht sind häufig auf Vertikalschnitten zu erkennen (Gordon, 1981; Atlas Oceanografico, 1972; Lusquinos \& Valdez, 1971; Schemainda, 1980).

\section{Provinz La Plata}

Referenz-Arten: Phellia exlex (McMurrich, 1904; p. 279); Riemann-Zürneck, 1975; p. 86; Hormathia pectinata (Hertwig, 1882; p. 81); Riemann-Zürneck, 1973; p. 283; Amphianthus aff. lacteus (McMurrich, 1893; p. 176).

Die Provinz La Plata schließt die sublitoralen und archibenthalen Lebensräume ein, nicht jedoch die Flachwassergebiete des La-Plata-Ästuars, wie von Dana $(1853$, zitiert von Palacio, 1982) dargestellt. Die Grenzen der Provinz liegen bei etwa $33^{\circ} \mathrm{S}$ im Norden und $38^{\circ} \mathrm{S}$ im Süden und umfassen die Tiefenzone zwischen 50 und $1200 \mathrm{~m}$.

Die folgenden Besonderheiten sind es, wodurch sich die sublitorale und archibenthale Fauna der Provinz La Plata nicht nur von den beiden benachbarten Provinzen (Tropische und Patagonische) unterscheidet, sondern die ihr auch den Rang einer Provinz verleihen:

(1) Die Seeanemonen erreichen hier ihre höchste Diversität (13 von insgesamt 19 Arten kommen hier vor); viele Arten zeigen hohe Siedlungsdichte, auffallende Körpergröße und hohe Variabilität. Von auffallender Artenvielfalt sind auch die Mollusken (Stuardo, 1964) und die Fische (Lopez, 1964), wobei erstere ebenfalls sehr variabel sind (Dell, 1956; Kaiser, 1977a). Viele Phyto- und Zooplankter haben über der südlichen Grenze der Provinz "Gedeihgebiete" (Lohmann \& Hentschel, 1939; Boltovskoy, 1964; Bückmann, 1974).

(2) Die Tiefenverbreitung vieler Aktinien-Arten ist innerhalb und außerhalb der Provinz verschieden: Neben einer auffallenden Eurybathie sublitoraler wie auch archibenthaler Arten, die bei wärmeliebenden wie auch bei kälteliebenden Arten beobachtet wurde, gibt es zwei Arten, die außerhalb der Provinz - teilweise weit entfernt - in einer anderen Tiefe gefunden wurden (Amphianthus aff. lacteus und Hormathia pectinata siehe Abb. 7). Ungewöhnliche Eurybathie wurde auch von Krefft (1968) bei Fischen festgestellt. 
(3) Fast alle Seeanemonen-Arten, die in der Provinz La Plata gefunden wurden, haben hier auch eine ihrer Verbreitungsgrenzen. Unter den sublitoralen Aktinien macht nur Antholoba achates eine Ausnahme, indem sie die Provinz offenbar völlig unbeeindruckt durchquert (Abb. 4,5). Somit wird auch von den Aktinien wie von zahlreichen anderen Taxa (Palacio, 1982) diese Provinz als die wohl wichtigste tiergeographische Grenze der südamerikanischen Ostküste beachtet. Im Sublitoral und oberen Archibenthal vollzieht sich der Faunenwechsel bei den Seeanemonen zwischen $36^{\circ}$ und $38^{\circ} \mathrm{S}$; auf dem Schelf liegt die Grenze näher bei $36^{\circ} \mathrm{S}$, wohingegen in der Tiefenzone zwischen 200 und $600 \mathrm{~m}$ die Fundorte von Isosicyonis alba, Isotealia antarctica und Actinauge longicornis die hydrographischen Befunde von Hubold (1980b; p. 39) bestätigen, daß die Grenzlinie der subtropischen Konvergenz ganzjährig zwischen $37^{\circ}$ und $39^{\circ} \mathrm{S}$ anzutreffen ist (Abb. 7). Die in der Literatur recht zahlreichen Beispiele von Arten, die nur in dieser Provinz gefunden wurden, dürfen jedoch vielfach nicht als Endemismen gewertet werden, da sie oft identisch sind mit Arten, die weit entfernt in zirkumantarktischen Lebensräumen angetroffen wurden. Unter den Seeanemonen sind dies Hormathia pectinata und Amphianthus aff. lacteus (siehe unten); von anderen Tiergruppen sind viele Arten der "Challenger"-Station 320 zu nennen.

(4) An der südlichen Grenze der Provinz La Plata liegt in der Tiefenzone zwischen 600 und $1200 \mathrm{~m}$ die "Challenger-Terrasse", eine Stufe im sonst steil abfallenden Kontinentalabhang. Die "Challenger-Terrasse" ist zwischen $37^{\circ}$ und $39^{\circ} \mathrm{S}$ besonders deutlich ausgebildet und hat eine Breite von 35 bis $70 \mathrm{~km}$. Die erste Benthos-Probe von dieser Terrasse wurde am 14. Februar 1876 von Bord des englischen Forschungsschiffes "Challenger" genommen (Station 320: $37^{\circ} 17^{\prime} \mathrm{S}, 53^{\circ} 52^{\prime} \mathrm{W}, 1097 \mathrm{~m}$; Bodentemperatur $2,88^{\circ} \mathrm{C}$, Oberflächentemperatur $19,7^{\circ} \mathrm{C}$ ). Das Grundschleppnetz enthielt einen der reichsten Fänge der gesamten "Challenger"-Expedition mit 127 Arten, wovon 103 neu für die Wissenschaft waren (Murray, 1895). Der besondere Charakter dieser Lebensgemeinschaft wurde erst in jüngerer Zeit diskutiert (Cairns, 1983; p. 61; Monniot \& Monniot, 1983; p. 9); viele der dort vorgefundenen Arten haben disjunkte Verbreitungsgebiete und wurden sonst nur viel weiter südlich gefunden, einige sogar nur in der Antarktis.

In Würdigung der Pionierleistung der historischen "Challenger"-Reise, aber auch um die tiergeographische Sonderstellung dieser archibenthalen Stufe an der südlichen Grenze der Provinz La Plata zu betonen, nenne ich sie "Challenger-Terrasse".

Zusammenfassend kann man sagen, daß in der Provinz La Plata SeeanemonenArten mit sehr verschiedenen ökologischen Ansprüchen und Toleranzen räumlich eng beieinander leben. Es wäre dennoch falsch, daraus den Schluß zu ziehen, daß im tieferen Sublitoral und oberen Archibenthal mittlere Lebensbedingungen herrschen, die all diesen Arten gerecht werden (Krefft, 1968; p. 38). Vielmehr reflektiert meiner Ansicht nach die Uppigkeit der Fauna offenbar das dreidimensionale Muster verschiedener Wassermassen und Lebensbedingungen (Boschi, 1964a; p. 14; Owen, 1981; p. 197), die in der Provinz La Plata in hohem Maße stabil und stationär zu sein scheinen.

Phellia exlex. Neben dem aus $100 \mathrm{~m}$ Tiefe $\left(36^{\circ} 5^{\prime} \mathrm{S}\right)$ stammenden, von "Walther Herwig" 1966, St. 450, gesammelten Exemplar sind nur noch die beiden Typus-Tiere aus dem Sublitoral der chilenischen Küste (Calbuco, ca. $42^{\circ} \mathrm{S}, 73^{\circ} \mathrm{W}$ ) bekannt. Die Fundorte zeichnen sich durch relativ hohe Temperaturen aus $\left(8-11^{\circ} \mathrm{C}\right)$; vermutlich handelt es sich um Vertreter einer amphiamerikanischen Warmwasserfauna, die in 
Warmzeiten vielleicht einmal in Verbindung stand (G. Hartmann, 1964; p. 283; Diskussion zu "Biogéographie et écologie des animaux marins").

Hormathia pectinata. Diese Seeanemone kommt nach gegenwärtiger Kenntnis in fünf relativ weit auseinanderliegenden Gebieten vor, wovon vier im Archibenthal liegen und eines im Archibenthal und Sublitoral (Abb. 10). Das erste Gebiet ist die "Challenger-Terrasse" mit vier Fundorten (sieben Tiere) zwischen 800 und $1220 \mathrm{~m}$ Tiefe. Fünf Fundorte befinden sich zwischen 400 und $950 \mathrm{~m}$ Tiefe südlich und südöstlich der Falkland-Inseln. Der Locus typicus (Hertwig, 1882) liegt im Archibenthal Südchiles $\left(49^{\circ} 24^{\prime} \mathrm{S}, 265 \mathrm{~m}\right)$, wo zwischen $52^{\circ}$ und $53^{\circ} \mathrm{S}$ ein weiteres Fundortgebiet der Art in 512 bis $845 \mathrm{~m}$ Tiefe liegt (McMurrich, 1893: 3 Tiere; Eltanin cruise 6, St. 339: 1 Tier; Eltanin cruise 7, St. 558: 1 Tier; Eltanin cruise 21, St. 291: 4 Tiere; Eltanin cruise 23, St. 1605: 1 Tier). Doumenc (1984) beschreibt 4 Tiere von 3 Fundorten aus Mittelchile $\left(32^{\circ}\right.$ bis $33^{\circ} \mathrm{S}$, $350-400 \mathrm{~m}$ ). Sieben Fundorte werden von Carlgren (1959; pp. 6-9) zwischen $41^{\circ} 30^{\prime} \mathrm{S}$ und $42^{\circ} 26^{\prime} \mathrm{S}(50$ bis $300 \mathrm{~m}$ ) an der chilenischen Küste genannt; die dort gefundenen Tiere haben allerdings wegen ihrer geringen Körpergröße und abweichender CnidomMerkmale (vgl. Riemann-Zürneck, 1973; Abb. 2, Tab. 3, p. 284) einen unsicheren taxonomischen Status. Möglicherweise handelt es sich um eine allochthone Kümmerform, die Pseudopopulationen im Sinne von Mileikovski (1971) bildet, entstanden aus Larven, die in Auftriebsgebieten Südchiles bis in das Sublitoral vordringen können (Brattström \& Johanssen, 1983).

Hertwig (1882; p. 72 und 1888; p. 25) hatte die ersten drei Exemplare dieser Art in Händen und vermutete auch, daß sie trotz der enormen Entfernung der Fundorte (Südchile und La Plata) derselben Art angehören (1888; p. 26). Durch die "WaltherHerwig"'-Funde bei den Falkland-Inseln ist diese Entfernung nun zwar etwas geringer geworden, es bleibt aber eine Verbreitungslücke von etwa $1500 \mathrm{~km}$ vor der argentinischen Küste. Die Überbrückung so großer Entfernungen mit der bei dieser Art zu erwartenden kurzlebigen Schopflarve ist nicht vorstellbar; möglicherweise handelt es sich bei Hormathia pectinata um eine Seeanemone, die an das Gradientenfeld von archibenthalen Fronten gebunden ist (siehe Zusammenfassung und Schlußfolgerungen).

Amphianthus aff. lacteus (Abb. 7 und 10). Diese Seeanemone, deren exakte Identifizierung ohne eine Revision der Gattungen Amphianthus und Stephanauge nicht möglich ist, hat ein ähnliches Verbreitungsmuster wie Hormathia pectinata, jedoch eine abweichende Tiefenverbreitung. Der Fundort des Typen-Materials liegt ebenfalls im Archibenthal Südchiles $\left(48^{\circ} 9^{\prime} \mathrm{S}, 810 \mathrm{~m}\right)$. McMurrichs Art A. lacteus wurde bisher nicht wieder gefunden, aber die bei Heezen \& Hollister (1971; Fig. 2.20) abgebildeten Seeanemonen scheinen in-situ-Exemplare dieser Art zu sein. Diese Tiere wurden am Durchlaß zwischen Staaten-Insel und Burdwood-Bank $\left(54^{\circ} \mathrm{S}, 62^{\circ} 2^{\prime} \mathrm{W}\right)$ in $398 \mathrm{~m}$ Tiefe fotografiert.

Die Exemplare von "Walther Herwig" stammen von sieben Stationen (Abb. 7). Nördlich der subtropischen Konvergenz (WH St. 400 und 450) und bei den FalklandInseln (St. 326 und 639) fand sich die Art in 100 bis $200 \mathrm{~m}$ Tiefe, auf der Südseite der subtropischen Konvergenz dagegen liegen die drei Fundorte (St. 261, 275, 388) 300 Meter tiefer. Dieser Vertikalsprung in der Verbreitung nördlich und südlich der subtropischen Konvergenz hängt vielleicht mit dem ozeanographischen Phänomen zusammen, daß das "Subantarktische Zwischenwasser" an der subtropischen Konvergenz 
einen Vertikalsprung um mehrere hundert Meter macht (Wüst \& Defant, 1936; Sverdrup, 1933; Lusquinos, 1966; Pizarro, 1967; Lusquinos \& Valdez, 1971; p. 15).

\section{Provinz Patagonien}

Die Provinz Patagonien erstreckt sich nach meiner Auffassung zwischen den beiden wohl schärfsten tiergeographischen Grenzen des südamerikanischen Sublitorals, nämlich $42^{\circ} \mathrm{S}$ auf der pazifischen Seite (vgl. Brattström \& Johanssen, 1983; p. 328) und $38^{\circ} \mathrm{S}$ auf der atlantischen Seite.

Breitengrade als Grenzen tiergeographischer Einheiten sind häufig ein Indiz für eine eher künstliche Gliederung, die weniger die hydrographischen Verhältnisse berücksichtigt als vielmehr terrestrische Grenzmarken oder die Sammelaktivität in bestimmten Küstenabschnitten (Brattström \& Johanssen, 1983; Ekman, 1967; p. 155). Hier jedoch sind die Breitengrade identisch mit hydrographischen Grenzen und beziehen sich ausdrücklich auf das Sublitoral und obere Archibenthal, nicht jedoch auf die litoralen und bathyalen Lebensräume. In den ausgeklammerten Tiefenzonen gelten andere Lebensbedingungen und tiergeographische Grenzen (vgl. Vasquez et al, 1980; summary; Monniot \& Monniot, 1983; p. 9), für deren genauere Analyse zur Zeit kein Material zur Verfügung steht.

Die sublitorale Provinz Patagonien zeichnet sich hydrographisch dadurch aus, daß trotz - vielleicht auch wegen - der Anwesenheit besonders kräftiger Fronten und Strömungen die Lebensbedingungen im Sublitoral erstaunlich stabil sind und kaum jahreszeitlichen oder latitudinalen Veränderungen unterworfen sind (für die chilenische Küiste stellen dies Brattström \& Johanssen [1983] fest).

Es scheint sogar, daß hydrographische Einflüsse bei Feuerland, den Falklands und vor Nordargentinien und Nordchile ausgleichend auf die jahreszeitlichen und latitudinalen Unterschiede wirken, indem leicht erhöhte Temperaturen im Herbst und Winter bei Feuerland und den Falklands vorkommen (WH 1978, St. 590 und St. 537), während an der subtropischen Konvergenz vor Nordargentinien gerade im Sommer (Januar/ Februar) besonders tiefe Temperaturen gemessen wurden (Klähn, 1911; p. 658; WH 1970/71, St. 340). Ahnlich mäßigende Einflüsse beschreiben Brattström \& Johanssen (1983) auch für die chilenische Küste.

Sublitorale Organismen, die ganzjährig gemäßigte Lebensbedingungen ohne Extreme bevorzugen, sind daher in der Provinz Patagonien weit verbreitet (vgl. Stuardo, 1964 ; p. 90). Unter den Seeanemonen ist dies Antholoba achates (Abb. 4), eine vivipare Art, die ein weites Spektrum von Habitaten und Substraten besiedelt (Sebens \& Paine, 1979; Table 4); sie ist von den äquatorialen Galapagosinseln im Pazifik entlang der peruanischen und chilenischen Küste verbreitet (Carlgren, 1949; Sebens \& Paine, 1979), kommt im Südwestatlantik sublitoral von Kap Horn bis Uruguay vor und wurde auch bei Südgeorgien nachgewiesen (Dunn, 1984).

Die Provinz Patagonien stößt an die Provinz La Plata mit drei zueinander parallel verlaufenden Subprovinzen, die jedoch eine unterschiedliche latitudinale Ausdehnung haben:

(1) Warmwasser-Sublitoral Argentiniens. Tiefenbereich 50 bis $90 \mathrm{~m}$; südliche Grenze bei $44^{\circ} \mathrm{S}$. Referenz-Art: die Corallimorpharie Corynactis carnea (Abb. 5). 
(2) Temperiertes Sublitoral Argentiniens. Tiefenbereich 80 bis $250 \mathrm{~m}$; südliche Grenze bei $50^{\circ} \mathrm{S}$. Referenz-Art: Isotealia antarctica (Abb. 6).

(3) Kaltwasser-Archibenthal Patagoniens. Tiefenbereich 100 bis etwa $1000 \mathrm{~m}$ (die untere Grenze ist durch das Material bestimmt); die Subprovinz umfaßt die gesamte patagonische Provinz in diesen Tiefen. Referenz-Arten: Isosicyonis alba, Bolocera tuediae kerguelensis, die Siphonophore Rhodalia miranda, Epiactis georgiana und Sicyonis erythrocephala (Abb. 1, 7, 8, 10).

\section{Subprovinz Warmwasser-Sublitoral Argentiniens}

Referenz-Art: die Corallimorpharie Corynactis carnea Studer, 1879.

Die Subprovinz schließt bei $38^{\circ}$ Süd an die Provinz La Plata an, bezieht sich aber nur auf den sublitoralen, 50 bis $90 \mathrm{~m}$ tiefen Küstenstreifen, der sich von Mar del Plata bis nahe an den Golfo San Jorge $\left(44^{\circ} \mathrm{S}\right)$ erstreckt. Die Litoralfauna der Subprovinz ist weitgehend unbekannt. Die von "Walther Herwig" im Sommer 1970/71 nahe der Küste gemessenen Oberflächen-Temperaturen sind regelmäßig tiefer als weiter außerhalb (ablandige Winde). Dies läßt vermuten, daß der Charakter der Litoralfauna von dem der Sublitoralfauna abweicht; das Vorkommen von Pinguinen (Hentschel, 1936; Abb. 116) und See-Elefanten (Castello, 1984) an der Küste mag ein Indiz hierfür sein. Hydrographisch begrenzt wird die Subprovinz von der besonders im Sommer kräftigen Sprungschicht, an der sich der Patagonische Strom beteiligt.

Das Verbreitungsgebiet der Referenz-Art reicht vielleicht in Küstennähe viel weiter nach Norden: Die von Den Hartog $(1980 ;$ p. 18) als "Corynactis spec. 2 " beschriebene, bei Cabo Frio $\left(23^{\circ} \mathrm{S}\right)$ gefundene Corallimorpharie ist möglicherweise identisch mit Corynactis carnea.

Wie ich schon 1979 (p. 234) feststellte, ist die von Zamponi (1976) als "Sphincteractis sanmatiensis gen. et $\mathrm{sp}$. nov." beschriebene Art sehr wahrscheinlich identisch mit $C$. carnea. Da die meisten von Zamponi (p. 131) angegebenen Fundorte auf dem Festland liegen, erlaube ich mir, die Längenangaben um 5 Grad nach Osten zu verlegen und seine Fundorte in meine Verbreitungskarte von $C$. carnea aufzunehmen (Abb. 5).

C. carnea ist eine bis $1 \mathrm{~cm}$ große Corallimorpharie, die von "Walther Herwig" 1971 an den Stationen $315,316,317,319$ und 338 gesammelt wurde in Tiefen zwischen 52 und $92 \mathrm{~m}$, bei Temperaturen von 9,2 bis $14,5^{\circ} \mathrm{C}$. Wie das von Studer (1879) beschriebene Typ-Material sitzen die gefundenen Tiere in großer Zahl auf den Zweigen von Hydroiden.

Aus dem Warmwasser-Sublitoral Argentiniens sind zahlreiche pelagisch und benthisch lebende Organismen bekannt, die aus brasilianischen Gewässern mit dem die hydrographischen Bedingungen bestimmenden oberflächlichen Ausläufer des Brasilstromes eindringen (Fische: Krefft, 1968; Stehmann \& Lenz, 1972; Ehrich, 1980. Echinodermen: Fell et al., 1969; sowie Fell \& Dawsey, 1969; Bernasconi, 1973; Bernasconi \& d'Agostino, 1977; Bartsch, 1982. Polychaeten: Hartmann-Schröder, 1983; p. 267. Gastropoden: Kaiser 1977a, b; Castellanos, 1982. Dekapoden: Boschi, 1964. Foraminiferen: Boltovskoy \& Watanabe, 1980).

Die Subprovinz beherbergt eine euryöke Warmwasserfauna, die sich durch Artenarmut und hohe Konzentrationen weniger Arten zu bestimmten Jahreszeiten auszeichnet (Boschi, 1964b). Als negatives Charakteristikum kann für die Seeanemonen hinzugefügt werden, daß die Subprovinz von allen anderen auf dem argentinischen Schelf vorkom- 


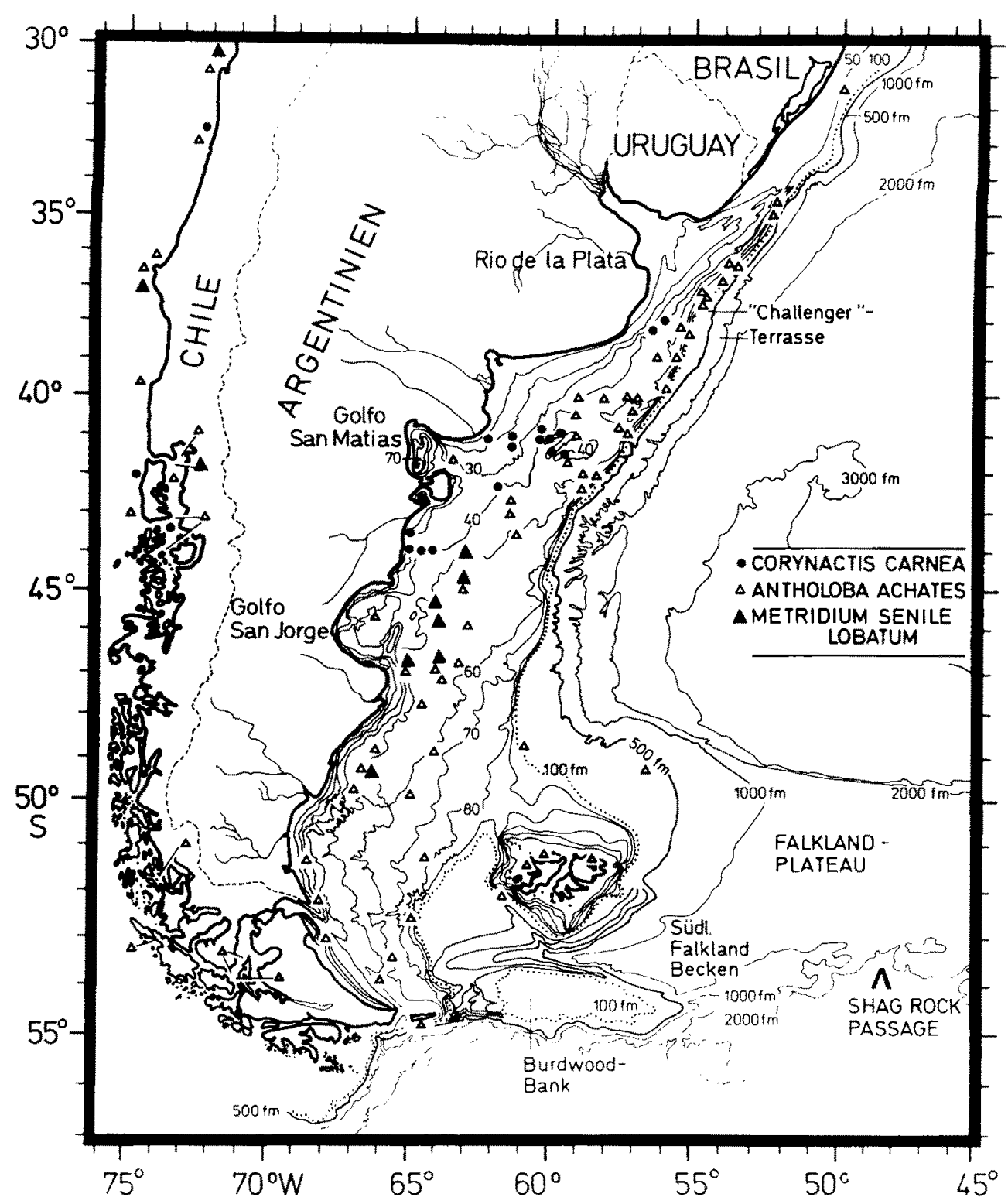

Abb. 5. Fundorte von Corynactis carnea, Antholoba achates und Metridium senile lobatum. Corynactis carnea (Corallimorpharia) ist ein typischer Bewohner der Subprovinz "WarmwasserSublitoral Argentiniens" und kommt auch an der chilenischen Küste vor. Metridium senile lobatum scheint auf dem argentinischen Schelf korreliert mit dem "Patagonischen Strom" 
menden Arten gemieden wird. Es handelt sich offenbar um eine opportunistische Lebensgemeinschaft, die sich immer wieder aus Einwanderern rekrutieren muß, die mit dem Warmwasser (besonders im Sommer) eindringen (vgl. Balech, 1964; p. 110). Die instabilen und unregelmäßigen hydrographischen Verhältnisse in Bodennähe erlauben offensichtlich nicht die Ansiedlung einer langlebigen, sessilen Fauna. Okologische Existenzgrundlage dieser stürmischen Populationsdynamik ist die durch Konvektion, Auftrieb und bodennahen Einstrom nährstoffreichen Wassers bedingte hohe Primärproduktion (Brandhorst \& Castello, 1971; p. 30; El Sayed, 1967; p. 36; Mandelli, 1965) mit hohen Planktondichten im Frühling (Ciechomski \& Sanchez, 1983; Figs 2 und 3).

Tiergeographisch bedeutsam ist, daß die T/S-Schwankungen in den Buchten und Golfen (Bahia Blanca, Golfo San Matias, Golfo San Jorge) viel geringer sind und im Jahresmittel relativ stabile Bedingungen bieten; sie werden daher auch von einigen Fischen (Ehrich, 1980) und Cephalopoden (Schöne, 1974) als Winterquartier genutzt. Zur Verbreitung der Seeanemonen ist lediglich zu sagen, daß Antholoba achates, die in der Subprovinz sonst nicht vorkommt, jeweils einen Fundort im Golfo San Matias und einen im Golfo San Jorge hat.

C. carnea kommt auch an der chilenischen Küste zwischen $38^{\circ}$ und $42^{\circ} \mathrm{S}$ vor (Carlgren, 1927; Carter, 1965), offenbar jedoch nicht südlich davon (Abb. 5). Ein solches Verbreitungsbild ist auch bei einigen anderen Arten verschiedener Taxa bekannt (Stuardo, 1964; pp. 86/87; Stehmann \& Lenz, 1972). Neben der schon bei Phellia exlex genannten Hypothese, daß eine früher zusammenhängende Warmwasserfauna zurückgedrängt wurde, vermuten Stehmann \& Lenz (1972) für ähnlich getrennte Fischbestände von Seriolella punctata, daß die Populationen auch heute noch zumindest zeitweise miteinander in Verbindung stehen. Dies sei entweder durch passive Verdriftung von Eiern und Larven möglich oder durch aktive Einwanderung der Adulten; die beiden Autoren betonen (p. 196), daß die Einwanderung nur in der Richtung von der chilenischen zur argentinischen Küste möglich sei.

Auch die Populationen von C. carnea könnten während der wärmsten Jahreszeit (Spätsommer, Oberflächen-Temperaturen auch bei Feuerland noch $10^{\circ} \mathrm{C}$ : nach Gordon \& Molinelli, 1982), vielleicht aber auch nur in besonders warmen Ausnahmejahren diese Einwanderungsroute benützen. Die geringe Körpergröße der Art und die Besiedlung leicht verdriftbarer Hydroiden-Zweige, möglicherweise auch Großalgen (vgl, den Hartog, 1980; p. 77), läßt die adulten Tiere als Verbreitungsstadien geeignet erscheinen. Sexuelle Fortpflanzung ist innerhalb der Gattung Corynactis offenbar nur bei besonders günstigen Temperaturverhältnissen üblich (Schmidt \& Zissler, 1979; p. 8); solche Ausnahmebedingungen würden gleichzeitig der südamerikanischen $C$. carnea die Umwanderung Kap Horns erleichtern. Leider sind bisher von keiner Corallimorpharie Larven oder Entwicklungsstadien bekannt.

Eine Art, die Corynactis carnea nahesteht, vielleicht sogar identisch mit ihr ist, ist die südafrikanische Corynactis annulata (siehe Carlgren, 1938; p. 14 und 1941; pp. 2-4), die auch an einigen Inseln des mittelatlantischen Rückens vorkommt (vgl. den Hartog, $1980 ;$ p. 77).

\section{Subprovinz Temperiertes Sublitoral Argentiniens}

Referenz-Art: Isotealia antarctica (Carlgren, 1899); Riemann-Zürneck, 1980; p. 29 , Abb. 5 und Tafel II, Figs 5, 6 (s. Abb. 6). 


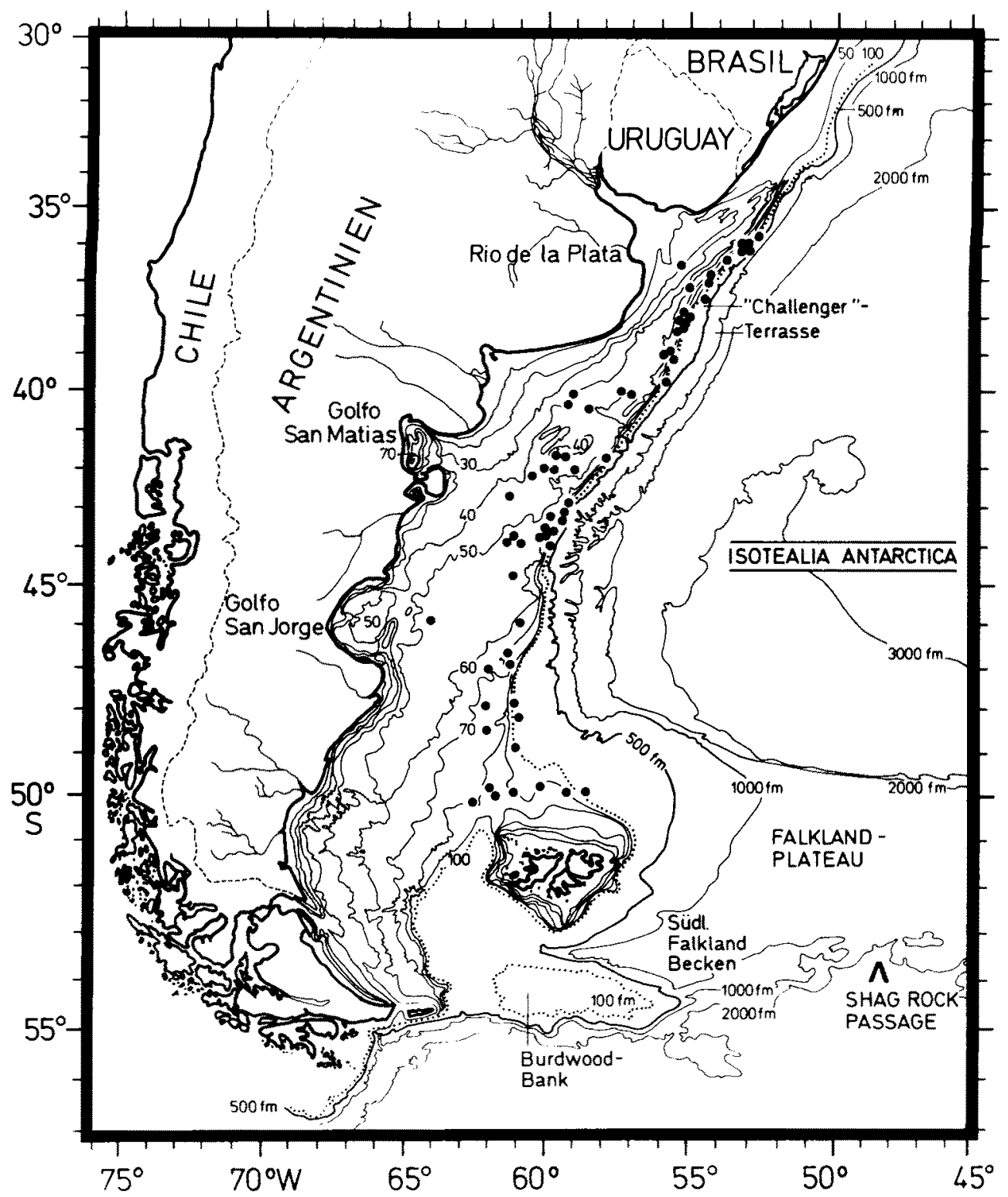

Abb. 6. Fundorte der Seeanemone Isotealia antarctica. Die Art charakterisiert die Subprovinz "Temperiertes Sublitoral Argentiniens", dringt aber auch an einigen Stellen in das Archibenthal vor (vgl. Abb. 7) 
Das temperierte Sublitoral Argentiniens schließt sich bei $38^{\circ} \mathrm{S}$ an die Provinz "La Plata" an, verläuft parallel zur Subprovinz Warmwasser-Sublitoral, aber in etwas größeren Tiefen ( 80 bis $250 \mathrm{~m}$ ); bei $44^{\circ} \mathrm{S}$ löst sich die Subprovinz von der 80 -Meter-Linie und nähert sich, nach Süden vorstoßend, den Falkland-Inseln, wo ihre südliche Grenze mit dem 50. Breitengrad zusammenfällt.

Die Subprovinz wird küstenwärts begrenzt durch den "Patagonischen Strom", derzumindest im Sommer - an der Bildung einer kräftigen Sprungschicht beteiligt ist. Eine Seeanemone, die offenbar diesen Strom oder die damit verbundene Front begleitet, ist Metridium senile subsp. lobatum (Riemann-Zürneck, 1975a; pp. 88-94), die südamerikanische Unterart der sonst nur in borealen Regionen bekannten Nominatform (s. Abb. 5).

Wie aus meiner Beschreibung der Fundort-Daten von Isotealia antarctica hervorgeht $(1980 ;$ p. 31$)$, ist der Artname "antarctica" nicht sehr glücklich gewählt, denn die insgesamt 146 Tiere von 53 Stationen der "Walther-Herwig" -Reisen stammen von Fundorten, an denen Temperaturen zwischen 5 und $7^{\circ} \mathrm{C}$ gemessen wurden und die damit keineswegs antarktischen Charakter haben.

Auf kleinmaßstäbigen detailarmen Karten (vgl. Bellisio \& Lopez, 1973; carta No. 4) scheinen die 5- bis 7-Grad-Isothermen wie auch die Fundorte von Isotealia (Abb. 5 bei Riemann-Zürneck, 1980) parallel zur Schelfkante zu verlaufen. Wählt man jedoch einen größeren Maßstab, so wird deutlich, daß ganz besonders zwischen $40^{\circ} \mathrm{S}$ und $42^{\circ} \mathrm{S}$ die Isothermen wie auch die Isotealia-Fundorte von der Schelfkante zurückweichen (Abb. 6). Das Meiden dieses offenbar ständig unter Kaltwassereinfluß stehenden Schelfkanten-Abschnittes (Haupt des Bahia-Blanca-Canyons) zeigt auch Choriactis laevis.

Noch deutlicher wird das Verteilungsmuster von $I$. antarctica auf einer Karte der Vertikalverteilung (Abb. 7), die veranschaulicht, daß die Tiefenverbreitung der Art $(100-200 \mathrm{~m})$ in drei fest umrissenen Gebieten ausgedehnt wird: Die ersten beiden Unregelmäßigkeiten finden sich in der Provinz La Plata, wo die Art zwischen 35 und $600 \mathrm{~m}$ Tiefe gefunden wurde, wobei sich die Fundorte in zwei vertikalen Streifen anordnen, der erste entlang des 38. Breitengrades (von 150 bis $600 \mathrm{~m}$ Tiefe) und der zweite, etwas unregelmäßigere, zwischen $35^{\circ} \mathrm{S}$ und $36^{\circ} 30^{\prime} \mathrm{S}$ (von 35 bis $400 \mathrm{~m}$ Tiefe). Während die erste Linie, die auch durch die Fundorte zweier anderer Seeanemonen (Isosicyonis alba und Actinauge longicornis) belegt ist, identisch ist mit der Konvergenzlinie zwischen subtropischem und subantarktischem Wasser, dokumentiert die zweite Linie der Isotealia-Fundorte vielleicht die im Winter etwas nördlicher liegende Konvergenzlinie (Aragno, 1968; p. 158; Hubold, 1980b; Fig. 16: Section I) oder die ebenfalls in diesen Breiten liegende Windgrenze (Deacon, 1982).

Die dritte Abweichung aus ihrer normalen Tiefenverbreitung zeigt Isotealia antarctica zwischen dem 43. und 44. Grad südlicher Breite, wo sie zwischen 100 und $350 \mathrm{~m}$ Tiefe vorkommt. Noch tiefer (bis $900 \mathrm{~m}$ ) und in einem noch breiteren Abschnitt des Schelfhanges (zwischen $41^{\circ}$ und $45^{\circ} \mathrm{S}$ ) dringt hier eine andere Schelfaktinie (Choriactis laevis) ins Archibenthal vor. Meiner Auffassung nach ist der Abstieg von Schelfarten zwischen 41 und 45 Grad Süd bedingt durch die von Lonardi \& Ewing (1971; p. 99) beschriebenen "turbidity currents", die über das Colorado-Negro-Canyon-System bis in die Tiefsee vordringen. Biologische Auswirkungen der über den Schelfhang abgleitenden Wassermassen waren bisher nicht bekannt; jedoch könnten die hohen ChlorophyllKonzentrationen, die Nehring \& Brosin (1968; p. 15) in Tiefen zwischen 70 und $150 \mathrm{~m}$ 
fanden, ebenso auf diese Wassermassen hinweisen, wie einige rätselhafte Funde neritischer Tiere im Tiefenwasser außerhalb des Schelfes (z. B. Thiel, 1935: Leptomeduse).

Wie gesagt, lassen sich die Fundorte von Isotealia mit Temperaturen zwischen 5 und $7^{\circ} \mathrm{C}$ korrelieren, häufig liegen sie nahe $6^{\circ} \mathrm{C}$. Die Aufrechterhaltung derart gleichmäßiger Temperaturen über 15 Breitengrade (ca. $1600 \mathrm{~km}$ ) hinweg - offenbar auch unabhängig von den Jahreszeiten - setzt meiner Ansicht nach eine stabile, südwärts gerichtete Warmwasserkomponente voraus.

Hydrographisch scheint über einen stabilen "warmen" Unterstrom westlich der Schelfkante nichts bekannt zu sein. Anders jedoch im freien Ozean: Dort findet sich zwischen $35^{\circ}$ Süd und $55^{\circ} \mathrm{S}$ (auf $30^{\circ}$ West) in 80 bis $200 \mathrm{~m}$ (Deacon, 1937; p. 48, Fig. 13) bzw. in 100 bis $300 \mathrm{~m}$ (Heath, 1976; nach Deacon, 1982, p. 5) eine Schicht salzreichen Wassers, die sich als Unterstrom in südlicher Richtung bis etwa $48^{\circ} \mathrm{S}$ bewegt. Diese Schicht entsteht nach Deacon an der Windgrenze nördlich der subtropischen Konvergenz. Einige Hinweise, daß dieser schwache, aber beständige Unterstrom auch nahe der südwestatlantischen Schelfkante vorhanden ist, finden sich bei Nehring \& Brosin (1968), Brandhorst \& Castello (1971) und Zyryanov \& Severov (1979). Nehring \& Brosin fanden (p. 49) Temperatur-Inversionen in 110 bis $140 \mathrm{~m}$ nahe der Schelfkante (St. 350 und St. 428). Bei Brandhorst \& Castello (1971) können die Minimal-Gebiete der ChlorophyllVerteilung (p. 36, Fig. 22) an der Oberfläche als Indiz für nährstoffarmes, aus dem Norden eindringendes Wasser gedeutet werden. Zyryanov \& Severov (1979; p. 522 und Fig. 2 und 3) beschreiben an der Oberfläche und in $100 \mathrm{~m}$ Tiefe eine schwache Strömung mit südlicher Tendenz zwischen Falkland-Inseln und subtropischer Konvergenz. Hydrographische Schnitte, die an der Schelfkante Einschlüsse von Wasser subtropischen Ursprungs erkennen lassen, finden sich bei Aragno, 1968 (p. 158), im Atlas Oceanografico (Anonymus, 1972) und bei Hubold, 1980 b (p. 38, Fig. 19).

Diese hydrographischen Hinweise geben mir Grund zu der Annahme, daß ein südwärts gerichteter Unterstrom zumindest im nördlichen Teil des Schelfs nahe der Schelfkante verläuft und der an gemäßigte Temperaturen gebundenen Seeanemone I. antarctica Lebens- und Ausbreitungsbedingungen bietet. Der südlichste Teil ihres Fundort-Gebietes wird vermutlich, wie im Abschnitt "Warmwasser-Archibenthal" beschrieben, zusätzlich von Warmwasserkörpern beeinflußt, die an und unter der Oberfläche aus nordöstlicher Richtung auflaufen.

Wie ich schon 1980 (p. 32) feststellte, sprechen die Bindung von I. antarctica an gemäßigte Temperaturen und ihre entsprechende Verbreitung im Südwestatlantik dagegen, daß die Art auch in der Antarktis vorkommt, wie von Pax (1926) und von Dayton et al. (1970; p. 247) berichtet wird. Dagegen erscheint mir ihr Vorkommen an der chilenischen Küste, das ich 1980 ebenfalls für unwahrscheinlich hielt, im Lichte der hydrographischen Informationen von Brattström \& Johanssen (1983) möglich.

Entwicklungsstadien und Verbreitungsmechanismen sind von I. antarctica bisher nicht bekannt; aus der Größe der reifen Oocyten kann auf eine lecithotrophe Larve geschlossen werden (Riemann-Zürneck, 1976), die vermutlich freilebend (pelagisch oder demersal) ist, da es keine Hinweise auf Viviparie gibt.

\section{Subprovinz Kaltwasser-Archibenthal}

Referenz-Arten: Isosicyonis alba (Studer, 1879) Riemann-Zürneck, 1980; p. 24, Abb. 3, 4; Tafel II, Fig. 1-3; Tafel III, Fig. 1; Dunn, 1984; p. 9, Fig. 11 (s. Abb. 1). 
Epiactis georgiana Carlgren, 1927; Dunn, 1983; p. 21 (Abb. 10).

Sicyonis erythrocephala (Pax, 1922); Dunn, 1984; p. 25, Fig. 11 (s. Abb. 10).

Die Siphonophore Rhodalia miranda Haeckel, 1888 (s. Abb. 8).

Bolocera tuediae subsp. kerguelensis (Studer, 1879) nov. comb.; vgl. RiemannZürneck, 1980; p. 20; Dunn, 1983; p. 13.

Taxonomische Bemerkung: Dunn (1983; pp. 13, 15-16) vollzieht die Synonymisierung von vier nominalen Bolocera-Arten aus der Antarktis und Subantarktis, darunter auch die von mir als Unterart der Nominatform bewertete Bolocera tuediae ssp. occidua (s. Riemann-Zürneck, 1980; p. 20). Auch ich bin der Ansicht (1980; p. 24), daß die meisten nominalen Bolocera-Arten Synonyme ein und derselben Art, nämlich der Nominatform Bolocera tuediae, sind. Die von mir als Unterart-Merkmale gewerteten Unterschiede gegenüber $B$. tuediae (vereinzeltes Auftreten von Brutpflege und unterschiedliche Größe des parasitischen Copepoden) betrachtet Dunn (1983) als Artkriterien, obwohl das von ihr untersuchte Material diese Merkmale nicht zeigte. Meiner Ansicht nach sind das sporadische Auftreten von Brutpflege und die veränderten allometrischen Verhältnisse des Parasiten schöne Beispiele der Variabilität und Unterartbildung bei veränderten Umweltbedingungen und genetischer Isolation (siehe Dell, 1956; p. 198; de Lattin, 1967; p. 134). Durch die Untersuchungen von Dunn ist nachgewiesen, daß die zirkumantarktischen und südwestatlantischen Funde der gleichen Art angehören. Durch die Priorität des Namens kerguelensis (Studer, 1879) gegenüber occidua (McMurrich, 1893) ergibt sich die Neukombination Bolocera tuediae kerguelensis.

Das Kaltwasser-Archibenthal der Provinz Patagonien beginnt an der subtropischen Konvergenz und umfaßt den obersten Abschnitt des Schelfhanges zwischen Schelfkante und $1200 \mathrm{~m}$ Tiefe. Bei den untersuchten Seeanemonen ist die vertikale Grenze der Subprovinz durch das zur Verfügung stehende Material vorgegeben; jedoch scheint in Tiefen zwischen 1000 und $1200 \mathrm{~m}$ eine natürliche Faunengrenze zu verlaufen, wie Monniot \& Monniot (1983; p. 9) für Ascidien feststellen.

Latitudinal umfaßt die Subprovinz die an und unter der Schelfkante liegenden Ausläufer der gewaltigen Canyon-Systeme, schließt bei $48^{\circ} \mathrm{S}$ den weniger erodierten und sanfter abfallenden Schelfhang nördlich und östlich der Falkland-Inseln ein, dringt als "Südliches Falkland-Becken" zwischen Falkland-Inseln, Burdwood-Bank und Feuerland weit nach Westen und Nordwesten vor und geht dann über in die fast senkrecht in die Tiefsee abfallende Wand des Kontinentalhanges am Südrand der Burdwood-Bank und Feuerlands, die sich auf der pazifischen Seite fortsetzt.

Im Kaltwasser-Archibenthal der patagonischen Provinz herrschen ähnlich komplexe hydrographische und ökologische Verhältnisse wie im Archibenthal der Provinz "La Plata" mit einem Mosaik verschiedener Lebensräume, das die topographischen und ozeanographischen Bedingungen reflektiert. Gewaltige Canyon-Systeme und verschiedene Wassermassen, die sich in allen Richtungen des Raumes bewegen, prägen den Charakter von Schelfkante und oberem Schelfhang. Wie im hydrographischen Teil dargestellt, halten Ozeanographen das dynamische System im Südwestatlantik für stabil und stationär, obwohl auch periodische Veränderungen von Richtung, Geschwindigkeit und Tiefenlage der beteiligten Wassermassen bis in die Tiefsee hinab beobachtet oder vermutet werden. Ob dieses ozeanographische System so stabil ist, daß es sich in der Verteilung langlebiger sessiler Benthostiere wie der Seeanemonen widerspiegelt, soll in den folgenden beiden Unterkapiteln untersucht werden. 


\section{Charakter und Herkunft des Zoobenthos der "Challenger-Terrasse"}

Die Analyse des Benthos, insbesondere der sessilen Tiere, erlaubt die Feststellung, daß die seit dem Jahre 1876 (Challenger-St. 320) bekannte Lebensgemeinschaft im Archibenthal südöstlich des La-Plata-Deltas offenbar nördlichster Außenposten einer Fauna ist, die auf Gebiete nahe der antarktischen Konvergenz und dem antarktischen Kontinent beschränkt ist. Für viele der damals gesammelten Invertebraten ist inzwischen nachgewiesen, daß sie Arten angehören, die sonst weiter südlich vorkommen.

Beispiele einiger an der Challenger-Station 320 gesammelter Invertebraten, unter denen mindestens eine Art mit subantarktisch-antarktischen Beziehungen festgestellt wurde: Stylasterina: Boschma \& Lowe (1969), Cairns (1983); Scleractinia: Squires (1969) Cairns (1982); Actiniaria (Hormathia pectinata): eigene Ergebnisse; Siphonophora (Rhodalia miranda): eigene Ergebnisse; Mollusca: Stuardo (1964); Polychaeta: McIntosh (1885), O. Hartman (1964, 1966); Echinodermata: Pawson (1969), Bernasconi (1973); Ascidia: Kott (1969), Monniot \& Monniot (1983); Bryozoa: Hastings (1943), Moyano (1982b).

Auch im freien Wasser wurden südlich und über der "Challenger-Terrasse" mehrfach Arten oder ganze Lebensgemeinschaften entdeckt, die sonst nur in subantarktischer oder antarktischer Umgebung bekannt waren (Lohmann \& Hentschel, 1939: Appendicularien; Lohmann, 1912: Diatomeen; Krüger, 1939: Thaliacee; Balech, 1968: Dinoflagellaten; Esnal, 1968: Salpe; D. Boltovskoy, 1971: Pteropode; Vaz-Ferreira, 1965: Weddell-Robbe und Südlicher See-Elefant).

Wie "antarktisch" die im Archibenthal Nordargentiniens lebende Fauna ist, bedarf einer Analyse der einzelnen Arten und ihrer Verbreitung. Die Definition, wonach Arten dann als subantarktisch oder antarktisch gelten können, wenn sie an entsprechende ozeanographische Bedingungen gebunden sind, versagt in einer hydrographisch und topographisch so komplexen Umgebung, die für viele Arten auch Grenzgebiet ihrer Verbreitung ist. In solchen Fällen kann nur die übrige Verbreitung Auskunft darüber geben, welcher faunistischen Region oder Provinz jede Art angehört.

Von den im Südwestatlantik bis $1200 \mathrm{~m}$ Tiefe gefundenen Seeanemonen sind 4 Arten auch aus der Antarktis bekannt: Actinostola crassicornis (vgl. Riemann-Zürneck, 1978; Abb. 3; Dunn, 1984; Fig. 18), Bolocera tuediae (vgl. Riemann-Zürneck, 1980; Dunn, 1983: "Bolocera kerguelensis'), Isosicyonis alba (vgl. Riemann-Zürneck, 1980; Dunn, 1984) sowie Epiactis georgiana, die an den Stationen 191, 192 und 330 (WH 1971) gesammelt wurde (Abb. 7, 10; vgl. auch Dunn, 1983; Fig. 8). Als weitverbreitete und daher vermutlich euryöke Arten sind $A$. crassicornis und $B$. tuediae nicht als IndikatorArten für subantarktische oder gar antarktische Bedingungen geeignet.

Die zwei anderen Arten leben nach gegenwärtiger Kenntnis in der Antarktis in der gleichen Tiefenzone ( $I$. alba in 80 bis $670 \mathrm{~m}$, E. georgiana in 122 bis $870 \mathrm{~m}$ ), jedoch mit unterschiedlichen Verbreitungsmustern: In der Ross-See haben beide Arten gemeinsame Fundorte (Dunn, 1983), aber an der Westküste der antarktischen Halbinsel scheint nur $I$, alba vorzukommen, während $E$. georgiana häufig entlang des Scotia-Rückens gefunden wurde. Diese Verbreitungsbilder und der Vergleich mit den hydrographischen Charakteristika der betreffenden Gebiete (Gordon \& Molinelli, 1982: Southern Ocean Atlas) lassen vermuten, daß Isosicyonis alba etwas gemäßigtere Lebensbedingungen toleriert, vielleicht sogar bevorzugt. 
Die Fundortgebiete der beiden Arten im Südwestatlantik bestätigen dies nicht nur, sondern zeigen, daß nur Epiactis georgiana als antarktisch angesehen werden kann (Fundorte nur in 800 und $1000 \mathrm{~m}$ Tiefe; s. Abb. 7). Isosicyonis alba und ihre Partnerschnecke Provocator corderoi zeigen dagegen an der argentinischen Schelfkante eine so große Eurybathie ( 45 bis $940 \mathrm{~m}, \mathrm{Abb} .7$ ), daß sie als relativ euryöke subantarktische Arten anzusehen sind, die auch gemäßigtere Lebensräume in der Antarktis besiedeln können.

Dieses tiergeographisch-ökologische Verhalten von Isosicyonis und Provocator scheint für viele Bewohner der archibenthalen "Challenger-Terrasse" typisch zu sein, denn eine ganze Reihe der im Jahre 1876 durch die Challenger-Station 320 wissenschaftlich erfaßten Arten zeigt ähnliche Verbreitungsmuster.

Von dieser historischen Station stammt auch das Typ-Material der TiefwasserSiphonophore Rhodalia miranda Haeckel, 1888, die nach meiner Kenntnis (Totton \& Bargman, 1965) bisher nicht wieder gefunden wurde. $R$. miranda wurde von "Walther Herwig" 1966 und 1970/71 an 13 Stationen gesammelt und mir als "Seeanemone" übergeben, wobei jedoch nicht sicher ist, ob das gesamte Rhodalia-Material zu mir gelangt ist. Die 25 Tiere wurden anhand der Original-Beschreibung von Haeckel identifiziert.

R. miranda hat am argentinischen Schelfhang weitauseinanderliegende Fundortgebiete (Abb. 8): Nordwand der Drake-Straße bei $57^{\circ} 25^{\prime} \mathrm{W}$ in $1000 \mathrm{~m}$ (Februar 1971: St. 242); Schelfhang östlich und nordöstlich der Falkland-Inseln in 350 bis $500 \mathrm{~m}$ (29. Juni 1966 und Januar/Februar 1971); Haupt des Malvinas-Canyon bei 46 bis $47^{\circ} \mathrm{S}$ in 480 und $805 \mathrm{~m}$ (Januar/Februar 1971); "Challenger-Terrasse " bei $37^{\circ} 17^{\prime} \mathrm{S}$ und $37^{\circ} 56^{\prime} \mathrm{S}$ in 1097 und $800 \mathrm{~m}$ (Februar 1876: Locus typicus und St. 121 vom 31. 12. 1970). Die ungewöhnlichsten Fundorte der Siphonophore liegen nördlich der subtropischen Konvergenz, wo sie im Südwinter 1966 an den Stationen 447 und 451 in relativ seichtem (150 und $160 \mathrm{~m})$ und warmem $\left(6,3^{\circ}\right.$ und $\left.8,1^{\circ} \mathrm{C}\right)$ Wasser angetroffen wurde.

Gerade durch diese letzten ungewöhnlichen Fundorte weist sich $R$. miranda als Charakter-Art des "Falkland-Stromes" aus, der nur im Winter einen Ausläufer entlang der uruguayischen und brasilianischen Schelfkante nach Norden entsendet. Da pelagische Coelenteraten wie die Siphonophoren sich besonders dort ansammeln, wo der sie einschließende Wasserkörper auf Landmassen oder Konvergenzlinien stößt (Thiel, 1935; p. 61; Owen, 1981; p. 220), kann man aus den Fundorten von $R$. miranda nicht nur auf die Anwesenheit, sondern auch auf die Bewegungsrichtung des Subantarktischen Zwischenwassers im Südwestatlantik schließen, vielleicht sogar auf dessen hydrographische Grenzschichten.

Die Siphonophoren-Fundorte östlich und nordöstlich der Falkland-Inseln markieren eine Linie, die bei etwa $500 \mathrm{~m}$ Tiefe liegt (Abb. 7). Uberraschenderweise wird diese Linie auch von den Fundorten einer großen benthalen Seeanemone, Bolocera tuediae subsp. kerguelensis (nov. comb., siehe: Taxonomische Bemerkungen), bestätigt. Diese Übereinstimmung findet ihre Erklärung darin, daß Aktinien der Gattungen Bolocera und Liponema dem schlickigen Sediment nur lose aufliegen und offenbar schon von schwachen Strömungen über den Untergrund bewegt werden (Dunn \& Bakus, 1977; Riemann-Zürneck, 1979). Wie Rowe \& Menzies (1969) im Nordatlantik feststellten, ist Bolocera tuediae ein Bewohner der "no motion" -Grenzschicht zwischen sich bewegenden Wassermassen. 


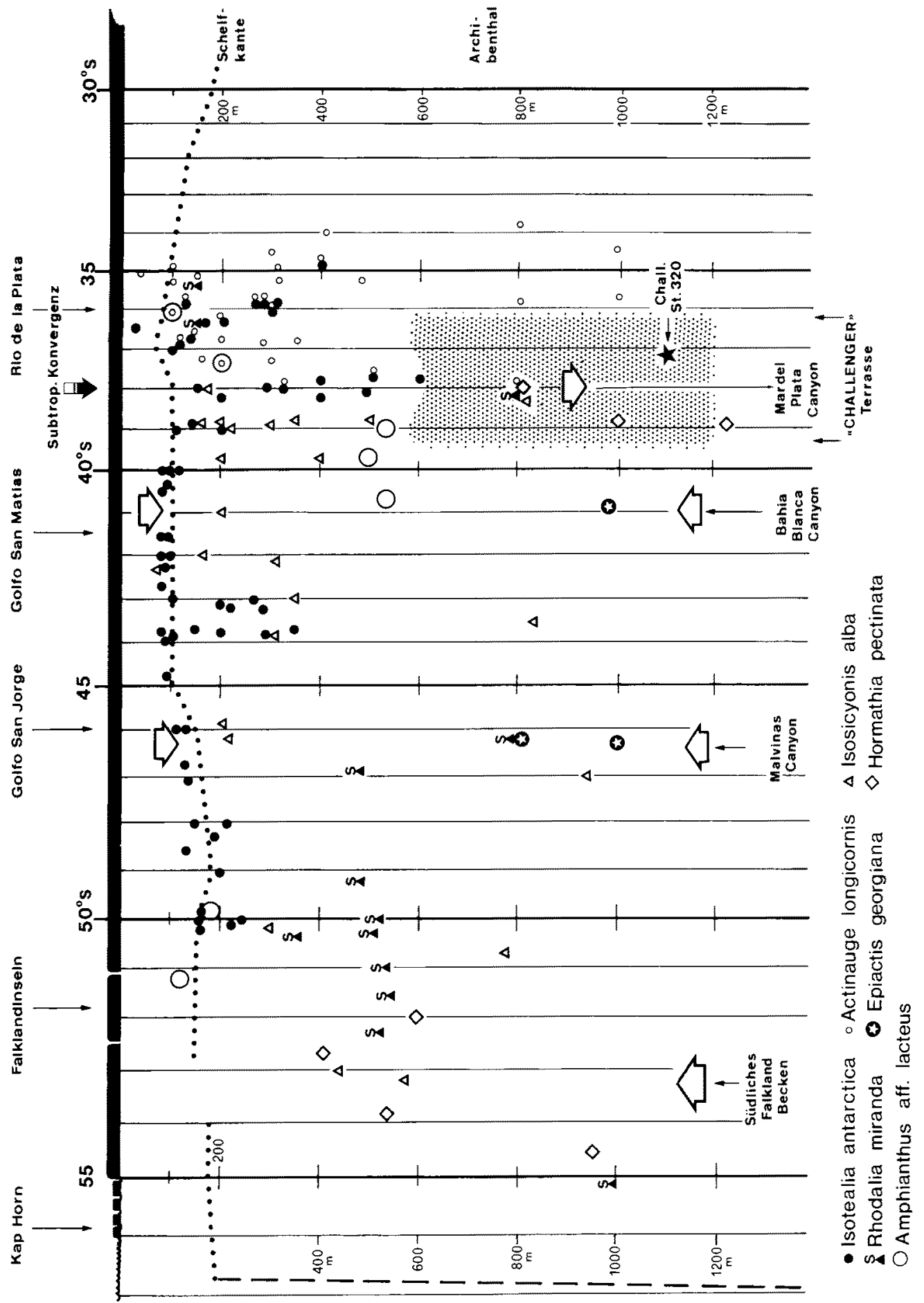


Am oberen Kontinentalhang der Falkland-Inseln bezeichnen die Siphonophore Rhodalia miranda und die Seeanemone Bolocera tuediae offenbar die Grenzlinie zwischen dem relativ warmen Wasser pazifischen Ursprungs und dem Subantarktischen Zwischenwasser, das vom Zirkumpolarstrom durch die Shag-Rock-Passage abzweigt und aus südöstlicher Richtung auf den Schelfhang der Falkland-Inseln aufläuft. Das Zentrum dieses Auflaufens (vielleicht auch Auftriebes, vgl. Deacon, 1933; p. 181 und Fig. 17) scheint zwischen 50 und $51^{\circ}$ Süd zu liegen, wo sowohl Rhodalia wie auch Bolocera emporsteigen und wo Isosicyonis alba und Provocator corderoi auf den Schelf vordringen.

Das nächste Fundortgebiet der Siphonophore Rhodalia, wie auch anderer subantarktischer Arten des Pelagials und Benthals, liegt am Haupt des Malvinas-Canyon zwischen 46 und $47^{\circ} \mathrm{S}$, wo Subantarktisches Zwischenwasser vermutlich zusammen mit tieferen Wasserschichten empordringt. Es ist aber auch möglich, daß sich ein weiterer Ast des Shag-Rock-Passagen-Stromes an diesen Vorgängen beteiligt, indem die oberen Wasserschichten analog zu den Messungen in den tieferen Schichten dieses Stromes (Zenk, 1981) abhängig von Topographie, Tiefe und Geschwindigkeit unterschiedliche Richtungen nach Verlassen der Passage einschlagen.

Etwa $900 \mathrm{~km}$ vom Haupt des Malvinas-Canyon entfernt liegen die nächsten beiden Fundorte von Rhodalia miranda im Archibenthal der "Challenger-Terrasse". Diese große Verbreitungslücke könnte bei der Siphonophore durch das zur Verfügung stehende geringe Material bedingt sein; jedoch ist eine mehr oder weniger große Verbreitungslücke in diesem Abschnitt des Südwestatlantik ein Charakteristikum vieler Verbreitungsmuster subantarktischer Arten: So stellen Lohmann \& Hentschel (1939; p. 207) eine solche Lücke zwischen " 40 und $50^{\circ} \mathrm{S}$ für die gesamte Appendicularien-Fauna " fest, andere Autoren nennen Lücken zwischen "Falkland-Inseln und La Plata" (Bernasconi, 1973; p. 289: Echinodermen; Monteiro \& Tommasi, 1983a: Gorgonocephalus chilensis; Hastings, 1943; p. 207: 3 Bryozoen-Arten; Scelzo, 1973: 3 Dekapoden-Arten; O. Hartman, 1966: Polychaeten; Koltun, 1969: Poriferen). Unter den Seeanemonen hat Hormathia pectinata die größte Verbreitungslücke $\left(39^{\circ} \mathrm{S}\right.$ bis $52^{\circ} \mathrm{S}=$ fast $\left.1500 \mathrm{~km}\right)$, wobei die Art wie Rhodalia auf der "Challenger-Terrasse" etwa $300 \mathrm{~m}$ tiefer als bei den FalklandInseln angetroffen wurde (Abb, 7).

Abb. 7. Vertikalverbreitung einiger Seeanemonen im argentinischen Sublitoral und Archibenthal. Isotealia antarctica, deren Fundorte häufig nahe der $6 .{ }^{\circ} \mathrm{C}$-Isotherme liegen, reflektiert in ihrer Tiefenverbreitung die an der argentinischen Schelfkante offenbar permanent vorhandenen Frontensysteme. Actinauge longicornis bezeichnet als Bewohner der Subprovinz "Warmwasser-Archibenthal" die nördliche Grenze der subtropischen Konvergenzzone. Isosicyonis alba, eine Seeanemone mit disjunkten Fundortgebieten (vgl. Abb. 1), bezeichnet die südliche Grenze der subtropischen Konvergenzzone und zeigt an der argentinischen Schelfkante den stellenweisen Einfluß subantarktischer Wassermassen an. Die pelagische Tiefwasser-Siphonophore Rhodalia miranda (vgl. Abb. 8) lebt in subantarktischem Wasser (Locus typicus: Challenger-St. 320). Als pelagischer Organismus sammelt sie sich an Fronten und Landmassen an und kann auch Vermischungsvorgänge anzeigen: Nördlich der subtropischen Konvergenz zeigt die Art im Winter 1966 subantarktisches Wasser als Unterstrom vor der Küste Uruguays an. Epiactis georgiana, eine in der Antarktis häufige Seeanemone, wurde an 2 Stellen im argentinischen Archibenthal gefunden. Die Fundorte stehen offenbar unter dem Einfluß von zwei mächtigen, bis in die Tiefsee hinabreichenden Canyons. Hormathia pectinata hat besonders weit auseinanderliegende archibenthale Fundortgebiete. Die Art ist vermutlich Bewohner archibenthaler Frontensysteme. Amphianthus aff. lacteus scheint ebenfalls an sublitorale und archibenthale Frontensysteme gebunden 


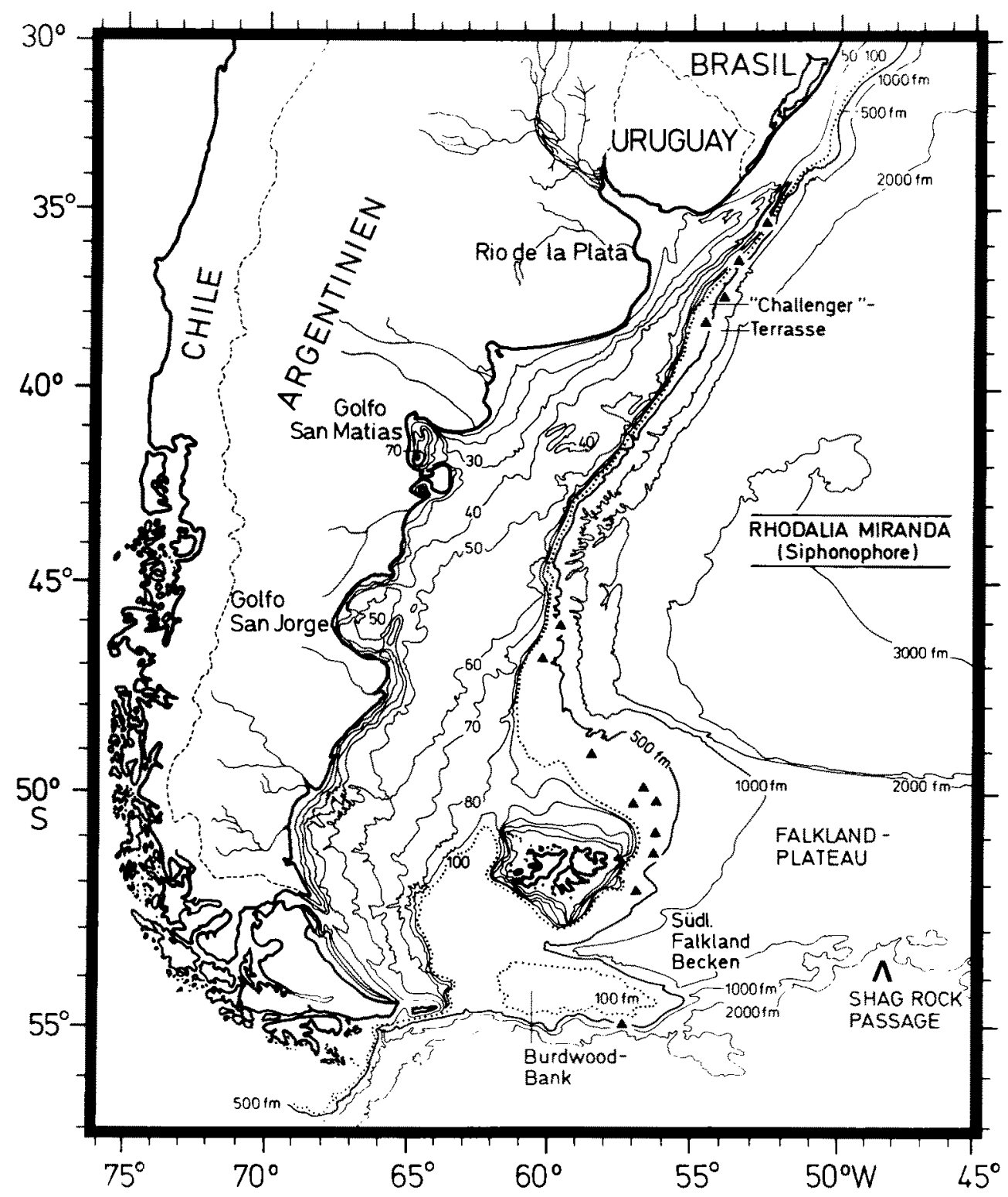

Abb. 8. Fundorte der pelagischen Tiefwasser-Siphonophore Rhodalia miranda (Locus typicus: Challenger-St. 320). Die Art wird als Indikator-Organismus für subantarktisches Wasser angesehen (vgl. Abb. 7). Die beiden nördlichsten Funde stammen vom 1. und 2. August 1966 (Winter), als Rhodalia miranda in 150 und $160 \mathrm{~m}$ Tiefe bei Temperaturen von 6,3 und $8,1^{\circ} \mathrm{C}$ angetroffen wurde. Die anderen Fundorte liegen zwischen 357 und $1097 \mathrm{~m}$ Tiefe und bei Temperaturen zwischen 2,9 und $4,4^{\circ} \mathrm{C}$ 
Ozeanographisch läßt sich diese Lücke mit dem kältesten archibenthalen Abschnitt des argentinischen Schelfhanges korrelieren (Buscaglia, 1971; p. 251. Fig. 7; Wüst \& Defant, 1936; Beilage L: $\mathrm{I}$ in $800 \mathrm{~m}$ Tiefe; Gordon \& Molinelli, 1982; Plates 14, 15: Potentielle Temperatur in 500 und $750 \mathrm{~m}$ Tiefe).

Schwieriger zu verstehen ist, daß die durch die Lücke getrennten Lebensräume offenbar unter dem Einfluß identischer Wassermassen stehen. Es wird zwar angenommen, daß die Wassermassen der nördlichen Drake-Straße zunächst das Sublitoral der Falkland-Inseln berühren, um dann in weitem Bogen vor Nordargentinien zu gelangen (Georgi, 1979), aber auf diesem monatelangen Weg könnten sich die subantarktischen Charakteristika des Wassers wohl kaum erhalten; eine Verbreitung von kurzlebigen Larven benthischer Tiere auf diesem Weg scheint unmöglich.

Frühere Spekulationen, wonach, ausgehend von der S-förmigen Schleife der Polarfront, das Subantarktische Zwischenwasser "stromartig" den Südwestatlantik durchquert, können nun neu belebt werden, nachdem Zenk (1981) in der unter der S-Schleife liegenden Shag-Rock-Passage Stromgeschwindigkeiten bis zu $65 \mathrm{~cm} / \mathrm{sec}$ (über $50 \mathrm{~km}$ pro Tag) in den tieferen Schichten festgestellt hat. Wenn auch die oberen Wasserschichten dieses Stromes mit ähnlichen Geschwindigkeiten und Richtungen aus der Passage austreten, so stoßen sie schon nach einigen Tagen an den argentinischen Kontinentalabhang. Falls es sich dabei um ein stabiles System handelt, können in den betreffenden Gebieten subantarktische Lebensräume entstehen; das Gebiet östlich und südöstlich der Falkland-Inseln (unter $500 \mathrm{~m}$ Tiefe) und die "Challenger-Terrasse" außerhalb des La Plata ( 800 bis $1200 \mathrm{~m}$ Tiefe) sind offenbar solche stabilen subantarktischen Lebensräume.

Einige Arten kommen auch zwischen diesen Gebieten vor, am häufigsten zwischen 43 und $44^{\circ} \mathrm{S}$ (im Gebiet der stärksten Erosion des Ameghino-Canyon-Systems) und bei etwa $41^{\circ} \mathrm{S}$ (Haupt des Bahia-Blanca-Canyon). Beispiele solcher Verbreitungsmuster finden sich bei allen zu Beginn dieses Kapitels genannten Tiergruppen wie auch in den folgenden Arbeiten: Kaiser, 1977a, b: Mollusken; Torti \& Boschi, 1973: Dekapoden; Foster, 1969: Brachiopoden; Koltun, 1969: Poriferen. Einige pelagische Tiere sind ebenfalls in dieser Weise verbreitet (Schöne, 1974: Cephalopoden; Hart, 1946: Tiefwasser-Rochen; Ehrich, 1980: Abb. 13-15, Grenadierfisch).

Auch die oft unglaubhaften Funde von subantarktischen Arten im Flachwasser des Schelfs lassen sich häufig mit diesen geographischen Breiten korrelieren (vgl. Isosicyonis, Abb. 1; Bolocera; die Scleractinie Flabellum curvatum nach Cairns, 1982 [Abb. 9]; die Ascidien Styela nordenskjoldi nach Kott, 1969; St. magalhaensis nach Diehl, 1977 ; die Echinodermen Bathybiaster loripes und Austrocidaris canaliculata nach Bernasconi, 1973; Astrotoma agassizii nach Bartsch, 1982; Mollusken der Gattung Bathydoris nach Kaiser, 1980; Brachiopode Aerothyris nach Foster, 1969; Cirripedier nach Ross \& Newman, 1969). Auch pelagische Tiefwasser-Organismen dringen an diesen Stellen gelegentlich bis an die Oberfläche oder auf den Schelf vor (Plankton-Ostracoden nach Hillman, 1969; Chaetognathen nach Kapp, 1980; Dinoflagellaten nach Balech, 1968; map 6).

Als Konsequenz der übereinstimmend disjunkten Verbreitungsmuster subantarktischer Arten im Sublitoral und Archibenthal des argentinischen Schelfhanges muß man annehmen, daß sich das als "Falkland-Strom" bekannte ozeanographische Phänomen aus mehreren subantarktischen Wasserkörpern zusammensetzt, die unabhängig vonein- 
ander den Schelfhang berühren und dort den Eindruck eines einheitlichen KaltwasserGebietes hervorrufen. Die einzelnen Strombänder subantarktischen Wassers leiten sich vielleicht von den oberen Schichten des Shag-Rock-Passagen-Stromes her und nähern sich - ausgehend von dieser Passage - dem argentinischen Kontinentalabhang mit

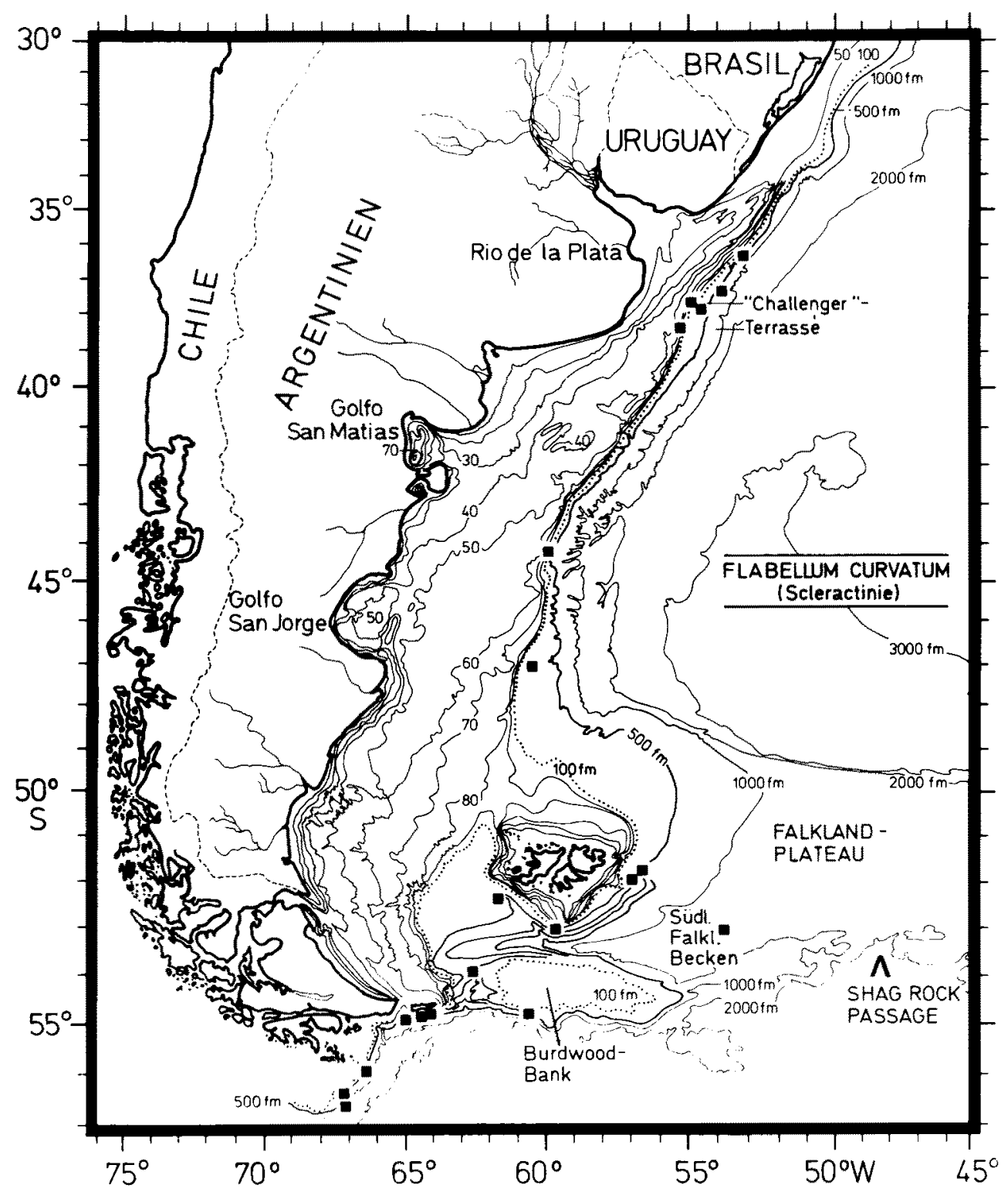

Abb. 9. Fundorte der Scleractinie Flabellum curvatum (nach Cairns, 1982; Locus typicus: Challenger-St. 320). Auch diese Art wird als Indikator-Organismus für subantarktische Einflüsse an der argentinischen Schelfkante angesehen 
etwas verschiedenen Richtungswinkeln. Die Verteilung des sessilen Benthos läßt vermuten, daß zwei Gebiete unter ständigem Einfluß subantarktischen Wassers stehen: Die Tiefenzone unter $500 \mathrm{~m}$ östlich und südöstlich der Falkland-Inseln und die "ChallengerTerrasse" ( 800 bis $1200 \mathrm{~m}$ ) vor Nordargentinien. In dem dazwischenliegenden Abschnitt des Kontinentalhanges kommen ebenfalls subantarktische Arten vor und dringen manchmal sogar weit auf den Schelf vor; die subantarktischen Lebensbedingungen scheinen jedoch an diesen Orten in Zeit und Raum viel weniger stationär und stabil zu sein.

Noch ein weiteres Gebiet scheint nach dem Charakter seiner Bodenfauna ständig subantarktisch zu sein: das "Südliche Falkland-Becken" (Falkland Southern Trough), wo verschiedene Autoren am Boden und im freien Wasser die "typischen Arten des Falkland-Stromes" festgestellt haben (siehe Palacio 1982; p. 77). Die wenigen Benthosproben von "Walther Herwig" aus dieser Region lassen lediglich die Aussage zu, daß 3 subantarktische Seeanemonen-Arten (Isosicyonis alba, Hormathia pectinata und Bolocera tuediae) zwischen Falkland-Inseln und Burdwood-Bank vorkommen. Die Untersuchungen amerikanischer Forschungsschiffe zeigten, daß B. tuediae auch zwischen den Falkland-Inseln und Feuerland weit verbreitet ist und dort sogar nahe der Küste vorkommt (Dunn, 1983).

Ein Verbreitungsmuster wie das von $B$. tuediae läßt den Eindruck entstehen, daß die auf dem südlichen Schelf weitverbreitete Art mit einem die Falkland-Inseln passierenden Strom ("Falkland-Strom") entlang der argentinischen Schelfkante nach Norden verbreitet wird. Soweit es das subantarktische oder Tiefwasser-Benthos betrifft, ist diese Annahme wohl falsch, denn es fehlen Nachweise der betreffenden Arten im Nordwesten der Falkland-Inseln, wo der "Falkland-Strom" die Inseln passieren soll.

Viele der Fundorte subantarktischer Bodentiere in diesem Tiefwasser-Becken lassen sich besser deuten, wenn man annimmt, daß das subantarktische Bodenwasser nicht aus dem Süden eindringt (wie die Oberflächenschicht), sondern aus dem Ostén. Neben den neueren ozeanographischen Erkenntnissen, daß vermutlich die tiefsten, kältesten und schnellsten Schichten des Shag-Rock-Passagen-Stromes in dieses Becken eindringen (Zenk, 1981), verdeutlichen auch die Fundorte einiger pelagischer Tiefwasser-Arten das Eindringen subantarktischen Wassers aus dem Osten $(z$. B. die Chaetognathen Sagitta gazellae und Eukrohnia hamata, wie von Kapp, 1980, Figs 2 und 3, dargestellt).

Die hier beschriebene disjunkte Verteilung von subantarktischen Benthostieren im Südwestatlantik ist nur denkbar, wenn man annimmt, daß ein Transport von Larven oder Adulten über große Entfernungen möglich ist. Für Arten mit lecithotrophen, langlebigen Larven scheint dies bei den gemessenen relativ hohen Stromgeschwindigkeiten kein Problem zu sein (vgl. Riemann-Zürneck, 1976; Soule \& Soule, 1979; p. 318); in einigen Fällen dürfte auch ein Transport von Jungaktinien stattfinden, wenn sie auf verdriftbaren Substraten angesiedelt sind (Hydroidenzweige, Macrocystis) oder wenn sie selbst eine ballonartige Form annehmen können, die eine Verdriftung erlaubt (vgl. RiemannZürneck, 1969; p. 222).

Gegenwärtig nicht zu erklären ist jedoch, wie Arten, die, nach ihrer Eigröße und Verwandtschaft zu urteilen, kleine, kurzlebige Planula-Larven besitzen, solche Entfernungen überwinden können (vgl. Cairns, 1983; p. 156). Gerade die Seeanemonen-Arten mit den größten Verbreitungslücken (Hormathia pectinata und Amphianthus aff. lacteus) gehören diesem Verbreitungstyp an. Die Hypothese, daß es sich in diesen Fällen 
vielleicht um Relikte früher weitverbreiteter Arten handelt, wird im Kapitel "Zusammenfassung und Schlußfolgerungen" diskutiert.

Antarktische Faunenelemente im argentinischen Kaltwasser-Archibenthal

Antarktische Benthos-Arten wie Epiactis georgiana scheinen - in Übereinstimmung mit den Befunden von Cairns (1982 und 1983) wie auch von Monniot \& Monniot (1983) nur in archibenthalen Tiefen vor Nordargentinien vorzukommen (vgl. auch Kusakin, 1967). Daß es ein zusammenhängendes Verbreitungsgebiet solcher Arten entlang der 600 - bis $1100-\mathrm{m}$-Zone gibt (Cairns, 1983; p. 152), wage ich zu bezweifeln, wenngleich die geringe Anzahl Benthosproben aus archibenthalen Tiefen kaum Aussagen zuläßt. Einige Fundortdaten von verschiedenen Expeditionen und Tiergruppen geben mir jedoch Grund zu der Annahme, daß es im 600- bis 1100-m-Tiefenbereich nur die folgenden drei Gebiete gibt, die sessilen antarktischen Benthos-Organismen Lebensbedingungen bieten; dies schließt nicht aus, daß unterhalb dieser Tiefenzone ein zusammenhängendes Faunengebiet existieren kann.

(1) Bei etwa $41^{\circ} \mathrm{S}$ am Haupt des Bahia-Blanca-Canyon. Beispiele antarktischer Benthos-Funde: Dearborn \& Rommel, 1969 (2 Tiefwasser-Crinoiden); Ross \& Newman, 1969 (Cirripedier); Torti \& Boschi, 1973 (Dekapode Campylonotus capensis); Monniot \& Monniot, 1983 (Ascidien); Cairns, 1983 (Stylasterine Errina (I) lowei); eigener Befund: Seeanemone Epiactis georgiana (WH St. 330, 23. 2. 1971: $40^{\circ} 57^{\prime} \mathrm{S}, 56^{\circ} 57^{\prime} \mathrm{W}, 980 \mathrm{~m}, \mathrm{~T}=$ $2,9^{\circ} \mathrm{C}$.

(2) Bei 46 bis $47^{\circ} \mathrm{S}$ in einem Gebiet, das ebenfalls am Haupt eines großen Canyons liegt (Malvinas-Canyon). Beispiele antarktischer Benthos-Funde: Kaiser, 1976 (Soleno* gastren); Diehl, 1977 (Tiefsee-Ascidie Culeolus sluiteri); eigener Befund: die Aktinie Epiactis georgiana (WH St. 191, 17. 1. 1971: $46^{\circ} 13^{\prime} \mathrm{S}, 59^{\circ} 49^{\prime} \mathrm{W}, 805 \mathrm{~m}, \mathrm{~T}=2,8^{\circ} \mathrm{C}$. $-\mathrm{WH}$ St. $\left.192,17.1 .1971: 46^{\circ} 18^{\prime} \mathrm{S}, 59^{\circ} 39^{\prime} \mathrm{W}, 1000 \mathrm{~m}, \mathrm{~T}=2,5^{\circ} \mathrm{C}\right)$.

(3) Das Südliche Falkland-Becken (Falkland Southern Trough) zwischen 53 und $54^{\circ} \mathrm{S}$. Von "Walther Herwig" wurde in diesem Gebiet kaum Benthos gesammelt; jedoch weist ein früherer Fund der im übrigen zirkumantarktisch verbreiteten Seeanemone Artemidactis victrix bei $53^{\circ} 45^{\prime} \mathrm{S}, 61^{\circ} 10^{\prime} \mathrm{W}$ (vgl. Carlgren, 1927; pp. 84, 99; Carlgren, 1949; p. 102; Dayton et al., 1970) auf antarktische Lebensbedingungen in Tiefen um $150 \mathrm{~m}$ hin. Vier antarktische Pycnogoniden-Arten (vgl. Hedgpeth, 1969; map 5), die als Ektoparasiten häufig mit Seeanemonen assoziiert sind, stützen diese Annahme. Nach Monteiro \& Tommasi (1983a) kommen dort auch Ophiuriden vor, die sonst antarktisch verbreitet sind. Das Eindringen einer tiefseeischen demersalen Rochen-Art in dieses Becken (Hart, 1946; Fig. 9) soll hier ebenfalls genannt werden, da die Art auch am Haupt des Malvinas-Canyon bei $46^{\circ} \mathrm{S}$ gefunden wurde.

Allen drei "antarktischen" Gebieten ist gemeinsam, daß sie am westlichen Ende von Canyons bzw. Tiefwassergräben liegen, deren Profil sich bis in die Tiefsee hinab verfolgen läßt. Entlang dieser Canyons dringt offenbar Tiefenwasser am Kontinentalabhang empor. Hydrographische Hinweise für das Eindringen von Tiefenwasser mit antarktischen Anteilen gibt es für alle 3 Gebiete, aber Details über Herkunft, Charakter und Bewegungen der betreffenden Wassermassen sind nicht bekannt.

Epiactis georgiana (vgl. p. 122; Abb. 7, 10) ist nach Dunn (1983) wie die anderen Arten der Gattung eine Aktinie mit externer Brutpllege, wobei die Jungtiere in der Region der Fossa bis zu einer Größe von $7 \mathrm{~mm}$ angeheftet sind. Bei den von "Walther 


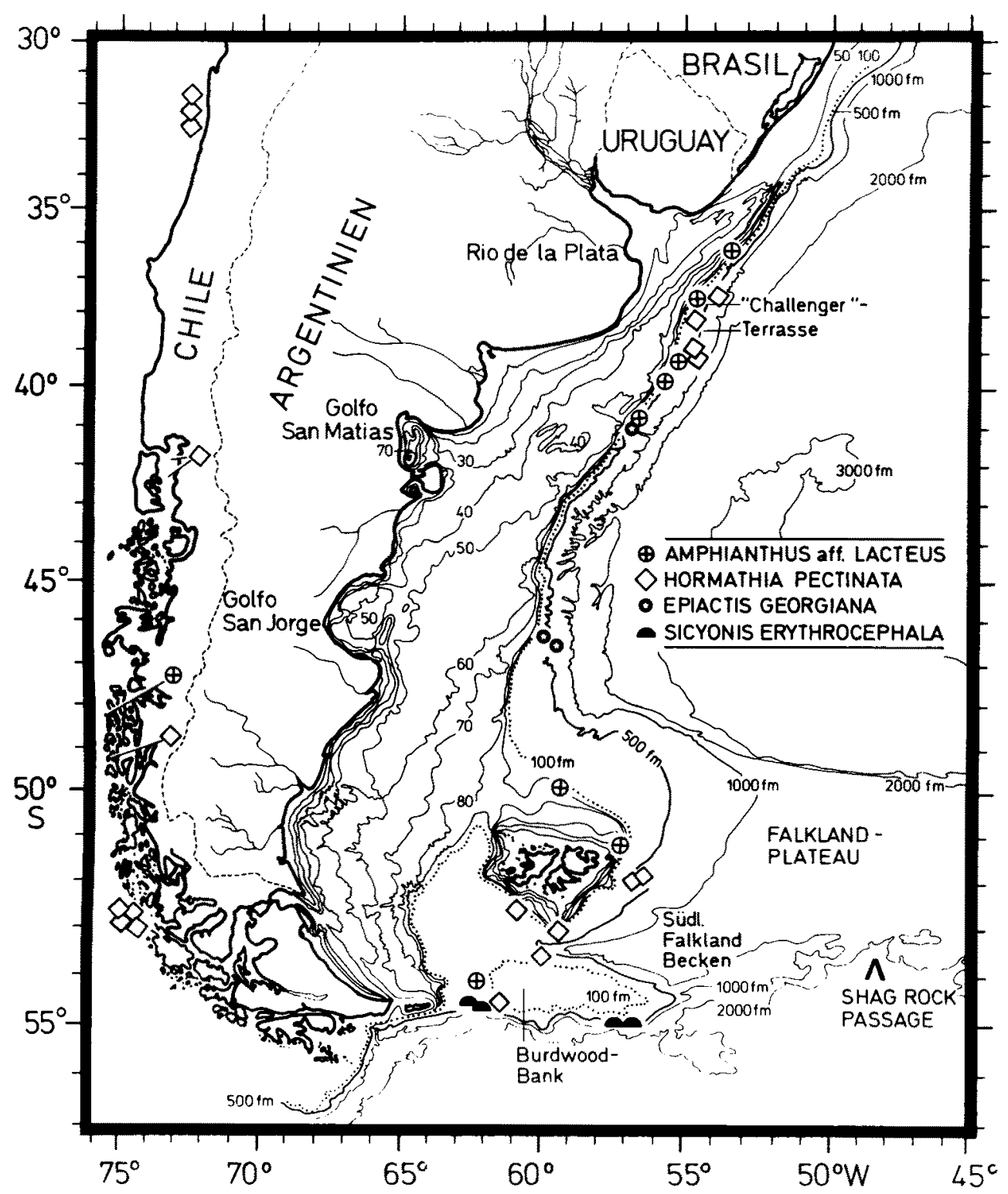

Abb. 10. Fundorte einiger Tiefwasser-Seeanemonen (vgl. Abb. 7). Sowohl Amphianthus aff. lacteus als auch Hormathia pectinata haben weit auseinanderliegende Fundortgebiete und sind vermutlich Bewohner von sublitoralen und/oder archibenthalen Frontensystemen. Epiactis georgiana scheint im Einflußbereich zweier bis in die Tiefsee hinabreichender Canyons in $800 \mathrm{bzw} .1000 \mathrm{~m}$ Tiefe geeignete Lebensbedingungen vorzufinden. Sicyonis erythrocephala ist eine zirkumpolar verbreitete Seeanemone, die an starke Strömungen im Archibenthal des antarktischen Ringozeans ange- 
Herwig" im Südsommer 1971 gesammelten Tieren fanden sich keine Jungtiere, jedoch sehr große, dotterreiche Oocyten in den Mesenterien, deren größte auf Schnittpräparaten 1,1 mm Durchmesser erreichten.

Eine weitere, offenbar zirkumantarktisch verbreitete Seeanemone ist Sicyonis erythrocephala, die von "Walther Herwig" im Archibenthal der Drake-Passage an 4 Stationen in 2 Fundort-Gebieten gefunden wurde (Abb. 10): St. 231 (2. 2. 1971), 54 $38^{\circ}$ ' S, $62^{\circ} 41^{\prime} \mathrm{W}, 510 \mathrm{~m}, \mathrm{~T}=3,8^{\circ} \mathrm{C}$. - St. $232(2.2 .1971), 54^{\circ} 46^{\prime} \mathrm{S}, 52^{\circ} 30^{\prime} \mathrm{W}, 800 \mathrm{~m}, \mathrm{~T}=3,5^{\circ} \mathrm{C}$. St. 242 (4. 2. 1971 ), $55^{\circ} 06^{\prime} \mathrm{S}, 57^{\circ} 25^{\prime} \mathrm{W}, 1000 \mathrm{~m}, \mathrm{~T}=2,9^{\circ} \mathrm{C}$. $-\mathrm{St} .243$ (4. 2. 1971), $54^{\circ} 57^{\prime} \mathrm{S}$, $56^{\circ} 54^{\prime} \mathrm{W}, 500 \mathrm{~m}, \mathrm{~T}=4,0^{\circ} \mathrm{C}$. Nach Dunn (1984; p. 29) kommt die Art in der DrakePassage und in der Scotia-See in Tiefen zwischen 261 und $3876 \mathrm{~m}$ vor. Die von "Walther Herwig" gesammelten Tiere haben ihre Fußscheibe an grobem Kies festgeheftet; grobes Sediment und Korallenbruchstücke fanden sich auch im Gastralraum der Tiere.

Die von mir als Sicyonis erythrocephala identifizierten Seeanemonen stimmen in Habitus und Nesselkapselausstattung mit der Beschreibung von Dunn (1984; pp. 25-29) überein. Leider sind die von Dunn dargestellten histologischen Details entweder nicht artspezifisch (Figs 24-26) oder von so geringer technischer Qualität (Fig. 27), daß es nicht möglich ist, sie bei der Bestimmung der Art heranzuziehen.

Sicyonis erythrocephala scheint eine Art zu sein, die an die besonderen Lebensbedingungen in mittleren und großen Tiefen des antarktischen Ringozeans angepaßt ist. Die ziemlich großen, dotterreichen Oocyten (etwa $1 \mathrm{~mm}$ ) und das Fehlen von Brutpflege lassen auf große, freilebende Larven schließen; vielleicht stehen die etwa $1 \mathrm{~mm}$ großen Larven, die nach Carlgren (1903; p. 4) von Mai bis November südlich des 70 . Breitengrades in 200 bis $450 \mathrm{~m}$ Tiefe gesammelt wurden, mit $S$. erythrocephala in Verbindung; von diesen Larven ist lediglich bekannt, daß sie sich im Edwardsia-Stadium befinden.

Zahlreiche, im Aussehen recht ungewöhnliche Aktinienlarven (Abb. 11) enthält eine am 16. 1. 1968 in der Ross-See von dem amerikanischen Forschungsschiff "Eltanin" gesammelte Benthosprobe aus $801 \mathrm{~m}$ Tiefe (Cruise 32, St. 2026, $75^{\circ} 05^{\prime} \mathrm{S}, 176^{\circ} 37^{\prime} \mathrm{W}$ ). Die Larven haben mit ihrem physaähnlichen Körperende äußerlich Ähnlichkeit mit edwardsiiden Seeanemonen.

\section{Die litoralen und sublitoralen Lebensräume Südamerikas zwischen Golfo San Jorge (Atlantik) und Insel Chiloe (Pazifik)}

Eine tiergeographische Gliederung dieser von $47^{\circ} \mathrm{S}$ auf der atlantischen Seite bis $42^{\circ} \mathrm{S}$ auf der pazifischen Seite reichenden Küstenregion ist ohne weitere Untersuchungen des Benthos nicht möglich. Gegenwärtig kann daher nur eine Literatur-Zusammenfassung gegeben werden mit einigen ergänzenden Daten, die sich aus dem AktinienMaterial von "Walther Herwig" und amerikanischen Forschungsschiffen ergaben.

Wie bereits beschrieben, hat das sublitorale Benthos Feuerlands bis nahe an die Küste subantarktischen Charakter und steht wahrscheinlich unter dem Einfluß von zirkumpolarem Wasser, das über die Shag-Rock-Passage und das Südliche FalklandBecken von Osten her eindringt.

Sowohl an der pazifischen wie an der atlantischen Küste Südamerikas ist der Eingang zur Magellan-Straße tiergeographische Grenze für viele Benthos-Arten, so daß sich die Faunen südlich und nördlich der Straße - besonders auf der pazifischen Seite unterscheiden (Stuardo, 1964; Balech, 1964; p. 110; Sebens \& Paine, 1979). Die Durch- 

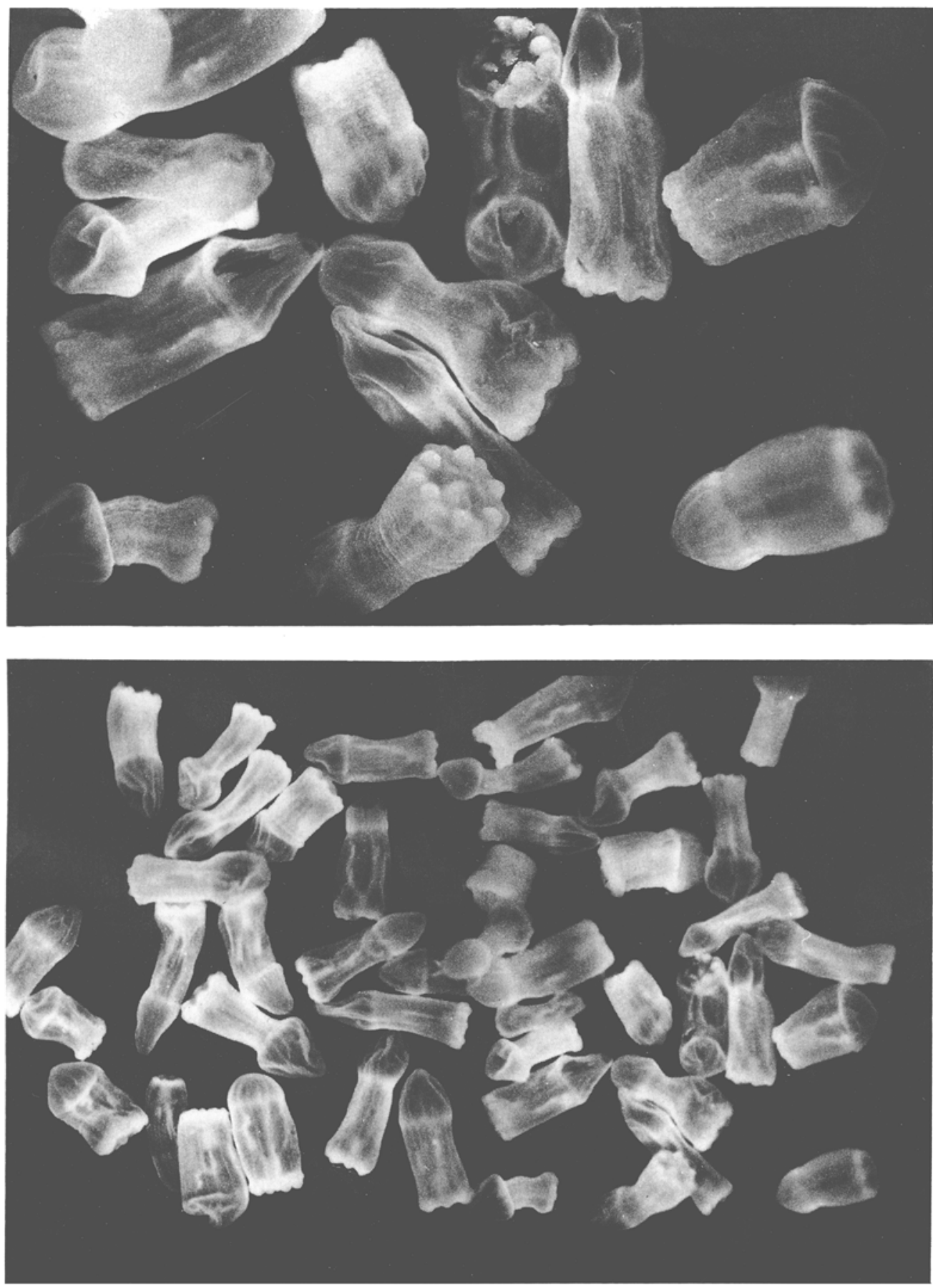

Abb. 11. Antarktische Aktinienlarven unbekannter taxonomischer Zugehörigkeit, gesammelt von dem amerikanischen Forschungsschiff "Eltanin" (Cruise 32, St. 2026) aus 801 m Tiefe der Ross-See. Das physa-ähnliche Körperende der Larven erinnert an edwardsiide Seeanemonen, aber es können auch Larven anderer Aktinien sein. Länge der Larven: 0,6 bis 1,7 mm 
querung der Magellan-Straße von einem Ozean zum anderen scheint ebenfalls schwierig zu sein, denn die Aussüßung der Deckschicht, die starken Temperaturunterschiede zwischen pazifischem und atlantischem Eingang der Meeresstraße (Brattström \& Johanssen, 1983; p. 304) sowie das Vorhandensein von Tiefenbecken bis $1170 \mathrm{~m}$ Tiefe (Andriashev, 1977) machen die Magellan-Straße für alle Zonierungen des Benthos, besonders aber wohl für Plankton-Larven, praktisch unpassierbar. Unter den Seeanemonen scheint nur der besonders anpassungsfähigen Metridium senile lobatum (vgl. Shoup, 1932) die Durchquerung dieser Meeresstraße gelungen zu sein (Abb. 5; vgl. Riemann-Zürneck, 1975a; p. 94).

Keine hydrographischen Schranken gibt es dagegen für sublitorale Benthostiere, wenn sie über die Kap-Horn-Route in den Südwestatlantik einwandern und Temperaturen um $6^{\circ} \mathrm{C}$ tolerieren können. Das aus dem Pazifik stammende Wasserband der nördlichen Drake-Passage, dessen oberste 200 Meter sich nach Passieren von Kap Horn nach Norden und Nordosten wenden, behält in 150 bis $200 \mathrm{~m}$ Tiefe auch im Südwinter Temperaturen um $6^{\circ} \mathrm{C}$ (Daten von "Walther Herwig", Juni/Juli 1966; vgl. Heron-Allen \& Earland, 1932; p. 292).

Zwei Seeanemonen, Antholoba achates (Abb. 5) und Choriactis laevis, demonstrieren diese Umwanderung des südamerikanischen Kontinentes; Ch. laevis kommt im Südwestatlantik bis an die subtropische Konvergenz vor, $A$. achates dringt noch weiter nach Norden vor, vermutlich bis zum Cabo Fio in Südbrasilien $\left(23^{\circ} \mathrm{S}\right.$, p. 115). Beide Arten sind an der chilenischen Küste Feuerlands südlich der Magellan-Straße nicht bekannt. Dies mag den Grund haben, daß dort bisher kaum Benthosproben gesammelt wurden oder aber daß die Arten dort in einer anderen Tiefe vorkommen ("Submergenz" von Arten an der chilenischen Küste: Brattström \& Johanssen, 1983; p. 321). Es ist aber auch möglich, daß die Verbreitungsgebiete der beiden Aktinien-Arten hier eine Lücke aufweisen, wie sie schon für anderes Benthos beschrieben wurde.

Beide Aktinien, die Kap Horn erfolgreich umwandern, sind brutpflegende Arten: Antholoba behält ihre Jungtiere bis zu einer stattlichen Größe im Gastralraum (Dunn, 1984), und Choriactis ist larvipar (Riemann-Zümeck, 1975a; p. 78). Das Vermeiden freier, kurzlebiger Larven-Stadien hat in subantarktisch-antarktischen Lebensräumen offenbar selektive Vorteile (Dell, 1972; p. 157), wobei Choriactis laevis die Vorteile der Brutpflege mit den Verbreitungs-Potenzen einer lecithotrophen Larve verbindet (Riemann-Zürneck, 1976).

Die von Zamponi (1982) beschriebenen Anthozoen-Larven, die im Jahre 1978 von "Walther Herwig" auf dem argentinischen Schelf gesammelt wurden, dürfen nicht, wie Zamponi es getan hat, bestimmten Seeanemonen-Arten zugeordnet werden. Zamponi nennt weder ökologische noch morphologische Kriterien, die diese Zuordnung rechtfertigen würden.

Das sublitorale und archibenthale Benthos, das von der pazifischen zur atlantischen Küste einwandert, besiedelt vor allem die entsprechenden Tiefen um die FalklandInseln, so daß die Ahnlichkeit der Faunen von Südchile und den Falkland-Inseln größer ist als die von Südargentinien und den Falklands (Moyano, 1982b; p. 90). Besonders üppige sublitorale Benthos-Gesellschaften von Invertebraten finden sich nach Hart (1946; p. 235) rings um die Falkland-Inseln in Tiefen von 80 bis $130 \mathrm{~m}$, besonders aber im Westen der Inselgruppe, wo dieses Benthos über die 200-m-Linie hinab vorhanden sein soll. Diese von Hart bezeichnete Stelle steht offenbar ganzjährig unter dem Einfluß 
des etwa $6^{\circ} \mathrm{C}$ warmen Wassers aus dem Pazifik (E. Boltovskoy, 1971, sowie Daten von "Walther Herwig" 1966 und WH 1978, St. 613). Diese Aussage impliziert zugleich, daß das zwischen Staaten-Insel und Burdwood-Bank eindringende bodennahe Wasser gemäßigte und keineswegs - wie bisher angenommen - subantarktische Lebensbedingungen bietet.

Unter bestimmten ozeanographischen Bedingungen scheint es sogar möglich, daß warmstenotherme Arten die Südspitze Südamerikas umwandern und vor Nordargentinien wieder Anschluß an dort lebende Warmwasser-Gesellschaften finden. Freilebende Warmwasser-Organismen wurden in der nördlichen Drake-Straße mehrfach sowohl an der Oberfläche als auch unter der Deckschicht angetroffen (E. Boltovskoy, 1971; p. 64). Für wärmeliebende benthische Invertebraten dürfte dieser Weg wohl nur in Ausnahmejahren passierbar sein (vielleicht nach besonders gravierenden El-Niño-Ereignissen), und auch dann dürfte eine erfolgreiche Besiedlung häufig am Mangel von geeigneten ökologischen Nischen auf dem südwestatlantischen Schelf scheitern. Dies mag der Grund sein, weswegen nur ein sehr geringer Teil der üppigen temperierten Fauna des südchilenischen Archipels von der atlantischen Seite Südamerikas bekannt ist. Bisher nahm man allerdings an, daß dies weniger den unterschiedlichen ökologischen Gegebenheiten zuzuschreiben sei als vielmehr der im Vergleich zur chilenischen Küste minimalen Sammelaktivität im südwestatlantischen Litoral und Sublitoral (Briggs, 1974; p. 128; Sebens \& Paine, 1979).

Im südchilenischen Archipel sind nicht nur die Seeanemonen besonders artenreich (Sebens \& Paine, 1979), sondern auch viele andere Tiergruppen (Mollusken: Stuardo, 1964; p. 86; Asteroiden: Madsen, 1956; Bryozoen: Moyano, 1982b; p. 85; Vögel: Shuntov et al., 1982; p. 347). Die Vielzahl von Substraten und Habitaten bei Lebensbedingungen, die ganzjährig ohne alle Extreme sind (Shuntov et al., 1982; Brattström \& Johanssen, 1983), sind offensichtlich Grundlage der hohen Diversität und Abundanz der dortigen Fauna. Es gibt Hinweise, daß diese Fauna Elemente aus dem westlichen Pazifik enthält (Australien, Neuseeland, Tasmanien: Hartmann \& Hartmann, 1962; p. 51; Kott, 1969; Moyano \& Gordon, 1980; El-Sayed, 1970). Einige der Autoren sind der Ansicht, daß die Fauna des südchilenischen Archipels die Rolle eines Verbreitungszentrums oder Speziationszentrums spielt (Moyano, 1982a, b; Stuardo, 1964; Shuntov et al., 1982).

Was die Seeanemonen anbetrifft, so ist die Zahl der in Südchile lebenden Arten sicher viel größer als die aus dem Südwestatlantik bekannten Arten, auch wenn man berücksichtigt, daß die argentinische und falkländische Litoralfauna kaum bekannt ist und einige der südchilenischen Arten einen unsicheren taxonomischen Status haben (vgl. Brattström \& Johanssen, 1983; p. 325; Carlgren, 1959). Obwohl aus diesem Grund die Verbreitung keiner der Arten näher betrachtet werden soll, lassen die Literaturangaben (Carlgren, 1959; Stuardo, 1964; p. 90; Sebens \& Paine, 1979; Doumenc, 1984) die Aussage zu, daß sich die Fauna des tieferen Sublitorals und oberen Archibenthals grundsätzlich von der Fauna geringerer Tiefen unterscheidet. Während die beschriebene üppige Flachwasserfauna temperierten Charakter hat und in hohem Maße für die Westküste Südamerikas endemisch zu sein scheint (Sebens \& Paine, 1979), sind viele der tiefer lebenden Seeanemonen typische Bewohner des patagonischen Kaltwasser-Archibenthals. Diese Tiefwasserfauna wird häufig auch im Südwestatlantik und in der Westantarktis gefunden; für sie gelten nicht die relativ engen tiergeographischen Grenzen der südchilenischen Küstenfauna (Vasquez et al., 1980; Brattström \& Johanssen, 1983; p. 322). 


\section{ZUSAMMENFASSUNG UND SCHLUSSFOLGERUNGEN}

Die Verbreitungsmuster von Seeanemonen und anderem Benthos im Südwestatlantik zeigen, daß die klassischen Ansichten über die Ozeanographie in diesem Teil des Südatlantiks revidiert werden müssen. Die sublitoralen und besonders die archibenthalen Lebensräume werden danach von Wassermassen beeinflußt, die sich nach Charakter, Herkunft und Bewegungsrichtung von den Wassermassen der Deckschicht unterscheiden.

Der Kaltwassereinfluß an der argentinischen Schelfkante, der sich an der Oberfläche als einheitliches Kaltwasserband mit nördlicher Versetzung ("Falkland-Strom") darstellt, setzt sich in den bodennahen Wasserschichten des Sublitorals und Archibenthals offenbar aus mehreren voneinander unabhängigen Kaltwassergebieten zusammen, die durch den Einstrom oder Auftrieb von subantarktischem Wasser entstehen. Einige dieser Gebiete unterliegen jahreszeitlichen Veränderungen, andere (Archibenthal der "Challenger-Terrasse" südöstlich der La-Plata-Mündung; Archibenthal östlich der Falkland-Inseln) scheinen so stabile Lebensbedingungen zu bieten, daß sich dort artenreiche und langlebige subantarktische Lebensgemeinschaften entwickelt haben.

Von besonderem wissenschaftlichen Interesse ist die seit dem Jahre 1876 (Challenger-Station 320) bekannte Fauna der "Challenger-Terrasse", deren subantarktischantarktischer Charakter erst in jüngerer Zeit deutlich wurde; diese Lebensgemeinschaft befindet sich unmittelbar an und unter der subtropischen Konvergenz. Es könnte sein, daß dieses Gebiet von einem bisher unbekannten Unterstrom berührt wird, der vielleicht von der Shag-Rock-Passage bei $54^{\circ} \mathrm{S}, 48^{\circ} \mathrm{W}$ ausgeht und den Südwestatlantik diagonal durchquert.

Kälteliebende Arten mit geringer Temperaturtoleranz (antarktische Arten) kommen im Südwestatlantik offenbar nur in drei eng begrenzten Gebieten vor, die wahrscheinlich unter dem Einfluß von Wassermassen mit antarktischen Anteilen stehen. Zwei der Gebiete liegen im Archibenthal ( 800 bis $1000 \mathrm{~m}$ ) und sind mit gewaltigen, bis in die Tiefsee hinabreichenden Canyons korreliert (Bahia-Blanca-Canyon und MalvinasCanyon), das dritte Gebiet liegt am westlichen Rand des Südlichen Falkland-Beckens. Während die Canyons vermutlich Randströme des tieferen Subantarktischen Zwischenwassers oder des oberen Antarktischen Bodenwassers auffangen, gelangt in das Südliche Falkland-Becken Tiefenwasser aus der Scotia-See.

Außer den Kaltwasserarten gibt es im südwestatlantischen Sublitoral und Archibenthal auch Arten, die eine - wenn auch geringe - positive Anomalie der Temperatur in dem jeweiligen Fundortgebiet anzuzeigen scheinen. Neben der aus dem WarmwasserArchibenthal stammenden Actinauge longicornis ist Phelliactis callicyclus zu nennen; beide Arten scheinen einen zumindest gelegentlichen Einfluß von tiefreichenden Brasilstromwirbeln anzuzeigen.

Die im Südwestatlantik offenbar permanent vorhandenen Frontensysteme werden besonders anschaulich von der Vertikalverbreitung der Seeanemone Isotealia antarctica wiedergegeben (Abb. 7): An der subtropischen Konvergenz wird neben einer tiefreichenden Front bei $38^{\circ} \mathrm{S}$ eine zweite Front zwischen 35 und $36^{\circ} \mathrm{S}$ markiert, bei der es sich entweder um die Konvergenzlinie im Winter handelt oder aber um die mit der Windgrenze korrelierte Front. Auch zwischen 43 und $44^{\circ} \mathrm{S}$ dringt $I$. antarctica in tieferes Wasser vor und folgt damit vermutlich dem über das Ameghino-Canyon-System abflie- 
Benden Schelfwasser. Noch deutlicher wird dieser Abstieg von einer anderen Seeanemone, Choriactis laevis, demonstriert.

Horizontal wie vertikal sind die Fundorte von Isotealia antarctica eng mit der $6-^{\circ} \mathrm{C}$ Isotherme korreliert, die ganzjährig einen schmalen, zur Schelfkante parallel verlaufenden Streifen auf dem äußeren Schelf umschließt, der sich im Norden der Falkland-Inseln noch etwas erweitert (Abb. 6). In diesem von Isotealia bewohnten Streifen (Subprovinz "Temperiertes Sublitoral Argentiniens") herrschen ähnlich gemäßigte und gleichförmige Bedingungen wie im Sublitoral der chilenischen Küste, denn auch hier sind die benthalen Temperaturen weitgehend unabhängig von der Jahreszeit und von der geographischen Breite. Solche gleichmäßigen Temperaturen über 15 Breitengrade hinweg sind nur möglich, wenn man einen permanenten, nach Süden gerichteten Unterstrom nahe der Schelfkante annimmt. Die Verbreitung von Isotealia läßt vermuten, daß dieser Unterstrom an der Windgrenze (bei etwa $35^{\circ} \mathrm{S}$ ) entsteht und von dort nach Süden zieht. Die Temperaturen im Benthal nördlich und nordwestlich der Falkland-Inseln werden vermutlich zusätzlich von Warmwasserlinsen beeinflußt, die sich vom Brasilstrom abgeschnürt haben und auf das Falkland-Plateau auflaufen.

Eine horizontale hydrographische Grenzschicht wird im Osten und Nordosten der Falkland-Inseln von der pelagischen Siphonophore Rhodalia miranda (Abb. 7, 8) und von der dem Substrat frei aufliegenden Seeanemone Bolocera tuediae kerguelensis in etwa $500 \mathrm{~m}$ Tiefe markiert. Zwei weitere Fundorte der Siphonophore nördlich der subtropischen Konvergenz bestätigen darüber hinaus, daß im Winter ein Unterstrom subantarktischen Wassers entlang der uruguayischen Schelfkante nach Norden zieht.

Eine euryöke Warmwasserfauna beherbergt die Subprovinz "Warmwasser-Sublitoral Argentiniens" in dem küstennahen Abschnitt zwischen La-Plata-Delta und dem Golfo San Jorge. Diese Subprovinz ist den stärksten jahreszeitlichen Veränderungen auf dem argentinischen Schelf ausgesetzt. Die üppige sommerliche Fauna, die auch tropische Elemente enthält, hat ephemeren Charakter und rekrutiert sich wahrscheinlich in jedem Jahr neu aus Larven und Adulten, die mit einem Ausläufer des Brasilstromes eindringen. Aktinien sind aus dieser Subprovinz nicht bekannt, wohl aber eine kleine Corallimopharie (Corynactis carnea), die im Sommer große Populationen bildet. Weniger extreme Lebensbedingungen bietet dagegen offenbar das Benthal der beiden Golfe San Matias und San Jorge, denn dort wurde die Seeanemone Antholoba achates angetroffen.

Die Verbreitungsmuster kälteliebender Benthostiere südlich des 50 . Breitengrades zeigen, daß das Sublitoral des argentinischen Schelfs und das Archibenthal des Südlichen Falkland-Beckens unter dem Einfluß von subantarktischem Wasser steht, das jedoch nicht wie die Deckschicht aus dem Süden, sondern aus dem Osten diese Gebiete erreicht. Trotzdem gibt es im Westen und Südosten der Falkland-Inseln in 80 bis etwa $200 \mathrm{~m}$ Tiefe Benthosgesellschaften, die auf gemäßigte Lebensbedingungen hinweisen. Dieser mäßigende Einfluß wird dem bodennahen, ganzjährig relativ warmen Stromband zugeschrieben, das östlich der Staaten-Insel nach Norden vordringt. Diese Feststellung bedeutet, daß für das Benthal auch im südlichen Teil des argentinischen Schelfs die klassische Ansicht eines vom Zirkumpolarstrom nach Norden abbiegenden kalten oder subantarktischen Stromes ("Falkland-Strom") revidiert werden muß. Vielmehr scheint das dort unter der Deckschicht eindringende, zu allen Jahreszeiten etwa $6^{\circ} \mathrm{C}$ warme Wasser die Umwanderung des südamerikanischen Kontinentes für temperierte Faunen- 
elemente des tieferen Sublitorals zu erlauben (Antholoba achates, Choriactis laevis). Vielleicht gibt es dort sogar manchmal Bedingungen, die auch bestimmten Warmwasser-Organismen eine erfolgreiche Umwanderung Kap Horns ermöglichen (siehe Corynactis carnea).

Die tiergeographische Gliederung der untersuchten Gebiete ergibt sich aus dem Gesamtcharakter des Benthos unter besonderer Berücksichtigung der Seeanemonen und aus dem tiergeographischen Verhalten der einzelnen Arten (Horizontal- und Vertikalverbreitung, Grenzlinien). Auch die hierarchische Gliederung in Provinzen und Subprovinzen erfolgte nach diesen Gesichtspunkten. Aussagen über endemische Arten im südwestatlantischen Benthal sind als Kriterien zur Abgrenzung und Gliederung biogeographischer Einheiten nicht geeignet, da viele der sublitoralen und archibenthalen Arten disjunkt verbreitet sind mit horizontal und vertikal weit verstreuten Fundortgebieten.

Durch die Abgrenzung einer Provinz "La Plata" und ihre Einstufung als eigenständige Provinz sollen die komplexen, jedoch in Zeit und Raum stabilen tiergeographischen und ozeanographischen Strukturen in diesem Gebiet hervorgehoben werden. Hier verläuft eine für alle Zonierungen geltende tiergeographische Grenze, die durch die Funde von Seeanemonen bis in $1000 \mathrm{~m}$ Tiefe verfolgt werden kann.

Die sublitorale und archibenthale Fauna ist im Südwestatlantik und in den angrenzenden zirkumantarktischen Lebensräumen nach einem Muster verteilt, das man mit einem Ausdruck von Owen (1981; p. 227) als "quasi-ordered patchiness" bezeichnen kann. Die quantitativ und qualitativ auffälligsten Benthosgesellschaften finden sich an den in Raum und Zeit beständigsten Fronten (subtropische Konvergenz sowie Frontensystem bei den Falkland-Inseln).

Aus pelagischen Okosystemen ist bekannt, daß solche mit permanent kräftigen Gradienten ausgestatteten Frontensysteme (thermal fronts) nicht nur biogeographische Grenzräume für die meisten Organismen sind, sondern auch neue, besondere Lebensräume darstellen können, die sich durch das Nebeneinander deutlich verschiedener Lebensräume auszeichnen (Brandt \& Wadley, 1981). In solchen Lebensräumen ("ecotone") sammeln sich aktiv und passiv Arten, die offenbar in den benachbarten Lebensräumen nicht vorkommen und daher als stenotop für solche Fronten angesehen werden können.

Obwohl Untersuchungen darüber erst beginnen, scheint es, daß Frontensysteme und ihre Auswirkungen auch für das Benthal wichtig sind. Die passive und aktive Anreicherung von Plankton-Larven benthischer Invertebraten an Fronten und verstärkter Larvenfall im Bereich der Front können sich in deutlich höheren Abundanzen wenig beweglicher oder sessiler Benthosorganismen widerspiegeln. So scheint die große, dem Sediment nur lose aufliegende Seeanemone Bolocera tuediae kerguelensis typisch für die "no motion" -Zone zwischen zwei sich bewegenden Wassermassen zu sein.

Quasi-stationäre "thermal fronts", die auch in archibenthalen Tiefen noch beachtliche Temperatur-Gradienten aufweisen, gibt es am Kontinentalhang außerhalb der LaPlata-Mündung und bei den Falkland-Inseln. In beiden Gebieten existieren GrenzLebensgemeinschaften mit subantarktisch-antarktischem Charakter, die offenbar von der enormen Produktivität dieser Gewässer profitieren. Diese Lebensgemeinschaften scheinen jedoch immer deutlich auf der kalten Seite der Front zu leben, und die meisten der dort gefundenen Arten kommen auch in anderen zirkumantarktischen Gebieten vor, 
unabhängig von kräftigen Fronten. Obwohl eine passive oder aktive Attraktion der Front für die Larven oder Adulten dieser Arten als sehr wahrscheinlich angesehen werden kann, so sind die adulten Tiere doch keine Bewohner der eigentlichen Front.

Eine Seeanemone, von der ich annehme, daß sie ein typischer, vielleicht nur dort vorkommender Bewohner archibenthaler "thermal fronts" ist, ist Hormathia pectinata, die bisher nur in den beiden südwestatlantischen Frontensystemen und in wahrscheinlich entsprechenden Lebensräumen im chilenischen Archibenthal gefunden wurde. Die Vertikalverbreitung der Art zeigt (Abb.7), daß sie bei den Falkland-Inseln offenbar zwischen "warmem" pazifischen Wasser und subantarktischem Wasser vorkommt und vor Nordargentinien in einem $200 \mathrm{~km}$ breiten Gürtel, der mit der "thermal front" der subtropischen Konvergenz identisch ist.

Grenzlebensgemeinschaften (boundary groups) sind nach Semenov $(1978 ;$ p. 86) die auffallendste Besonderheit in der Verteilung des südwestatlantischen Benthos und zugleich ein Indiz, daß der Südwestatlantik von dominanteren Arten besiedelt wird. Hierbei wird auf die Bedeutung solcher Lebensräume als Entwicklungs- und Verbreitungszentren von neuen Arten hingewiesen, ein Aspekt, der auch früher schon diskutiert wurde (Sverdrup et al., 1942; de Lattin, 1967; Briggs, 1974). Die Isolation von Arten innerhalb solcher Frontensysteme hat starke evolutive Wirkungen, die zu Variabilität, Unterart- und Artbildung führen können und das Vordringen in neue Lebensräume und Nischen ermöglichen.

Umgekehrt ist es aber auch denkbar, daß solche Grenzlebensräume Refugien für früher weitverbreitete Arten sind, die nur noch in dieser Umgebung dem Druck wettbewerbsfähigerer Arten widerstehen können (Semenov, 1978). Was die Frontensysteme im Südwestatlantik und die nur dort angetroffene Hormathia pectinata betrifft, so spricht

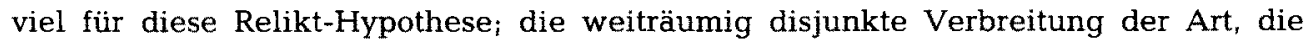
larvenökologisch nicht zu verstehen ist, ließe sich damit plausibel erklären. Die Tatsache, daß die Familie Hormathiidae zu den phylogenetisch ältesten Seeanemonen gerechnet wird (Schmidt, 1974), paßt ebenfalls gut in dieses Konzept. Daß die archibenthalen Lebensräume von vielen phylogenetisch und tiergeographisch arbeitenden Taxonomen als die im Laufe der Erdgeschichte stabilsten marinen Lebensräume angesehen werden (vgl. Briggs, 1974 ; p. 431) und auch andere Hormathiiden nur dort vorkommen, stützt diese Hypothese.

Danksagungen. Herrn Dr. R. Simonsen, Bremerhaven, danke ich für sein ermutigendes Interesse an dieser Arbeit und für die wertvollen Anregungen bei der Abfassung des Manuskriptes. Herrn Prof. S. A. Gerlach, Kiel, und Herrn Dr. H. Thiel, Hamburg, danke ich für die kritische Durchsicht des Manuskriptes und ihre konstruktive Hilfe. Herm Dr. W. Zenk, Kiel, verdanke ich einige Hinweise zu den ozeanographischen Kapiteln.

\section{LITERATUR}

Andriashev, A. P., 1977. Some additions to schemes of the vertical zonation of marine bottom fauna. In: Adaptations within antarctic ecosystems. Ed. by G. A. Llano. Smithsonian Inst, Washington, D.C., 351-360.

Anonymus, 1972. Atlas oceanografico (Atlantico Sul) - Condicoes no verao de 1972. Diretoria de Hidrografia e Navegacao, Rio de Janeiro.

Aragno, F. J. (Ed.), 1968. Datos y resultados preliminares de las campanas pesqueria "Pesqueria I". - Publnes Proy. Desarr. Pesq., 10,1-159. 
Balech, E., 1954. Division zoogeografica del litoral sudamericano. - Revta Biol. mar. 4, 184-195.

Balech, E., 1964. Caracteras biogeograficos de la Argentina y Uruguay. - Boln Inst. biol. mar. Univ. nac., B. Aires, 7, 107-112.

Balech, E., 1968. Dinoflagellates. In: Primary productivity and benthic marine algae of the antarctic and subantarctic. Ed. by S. Z. El-Sayed. Am. Geogr. Soc., New York, 8-9 (Antarct. Map Folio Ser. 10).

Barth, R., Bonel Rivas, L. \& Osario e Castro, M. L., 1965. Estudos na zona terminal da corriente do Brasil. - Not. tec. Inst. Pesq. mar. 23, 1-13.

Bartsch, I., 1982. Ophiuridea (Echinodermata) from the Patagonian shelf. - Mitt. hamb. zool. Mus. Inst. 79, 211-250.

Bé, A., 1969. Planktonic Foraminifera. In: Distribution of selected groups of marine invertebrates in waters south of $35^{\circ} \mathrm{S}$ latitude. Ed. by J. W. Hedgpeth. Am. Geogr. Soc., New York, 9-12 (Antarct. Map Folio Ser. 11).

Belem, M. J. C., 1980. Redescricao de Homostichanthus duerdeni Carlgren, 1900 (Anthozoa, Actiniaria) (Contribuicoes ao conhecimento da fauna de cnidarios do Esperito Santo, Brasil 2). Revta Nordest. Biol. 3 (Especial), 9-24.

Belem, M. J. C. \& Preslercravo, J. C., 1973. Contribuicoes ao conhecimento da fauna de cnidarios do Esperito Santo, Brasil I. Consideracoes sobre Actiniaria do Municipio de Aracruz, ES. - Bolm Mus. Biol. Prof. Mello-Leitão (Zool.) 80, 1-14.

Belem, M. J. C. \& Monteiro, D. C., 1977. Contribuicoes ao conhecimento da fauna de cnidarios do Rio de Janeiro. II. Haliplanella luciae (Verrill, 1898) (Actiniaria, Acontiaria) uma nova ocorrencia no Brasil. - Avulso UFRJ - CCS - Depto Zool. 26, 1-19.

Bellisio, N. B. \& Lopez, R. B., 1973. I. Merluza de Cola - Macruronus magellanicus Lönnberg. Monografias recursos pesq. 1, 1-46.

Bernasconi, I., 1964. Distribucion geografica de los Equinoideos y Asteroideas de la extremidad austral de Sudamerica. - Boln Inst. biol. mar. Univ. nac. B. Aires 7, 43-50.

Bernasconi, I., 1973. Los Equinodermos colectados por el "Walther Herwig" en el Atlantico sudoeste. - Revta Mus. argent. Cienc. nat. Bernardino Rivadavia (Hidrobiol.) 3, 287-334.

Bernasconi, I. \& d'Agostino, M. M., 1977. Ofiuroideos del mar epicontinental Argentino. - Revta Mus. argent. Cienc. nat. Bernardino Rivadavia (Hidrobiol.) 5, 65-114.

Bersch, M. \& Becker, G. A., 1984. Upper layer thermal structure in the Atlantic sector of the Southern Ocean. - Dt. hydrogr. Z. 37 (2), 71-86.

Boltovskoy, D., 1971. Contribucion al conocimiento de los pteropodos Thecosomados sobre la plataforma continental bonaerense. - Revta Mus. La Plata (Zool.) 11, 121-136.

Boltovskoy, D., 1981. Caracteristicas biologicas del Atlantico sudoccidental. In: Atlas del zooplankton del Atlantico sudoccidental y metodos de trabajo con el zooplancton marino. Ed. by D. Boltovskoy. Inst. Nac. Invest. Des. Pesq., Mar. del Plata, 239-251.

Boltovskoy, E., 1959. La corriente de Malvinas (un estudio en base a la investigacion de Foraminiferos). - Publ. Serv. Hidrogr. Naval, B. Aires H 1015, 1-93.

Boltovskoy, E., 1964. Provincias zoogeograficas de America del sur su sector antarctico segun los foraminiferos bentonicos. - Boln Inst. biol. mar. Univ. nac. B. Aires 7, 93-99.

Boltovskoy, E., 1968. Hidrologia de las aguas superficiales en la parte occidental del Atlantico sur. Revta Mus. argent. Cienc. nat. Bernardino Rivadavia (Hidrobiol.) 2, 199-224.

Boltovskoy, E., 1971. Ecology of the planktonic foraminifera living in the surface layer of Drake passage. - Micropaleontology 17, 53-68.

Boltovskoy, E., 1978. Problema de los indicadores biologicos en oceanografia. - An. Acad. Cienc. exact. fis. nat. B. Aires 30, 229-251.

Boltovskoy, E. \& Watanabe, S., 1980. Atlas of benthic shelf foraminifers of the Southwest Atlantic. Junk, 'S-Gravenhage, $153 \mathrm{pp}$.

Boschi, E., 1964a. Los crustaceos decapodos Brachyura del litoral bonaerense (R. Argentina). - Boln Inst. biol. mar. Univ. nac. B. Aires 6, 1-99.

Boschi, E., 1964b. Los Peneidos de Brasil, Uruguay y Argentina. - Boln Inst. biol. mar. Univ. nac. B. Aires 7, 1-42.

Boschi, E., 1979. Geographic distribution of Argentinian marine decapod crustaceans. - Bull. biol. Soc. Wash. 3, 134-143.

Boschma, H. \& Lowe, T. P., 1969. Stylasterina. In: Distribution of selected groups of marine 
invertebrates in waters south of $35^{\circ} \mathrm{S}$ latitude. Ed. by J. W. Hedgpeth. Am. Geogr. Soc., New York, 14-15 (Antarctic Map Folio Ser. 11).

Brandhorst, W. \& Castello, J. P., 1971. Evaluacion de los recrusos de anchoita (Engraulis anchoita) frente a la Argentina y Uruguay. - Contrnes Inst. biol. mar. Mar del Plata 166, 1-63.

Brandt, St. B. \& Wadley, V. A., 1981. Thermal fronts as ecotones and zoogeographic barriers in marine and freshwater systems. - Proc. ecol. Soc. Aust. 11, 13-26.

Brattström, H. \& Johanssen, A., 1983. Ecological and regional zoogeography of the marine benthic fauna of Chile. - Sarsia 68, 289-339.

Briggs, J., 1974. Marine zoogeography. MCGraw-Hill, New York, 475 pp.

Bückmann, A., 1974. Ergebnisse der Forschungsreisen des FFS "Walther Herwig" nach Südamerika XXXII. Die Appendicularienfänge der "Walther Herwig" auf dem Patagonischen Schelf im September 1971. - Arch. FischWiss. 25, 21-32.

Burckle, L. H. \& Stanton, D., 1975. Distribution of displaced antarctic diatoms in the Argentine basin. - Nova Hedwigia, Beih. 53, 283-292.

Burton, M., 1932. Sponges. - Discovery Rep. 6, 238-385.

Buscaglia, J. L., 1971. On the circulation of the intermediate waters in the Southwestern Atlantic Ocean. - J. mar. Res. 29, 245-255.

Cairns, S. D., 1982. Antarctic and subantarctic Scleractinia. - Antarct. Res. Ser. 34, 1-74.

Cairns, S. D., 1983. Antarctic and subantarctic Stylasterina (Coelenterata: Hydrozoa). - Antarct. Res. Ser. 38, 61-164.

Carlgren, O., 1899. Zoantharien. - Hamburger Magelhaensische Sammelreise 4, 1-47.

Carlgren, O., 1903. Actiniarien. - Résult. Voyage S. Y. Belgica (Zool.), 1903, 3-11.

Carlgren, O., 1927. Actiniaria and Zoantharia. - Further zool. Results Swed. Antarct. Exped. 2, $1-102$.

Carlgren, O., 1928. Actiniaria der Deutschen Tiefsee-Expedition. - Wiss. Ergebn. dt. Tiefsee-Exped. "Valdivia" 22, 126-266.

Carlgren, O., 1938. South African Actiniaria and Zoantharia. - K. svenska VetenskAkad. Handl. 17, 1-148.

Carlgren, O., 1939. Actiniaria and Zoantharia of the Scottish National Antarctic Expedition 1902-1904. - Trans. R. Soc. Edinb. 49, 791-803.

Carlgren, O., 1949. A survey of the Ptychodactiaria, Corallimorpharia and Actiniaria. - K. svenska VetenskAkad. Handl. (Ser. 4) 1, 1-121.

Carlgren, O., 1959. Corallimorpharia and Actiniaria with description of a new genus and species from Peru. Reports of the Lund University Chile Expedition 1948-49, Nr. 38. - Acta Univ. lund. (Avd. 2) 56, 1-39.

Carter, D., 1965. Actinias de Montemar, Valparaiso, - Revta Biol. mar, 12, 129-159.

Castello, J. P., 1984. Registros del elefante marino, Mirounga leonina (Carnivora, Phocidae) en las costas del Atlantico S.O., fuera del area de cria. - Revta Mus. argent. Cienc. nat. (Zool.) 13, 235-243.

Castellanos, Z. A. de, 1982. Los Pyramidellidae de la Republica Argentina (Moll. Entomotaeniata).Comun. Mus. nac. Hist. nat. Bernardino Rivadavia 2, 61-85.

Ciechomski $i_{t}$ J. D. de \& Sanchez, R. P., 1983. Ichthyoplankton abundance and associated zooplankton biomass in the shelf waters off Argentina. - Biol. Oceanogr. 3, 77-101.

Clowes, A. J., 1933. Influence of the Pacific on the circulation in the south-west Atlantic Ocean. Nature, Lond. 131, 189-191.

Coelho, P. A., 1980. Zoogeografia marinha do Brasil. I. Consideracoes gerais sobre o metodo e aplicacao a um grupo de Crustaceos (Paguros: Crustacea Decapoda, superfamilias Paguroidea e Coenobitoidea). - Bolm Inst. Oceanogr., S Paulo 29, 139-144.

Corrêa, D. D., 1964. Corallimorpharia e Actiniaria do Atlantico Oeste Tropical. Tese para provimento do cargo de Professor Catedratico, Universidade de Sao Paulo, $139 \mathrm{pp}$.

Corrêa, D. D. \& Schlenz, E., 1976. On the sea anemone Paracondylactis hertwigi (Wassilieff, 1908). Bolm zool. Univ. S. Paulo 1, 69-80.

Dayton, P. K., Robilliard, G. A. \& Paine, T. R., 1970. Benthic faunal zonation as a result of anchor ice at McMurdo Sound, Antarctica. In: Antarctic ecology. Ed. by M. W. Holdgate. Acad. Press, London, $1,244-258$. 
Deacon, G. E. R., 1933. A general account of the hydrology of the South Atlantic Ocean. - Discovery Rep. 7, 171-238.

Deacon, G. E. R., 1937. The hydrology of the Southern Ocean. - Discovery Rep, 15, 1-124.

Deacon, G. E. R., 1963. The Southern Ocean. In: The Sea. Ed. by M. N. Hill. Wiley, New York, $2,281-296$.

Deacon, G. E. R., 1977. Comments on a counterclockwise circulation in the Pacific subantarctic sector of the Southern Ocean suggested by McGinnis. - Deep Sea Res. 24, 927-930.

Deacon, G. E. R., 1982. Physical and biological zonation in the Southern Ocean. - Deep Sea Res. 29, $1-15$.

Dearborn, J. H. \& Rommel, J. A., 1969. Crinoidea. In: Distribution of selected groups of marine invertebrates in waters south of $35^{\circ} \mathrm{S}$ latitude. Ed. by J. W. Hedgpeth. Am. Geogr. Soc., New York, 35-36 (Antarct. Map Folio Ser. 11).

Defant, A., 1936. Zusammenfassende Ubersicht und allgemeine Beziehungen der troposphärischen Zirkulation zur Verteilung des Gehaltes an Sauerstoff, anderer chemischer Faktoren und des Planktons. - Wiss. Ergebn. dt. atlant. Exped. "Meteor" 6 (1), 1-411.

Defant, A., 1961. Physical oceanography. Pergamon Press, London, 1, 1-729.

Dell, R. K., 1956. The archibenthal Mollusca of New Zealand. - Bull. Dom. Mus., Wellington 18, $1-235$.

Dell, R. K., 1964. Zoogeography of antarctic benthic Mollusca. In: Biologie antarctique. Hermann, Paris, 259-262.

Dell, R. K., 1972. Antarctic benthos. - Adv. mar. Biol. 10, 11-216.

Diehl, M., 1977. Ascidien des argentinischen Schelfs aus den Grundtrawl-Fängen des FFS "Walther Herwig" auf seiner dritten Südamerika-Expedition. - Mitt. hamb. zool. Mus. Inst. 74, 139-153.

Dietrich, G. \& Ulrich, J. (Hrsg.), 1968. Atlas zur Ozeanographie. Bibliograph. Institut, Mannheim, $76 \mathrm{pp}$.

Dietrich, G., Kalle, K., Kraus, W. \& Siedler, G., 1975. Allgemeine Meereskunde. Bornträger, Berlin, 593 pp.

Doumenc, D., 1975. Actinies bathyales de l'océan Atlantique nord. Familles des Hormathidae (genres Paracalliactis et Phelliactis) et des Actinostolidae (genres Actinoscyphia et Sicyonis). Bull. Mus. natn. Hist. nat., Paris (Zool.) 197, 157-206.

Doumenc, D., 1984. Les Actinies bathyales du Chili: Un exemple d'utilization de fichiers informatiques. - Annls Inst. océanogr., Paris 60,143-162.

Drygalski, E. von, 1927. Ozean und Antarktis. - Dt. Südpolar-Exped. 7, 387-556.

Dube, V. M. C., 1974. Anemonas-do-mar (Ordem Actiniaria) do estado da Bahia. Dissertacao apresentada ao departamento de Zoologia do Instituto de Biociencias da Universidade de Sao Paulo paraobtencao do titulo de Mestrem Zoologia. Universidade Federal da Bahia, Salvador, Bahia, Sao Paulo, 112 pp.

Dube, V. M. C., 1975. Contribution to the study of the sea anemones from the state of Bahia, Brazil. I. Actinia bermudensis (McMurrich, 1899) und Anemonia sargassensis Hargitt, 1908. - Natura, Salvador 1, 104-110.

Dube, V. M. C., 1976a. Contribution to the study of the sea anemones from the state of Bahia, Brazil. II. Phyllactis praetexta (Dana, 1846) and Calliactis tricolor (Lesueur, 1817). - Natura, Bahia 76, $101-110$.

Dube, V. M. C., 1976b. Sea anemones of the State of Bahia, Brazil. 3. Bunodosoma cangicum. - Boln Inst. biol. Bahia 15, 27-30.

Dube, V. M. C., 1977. Contribution to the study of sea anemones from the State of Bahia IV. Anthopleura cascaia Corrêa, 1964. - Natura, Bahia 77, 43-48.

Dube, V, M. C., 1978. Sea anemones (Order Actiniaria) of the State of Bahia. - Atas Soc. Biol. Rio de J. $19,31-32$.

Dunn, D. F., 1982. Paraphelliactis pabista, a new species of hormathiid sea anemone from abyssal northeastern Pacific waters. - Syesis 15, 51-56.

Dunn, D. F., 1983. Some antarctic and subantarctic sea anemones (Coelenterata: Ptychodactiaria and Actiniaria). - Antarct. Res. Ser. 39, 1-67.

Dunn, D. F., 1984. More antarctic and subantarctic sea anemones (Coelenterata: Corallimorpharia and Actiniaria). - Antarct. Res. Ser, 41, 1-42.

Dunn, D. F. \& Bakus, G. J., 1977. Redescription and ecology of Liponema brevicornis (McMurrich, 
1893), with definition of the family Liponematidae (Coelenterata, Actiniaria). - Astarte 10, $77-85$.

Echols, R. J. \& Kennett, J. P., 1973. Distribution of Foraminifera in the surface sediments. In: Marine sediments of the southern oceans. Ed. by V. C. Bushnell. Am. Geogr. Soc., New York, 13-17 (Antarct. Map Folio Ser. 17)

Ehrich, S., 1980. Biologische Untersuchungen über die Grundfischbestände von Argentinien. Mitt. Inst. Seefisch. 30, 1-59.

Ekman, S., 1967. Zoogeography of the sea. Sidgwick \& Jackson, London, $417 \mathrm{pp}$.

El-Sayed, S. Z., 1967. On the productivity of the south west Atlantic ocean and the waters west of the antarctic peninsula. - Antarct. Res. Ser. 3, 15-47.

El-Sayed, S. Z., 1970. Phytoplankton production of the South Pacific and the Pacific sector of the Antarctic. - Contr. Oceanogr. 449, 127-144.

England, K. W., 1971. Actiniaria from Muroroa atoll Tuamotu, Polynesia. - Cah. Pacif, 15, 23-39.

Esnal, G. B., 1968. Salpas colectados por "El Austral" y el "Walther Herwig" en el oceano atlantico. - Revta Mus. argent. Cienc, nat. Bernardino Rivadavia (Hidrobiol.) 2, 257-277.

Ewing, M. \& Lonardi, A. G., 1971. Sediment transport and distribution in the Argentine Basin. 5. Sedimentary structure of the Argentine margin, basin and related provinces. In: Physics and chemistry of the earth. Ed. by L. H. Ahrens, F. Press, S. K. Runcorn \& H. C. Urey. Pergamon Press, New York, 8, 101-138.

Ewing, M., Eittreim, St., Ewing, J. \& Le Pichon, X., 1971. Sediment transport and distribution in the Argentine basin. 3. Nepheloid layer and processes of sedimentation. In: Physics and chemistry of the earth. Ed. by L. H. Ahrens, F. Press, S. K. Runcorn \& H. C. Urey. Pergamon Press, New York, 8, 51-77.

Fell, H. B. \& Dawsey, S., 1969. Asteroidea. In: Distribution of selected groups of marine invertebrates in waters south of $35^{\circ} \mathrm{S}$ latitude. Ed. by J. W. Hedgpeth. Am. Geogr. Soc., New York, 41 (Antarct. Map Folio Ser. 11).

Fell, H. B., Holzinger, T. \& Sherraden, M., 1969. Ophiuridea. In: Distribution of selected groups of marine invertebrates in waters south of $35^{\circ} \mathrm{S}$ latitude. Ed. by J. W. Hedgpeth. Am. Geogr. Soc., New York, 42-43. (Antarct. Map Folio Ser. 11).

Foster, M. W., 1969. Brachiopoda. In: Distribution of selected groups of marine invertebrates in waters south of $35^{\circ} \mathrm{S}$ latitude. Ed. by J. W. Hedgpeth. Am. Geogr. Soc., New York, 21-22 (Antarct. Map Folio Ser. 11).

General bathymetric chart of the oceans (GEBCO), 1978. Canadian Hydrographic Service, Ottawa. Chart 5.12.

General bathymetric chart of the oceans (GEBCO), 1981. Canadian Hydrographic Service, Ottawa. Chart 5.16.

Georgi, D. T., 1979. Modal properties of antarctic intermediate water in the south east Pacific and the south Atlantic. - J. phys. Oceanogr. 9, 456-468.

Gordon, A. L., 1966. Potential temperature, oxygen and circulation of bottom water in the southern ocean. - Deep Sea Res. 13, 1125-1138.

Gordon, A. L., 1981. South Atlantic thermocline ventilation. - Deep Sea Res. 28, 1239-1264.

Gordon, A. L. \& Goldberg, R. D., 1970. Circumpolar characteristics of antarctic waters. In: Circumpolar characteristics of antarctic waters. Ed. by V. C. Bushnell. Am. Geogr. Soc., New York, 1-5 (Antarct. Map Folio Ser. 13).

Gordon, A. L. \& Molinelli, E., 1982. Southern ocean atlas. Columbia Univ. Press, New York, 11 pp., 233 pls.

Gordon, A. L., Georgi, D. T. \& Taylor, H. W., 1977. Antarctic polar front zone in the western Scotia Sea - summer 1975. - J. phys. Oceanogr. 7, 309-328.

Haeckel, E., 1888. Report on the Siphonophorae collected by H.M.S. Challenger during the years 1873-1876. - Rep. scient. Results Voyage H.M.S. Challenger (Zool.) 28, 1-380.

Hart, T. J, 1946. Report on trawling surveys on the Patagonian continental shelf. - Discovery Rep. $23,223-408$.

Hartman, O., 1964. Polychaeta Errantia of Antarctica. - Antarct. Res. Ser. 3, 1-131.

Hartman, O., 1966. Polychaeta myzostomidae and sedenteria of Antarctica. - Antarct. Res. Ser. 7. $1-158$. 
Hartmann, G., 1964. Biogéographie et écologie des animaux marins - discussion. In: Biologie antarctique. Hermann, Paris, 283-286.

Hartmann-Schröder, G., 1983. Die Polychaeten der 15., 36. und 76. Reise von FFS "Walther Herwig" zum patagonischen Schelf (Südwest-Atlantik). - Senckenb. marit. 15, 251-271.

Hartmann-Schröder, G. \& Hartmann, G., 1962. Zur Kenntnis des Eulitorals der chilenischen Pazifikküste und der argentinischen Küste Südpatagoniens unter besonderer Berücksichtigung der Polychaeten und Ostracoden. - Mitt. hamb. zool. Mus. Inst. 60 (Suppl.), 1-270.

Hartog, J. C. den, 1980. Caribbean shallow water corallimorpharia. - Zool. Verh., Leiden 176, 1-83.

Hastings, A. B., 1943. Polyzoa (Bryozoa). - Discovery Rep. 22, 301-510.

Hayden, B. P. \& Dolan, R., 1976. Coastal marine fauna and marine climates of the Americas. J. Biogeogr. 3, 71-81.

Hedgpeth, J. W., 1969. Pycnogonida. In: Distribution of selected groups of marine invertebrates in waters south of $35^{\circ} \mathrm{S}$ latitude. Ed. by J. W. Hedgpeth. Am. Geogr. Soc., New York, 26-28 (Antarct. Map Folio Ser. 11).

Heezen, B. C. \& Hollister, Ch. D., 1971. The face of the deep. Oxford Univ. Press, New York, 659 pp.

Hentschel, E., 1936. Allgemeine Biologie des südatlantischen Ozeans. - Wiss. Ergebn. dt. atlant. Exped. "Meteor" 11, 1-344.

Heron-Allen, E. \& Earland, A., 1932. Foraminifera Part I. The ice-free area of the Falkland-Islands and adjacent seas. - Discovery Rep. 4, 293-459.

Hertwig, R., 1882, Die Actinien der Challenger-Expedition. Fischer, Jena, 119 pp.

Hertwig, R., 1888. Report on the Actiniaria dredged by H.M.S. Challenger during the years 1873-1876. - Rep. scient. Results Voyage H.M.S. Challenger (Zool.) 26 (Suppl.), 1-56.

Hillman, N. S., 1969. Halocypridae. In: Distribution of selected groups of marine invertebrates in waters south of $35^{\circ} \mathrm{S}$ latitude. Ed. by J. W. Hedgpeth. Am. Geogr. Soc, New York, 29-30 (Antarct. Map Folio Ser. 11).

Hollister, C. D. \& McCave, I. N., 1984. Sedimentation under deep-sea storms. - Nature, Lond. 309, 220-225.

Hoyle, W. E., 1886. Report on the Cephalopoda collected by H.M.S. Challenger. - Rep. scient. Results Voyage H.M.S. Challenger (Zool.) 16, 1-246.

Hubold, G., 1980a. Hydrography and plankton off southern Brazil and Rio de la Plata, August November 1977. - Atlantica, Rio Grande 4, 1-21.

Hubold, G., 1980b. Second part on hydrography and plankton off southern Brazil and Rio de la Plata. - Atlantica, Rio Grande 4, 23-42.

Institut für Seefischerei, 1966. FFS "Walther Herwig" im Südatlantik. Forschungsfahrt zum südamerikanischen Schelfgebiet von Südbrasilien bis Kap Horn. - Infn Fischw, 13, 146-148.

Johnson, M. W. \& Brinton, E., 1963. Biological species, watermasses and currents. In: The sea. Ed. by M. N. Hill. Wiley, New York, 2, 381-414.

Joly, A. B., 1965. Marine flora of the tropical and subtropical western south Atlantic. - Anais Acad. bras. Cienc. 37, 279-382.

Kaiser, P., 1976. Neomenia herwigi sp. n., ein bemerkenswerter Vertreter der Solenogastren (Mollusca, Aculifera) aus argentinischen Schelfgewässern. - Mitt. hamb. zool. Mus. Inst. 73, $57-62$.

Kaiser, P., 1977a. Beiträge zur Kenntnis der Voluten (Mollusca) in argentinisch-brasilianischen Gewässern (mit der Beschreibung zweier neuer Arten). - Mitt. hamb. zool. Mus. Inst. 74, 11-26.

Kaiser, P., 1977b. Uber den Fund einer neuen Buccinide (Mollusca), Echinosipho aculeatum gen. n. und sp. $n$. in patagonischen Gewässern. - Mitt. hamb. zool. Mus. Inst. 74, 27-30.

Kaiser, P., 1980. Die Gattung Bathydoris Bergh 1884 in patagonischen Gewässern. - Spixiana 3, 43-51.

Kapp, H., 1980. Results of the research cruises of FRV "Walther Herwig" to South America. LV. Chaetognatha from the Patagonian shelf in February 1971. - Arch. FischWiss. 30, 125-135.

Klähn, J., 1911. Über die Meeresströmungen zwischen Kap Horn und La Plata-Mündung. - Annln Hydrogr., Berlin 39, 647-665.

Klappenbach, M. A., 1965. Lista preliminar de los Mytilidae brasilenos con claves para su determinacion y notas sobre su distribucion. - Anais Acad. bras. Cíenc. 37, 327-352.

Knox, G. A., 1977. The antarctic polychaete fauna: Its characteristics, distribution patterns and 
evolution. In: Adaptations within antarctic ecosystems. Ed. by G. A. Llano. Smithsonian Inst., Washington, D.C., 1111-1127.

Koltun, V. M., 1969. Porifera. In: Distribution of selected groups of marine invertebrates in waters south of $35^{\circ} \mathrm{S}$ latitude. Ed. by J. W. Hedgpeth. Am. Geogr. Soc., New York, 13-14 (Antarct. Map Folio Ser. 11).

Kott, P., 1969. Ascidiacea. In: Distribution of selected groups of marine invertebrates in waters south of $35^{\circ} \mathrm{S}$ latitude. Ed. by J. W. Hedgpeth. Am. Geogr. Soc., New York, 43-44 (Antarct. Map Folio Ser. 11).

Krefft, G., 1968. Neue und erstmalig nachgewiesene Knorpelfische aus dem Archibenthal des Südwestatlantiks, einschließlich einer Diskussion einiger Etmopterus-Arten südlicher Meere. Arch. FischWiss. 19, 1-42.

Krepper, C. M. \& Rivas, A. L., 1979. Analisis de las caracteristicas oceanograficas de la zona austral de la plataforma continental Argentina y aguas adyacentes. - Acta oceanogr. Argent. 2, 55-82.

Krüger, H., 1939. Die Thaliaceen der Meteor-Expedition. - Wiss. Ergebn. dt. atlant. Exped. "Meteor" 13, 1-43.

Kusakin, O. G., 1967. Fauna of the Isopoda and Tanaidacea in the coastal zones of the Antarctic and subantarctic waters. - Biol. Rep. Sov, antarct. Exped. (1955-1958) 3, 220-389.

Lattin, G. de, 1967. Grundriß der Zoogeographie. Fischer, Stuttgart, 602 pp.

Legeckis, R. \& Gordon, A. L., 1982. Satellite observations of the Brazil and Falkland currents 1975 to 1976 and 1978. - Deep Sea Res. 29, 375-401.

Leipper, D. \& Capurro, L., 1964. Continuation of surface and deep water current measurements in the Antarctic ocean (Drake Passage). - Contr. Tex. A \& M Univ. Coll. Geosci. 261, 161-163.

Lenz, W., 1975. Untersuchungen zur inneren hydrographischen Struktur des südlichen und mittleren Atlantiks (0-2000 m Tiefe) mit zoogeographischen Anmerkungen. - Ber. dt. wiss. Kommn Meeresforsch. 24, 1-22.

Le Pichon, X., Ewing, M. \& Truchan, M., 1971. Sediment transport and distribution in the Argentine basin. 2. Antarctic bottom current passage into the Brazil basin. In: Physics and chemistry of the earth. Ed. by L. H. Ahrens, F. Press, S. K. Runcorn \& H. C. Urey. Pergamon Press, New York, $8,31-47$.

Lohmann, H., 1912. Beiträge zur Charakterisierung des Tier- und Pflanzenlebens in den von der "Deutschland" während ihrer Fahrt nach Buenos Aires durchfahrenen Gebieten des atlantischen Ozeans. - Int. Revue ges. Hydrobiol. Hydrogr. 4, 407-432.

Lohmann, H. \& Hentschel, E., 1939. Die Appendicularien im südatlantischen Ozean. - Wiss. Ergebn. dt. atlant. Exped. "Meteor" 13, 1-243.

Lonardi, A. \& Ewing, M., 1971. Sediment transport and distribution in the Argentine Basin. 4. Bathymetry of the continental margin, Argentine basin and other related provinces, canyons and sources of sediments. In: Physics and chemistry of the earth. Ed. by L. H. Ahrens, F. Press, S. K. Runcorn \& H. C. Urey. Pergamon Press, New York, 8, 79-121.

Lopez, R. B., 1964. Problemas de la distribucion geografica de los peces marinos suramericanos. Boln Inst. biol mar. Univ. nac., B. Aires 7, 57-63.

Lorenz, M., 1979. Echinoidea des argentinischen Schelfs aus den Grundtrawlfängen des FFS "Walther Herwig" auf seiner dritten Südamerikaexpedition. - Dipl.-Arb., Univ. Hamburg, $126 \mathrm{pp}$.

Lusquinos, A. J., 1966. Determinacion de la convergencia subtropical sobre la base de temperatura y salinidad obtenida en la campanas Tridente I y II. - Boln Serv. Hidrogr. Naval, B. Aires, 3, $79-89$

Lusquinos, A. J. \& Valdez, A. J., 1971. Aportes al conocimiento de las masas de agua del Atlantico sudoccidental. - Publ. Serv. Hidrogr. Naval, B. Aires, H 659, 1-48.

Madsen, F. J., 1956. Reports of the Lund University Chile Expedition: Asteroidea. - Acta Univ. lund. (Avd. 2) 52, 1-53.

Mandelli, E. F., 1965. Contribucio al conocimiento de la produccion organica primera en aguas subantarcticas (Oceano Atlantico Sudoccidental). - Anais Acad. bras. Cienc. 37, 399-407.

Mantyla, A. W. \& Reid, J. L., 1983. Abyssal characteristics of the world ocean waters. - Deep Sea Res. 30, 805-833.

Maslennikov, V. V. \& Parfenovich, S. S., 1979. Some features of water dynamics off Falkland 
Islands. - Trudy vses. nauchnoissled. Inst. morsk. ryb Khoz. Okeanogr. 136, 57-60 (Abstract: Deep Sea Res. 27B 1980, 71).

Matthews, H. L., 1934. The marine deposits of the Patagonian continental shelf. - Discovery Rep. 19, $175-206$.

McGinnis, R. F, 1974. Counter-clockwise circulation in the Pacific subantarctic sector of the southern ocean. - Science, N.Y. 186, 736-738.

McIntosh, W. C., 1885. Report on the Annelida Polychaeta collected by H.M.S. "Challenger" during the years 1873-1876. - Rep. scient. Results Voyage H.M.S. Challenger (Zool.) 12, 1-554.

McMurrich, J. P., 1893. Report on the Actiniae collected by the U.S. Fish Commission steamer "Albatros" during the winter of 1887-1888. - Proc. U.S. natn. Mus. 16, 119-216.

McMurrich, J. P., 1904. The Actiniae of the Plate collection. - Zool. Jb. (Suppl.) 6, 215-306.

Mileikovski, A. A., 1971. Types of larval development in marine bottom invertebrates. - Mar. Biol. $10,193-213$.

Molinelli, E., 1978. Isohaline thermocline in the southeast Pacific ocean. - J. phys. Oceanogr. 8, 1139-1145.

Molinelli, E., 1981. The antarctic influence on antarctic intermediate water. - J. mar. Res. 39, 267-293.

Monniot, C. \& Monniot, F, 1983. Les Ascidies antarctiques et subantarctiques: morphologie et biogéographie. - Mém. Mus. natn. Hist. nat., Paris (Zool.) 125, 1-165.

Monteiro, A. M. G. \& Tommasi, L. R., 1983a. Ophiuridea das regioes antarctica e subantarctica. 1. Sobre tres especies de Gorgonocephalidae e Ophiacanthidae. - Bolm Inst. oceanogr., S. Paulo $32,33-54$.

Monteiro, A. M. G. \& Tommasi, L. R., 1983b. 2. Variacoes em Gorgonocephalus chilensis (Philippi). - Bolm Inst. oceanogr., S. Paulo 32, 55-61.

Moyano, H. I., 1982a. Bryozoa marinos de centro y sudamerica: Evaluacio preliminar (1). - Cah. Biol. mar. 23, 365-381.

Moyano, H. I., 1982b. Magellanic Bryozoa: Some ecological and zoogeographical aspects. - Mar. Biol. 67, 81-96.

Moyano, H. I. \& Gordon, A. L., 1980. New species of Hippothoidae (Bryozoa) from Chile, Antarctica and New Zealand. - J. R. Soc. N.Z. 10, 75-95.

Murray, J., 1895. A summary of the scientific results obtained at the sounding, dredging, and trawling stations of H. M. S. Challenger- - Rep. scient. Results Voyage H. M. S. Challenger 2 , $1-1604$.

Nehring, D. \& Brosin, H. J., 1968. Ozeanographische Beobachtungen im äquatorialen Atlantik und auf dem patagonischen Schelf während der 1. Südatlantik-Expedition mit dem Fischereiforschungsschiff "Ernst Haeckel" von August bis Dezember 1966. - Geod. geophys. Veröff. (R. 4) 3, $1-93$.

Ottaway, J. R., 1980. Population ecology of the intertidal anemone Actinia tenebrosa. IV. Growth rates and longevities. - Aust. J. mar. Freshwat. Res. 31, 385-395.

Owen, R. W., 1981. Fronts and eddies in the sea: mechanisms, interactions and biological effects. In: Analysis of marine ecosystems. Ed. by A. R. Longhurst. Acad. Press, London, 197-234.

Palacio, F. J., 1982. Revision zoogeografica marina del sur de Brasil. - Bolm Inst. oceanogr., S. Paulo $31,69-92$.

Pawson, D. L., 1969. Holothuroidea. In: Distribution of selected groups of marine invertebrates in waters south of $35^{\circ}$ S latitude. Ed. by J. W. Hedgpeth. Am. Geogr. Soc., New York, 36-38 (Antarct. Map Folio Ser. 11).

Pax, F., 1922. Diagnosen neuer Actiniarien aus der Ausbeute der Deutschen (1901-1903) und der Französischen Südpolar-Expedition. - Zool. Anz. 54, 74-92.

Pax, F., 1923. Antarktische Aktinien aus der Ausbeute des "Pourquoi pas". - Zool. Jb. (System. Ókol. Geogr. Tiere) 47, 1-28.

Pax, F., 1926. Die Aktinien der Deutschen Südpolar-Expedition 1901-1903. - Dt. Südpolar-Exped. (Zool.) 18, 1-62.

Piola, A. R. \& Georgi, D. T, 1982. Circumpolar properties of antarctic intermediate water and subantarctic mode water. - Deep Sea Res. 29, 687-711.

Pizarro, N. J., 1967. Distribucion del oxigeno disuelto en la zona oeste de la convergencia subtropical de Atlantico sud. - Bolm Inst. oceanogr., S. Paulo 16, 67-85. 
Rayner, G. W., 1935. The Falkland species of the crustacean genus Munida, - Discovery Rep. 10, $209-245$.

Reid, J. L., Nowlin, W. D. \& Patzert, W. C., 1977. On the characteristics and circulation of the southwestern Atlantic ocean. - J. phys. Oceanogr. 7, 62-91.

Riemann-Zürneck, K, 1969. Sagartia troglodytes (Anthozoa). Biologie und Morphologie einer schlickbewohnenden Aktinie. - Veröff. Inst. Meeresforsch. Bremerhaven 12, 169-230.

Riemann-Zürneck, K, 1973. Actiniaria des Südwestatlantik. I. Hormathiidae. - Helgoländer wiss. Meeresunters. 15, 273-325.

Riemann-Zürneck, K., 1975a. Actiniaria des Südwestatlantik. II. Sagartiidae und Metridiidae. Helgoländer wiss. Meeresunters. 27, 70-95.

Riemann-Zürneck, K., 1975b. Actiniaria des Südwestatlantik. III. Calliactis androgyna sp. n. (Hormathiidae). - Veröff. Inst. Meeresforsch. Bremerhaven 15, 387-395.

Riemann-Zürneck, K., 1976. A new type of larval development in the Actiniaria: Giant Larvae. Morphological and ecological aspects of larval development in Actinostola spetsbergensis. In: Coelenterate ecology and behavior. Ed. by G. O. Mackie. Plenum Press, New York, 355-364.

Riemann-Zürneck, K., 1978. Actiniaria des Südwestatlantik. IV. Actinostola crassicornis (Hertwig 1882) mit einer Diskussion verwandter Arten. - Veröff. Inst. Meeresforsch. Bremerhaven 17, $65-85$.

Riemann-Zürneck, K., 1979. Two disc-shaped deep-sea Anthozoa from the Gulf of Biscay, with a survey of adaptation types in the Actiniaria. - Zoomorphologie 93, 227-243.

Riemann-Zürneck, K., 1980. Actiniaria des Südwestatlantik. V. Bolocera, Isotealia, Isosicyonis (Actiniidae), - Mitt. hamb. zool. Mus. Inst. 77, 19-33.

Ross, A. \& Newman, W. A., 1969. Cirripedia. In: Distribution of selected groups of marine invertebrates in waters south of $35^{\circ} \mathrm{S}$ latitude. Ed. by J. W. Hedgpeth. Am. Geogr. Soc., New York, 30-32 (Antarct. Map Folio Ser. 11).

Rowe, G. T. \& Menzies, R. J., 1969. Zonation of large benthic invertebrates in the deep-sea off the Carolinas. - Deep Sea Res. 16, 531-537.

Sassaman, C. \& Mangum, C., 1970. Patterns of temperature adaptation in North American coastal actinians. - Mar, Biol. 7, 123-130.

Scelzo, M. A., 1973. Lista de los crustaceos decapodos Anomura obtenidos en 1966 por el expedicion "Walther Herwig" en el Atlantico sur y depositados en las colecciones del Instituto de biologia marina. - Physis, B. Aires (A) 32, 161-174.

Schemainda, R., 1980. Ergebnisse ozeanologischer Untersuchungen mit dem FFS "Ernst Haeckel" im Konvergenzgebiet von Brasil- und Falklandstrom im Juni/Juli 1978. - Beitr. Meeresk. 44-45, $109-121$

Schlenz, E. \& Belem, M. J., 1982. Primeira ocurrencia de um Discosomatidae no Brasil (Anthozoa, Corallimorpharia) com a redescricao de Discosoma carlgreni (Watzl, 1922). - Revta bras. Zool. S. Paulo 1,11-21.

Schmidt, H., 1974, On evolution in the Anthozoa. In: Proceedings of second international symposium on coral reefs. Ed. by A. E. Cameron \& M. Campbell. The Great Barrier Reef Comm., Brisbane, $1,533-560$.

Schmidt, H. \& Zissler, D., 1979. Die Spermien der Anthozoen und ihre phylogenetische Bedeutung. - Zoologica, Stuttg. 44 (129), 1-96.

Schöne, R, 1974. Cephalopoden des Südwestatlantik. Dipl-Arb., Univ. Hamburg, 137 pp.

Schott, G., 1942. Geographie des Atlantischen Ozeans. Boysen, Hamburg, 438 pp.

Sebens, K. P. \& Paine, R. T., 1979. Biogeography of anthozoans along the west coast of South America: Habitat, disturbance, and prey availability. In: Proceedings of the international symposium on marine biogeography and evolution of the S. Hemisphere 1, 219-237 (N.Z. DSIR Inf. Ser. 137).

Semenov, V. N., 1977. Biogeographical latitudinal-zonal nomenclature of coastal marine biota. Oceanology 17, 90-96.

Semenov, V. N., 1978. Geographical distribution of benthos on the south American shelf as a function of the distribution of coastal waters. - Oceanology 18, 90-96.

Semenov, V. N. \& Berman, I. S., 1977. Biogeographic aspects of the distribution and dynamics of water masses off the South American coast. - Oceanology 17, 710-718. 
Servicio de Hidrografia Naval, 1974. Sedimentologia de la plataforma continental Argentina. Texturas. - Publ. Serv. Hidrografia Naval, B. Aires H. 669 (1), 24 Kt.

Shoup, C. S., 1932. Salinity of the medium and its effects on respiration in the sea anemone. Ecology 13, 81-85.

Shuntov, V. P., Kirlan, D. F., Batytskaya, L. V., Glebova, S. Y. \& Kolesova, N. G., 1982. Geographical distribution of sea birds in connection with zonality of oceanological environments in the southern ocean. - Sov. J. mar. Biol. 7, 342-350.

Sievers, H. A. \& Nowlin, W. D., 1984. The stratification and water masses at Drake Passage. J. geophys. Res. $89(\mathrm{C} 6), 10,489-10,514$.

Silva, S. \& Neshyba, S., 1977. Corrientes superficiales frente la costa austral de Chile. - Cienc. Tecnol. mar. Valparaiso 3, 37-41.

Soule, D. F. \& Soule, J. D., 1979. Marine zoogeography and evolution of Bryozoa in the southern hemisphere. In: Proceedings of the international symposium on marine biogeography and evolution of the S. Hemisphere 1,43-82 (N.Z. DSIR Inf. Ser. 137).

Squires, D. F. 1969. Scleractinia. In: Distribution of selected groups of marine invertebrates in waters south of $35^{\circ} \mathrm{S}$ latitude. Ed, by J. W. Hedgpeth. Am. Geogr. Soc. New York, 15-18 (Antarct. Map Folio Ser. 11).

Stehmann, M. \& Lenz, W, 1972. Ergebnisse der Forschungsreisen des FFS "Waither Herwig" nach Südamerika XXVI. Systematik und Verbreitung der Artengruppe Seriolella punctata (Schneider, 1801) sowie taxonomische Bemerkungen zu Hyperoglyphe (Osteichthyae Stromateoidei, Centrolophidae). - Arch. FischWiss. 23, 197-201.

Stephenson, T. A., 1918. Coelenterata. Pt. 1: Actiniaria. -- Br. Antarct. Terra Nova Exped. 1910 (Zool.) 5, 1-68.

Stuardo, J., 1964. Distribucion de los moluscos marinos litorales en Latinoamerica. - Boin Inst. biol. mar. Univ. nac., B. Aires 7, 79-91.

Studer, T., 1879. Zweite Abteilung der Anthozoa polyactinia, welche während der Reise S.M.S. Corvette "Gazelle" um die Erde gesammelt wurden. - Mber K. Akad. Wiss. Berlin 1878, 542-550.

Sverdrup, H. U., 1933. On vertical circulation in the ocean due to the action of the wind with application to conditions within the antarctic circumpolar current. - Discovery Rep. 7, 139-170.

Sverdrup, H. U., Johnson, M. W. \& Fleming, R. H., 1942. The oceans. Prentice Hall, New York, $1087 \mathrm{pp}$.

Taft, B. A., 1963. Distribution of salinity and dissolved oxygen in surfaces of uniform potential specific volume in the South Atlantic, South Pacific and Indian Ocean. - J. mar. Res. 21, 129-146.

Thiel, M. E., 1935. Die Besiedlung des südatlantischen Ozeans mit Hydromedusen. - Wiss. Ergebn. dt. atlant. Exped. "Meteor" 12, 32-100.

Tommasi, L. R., 1965. Faunistic provinces of the western South Atlantic littoral region (summary). Anais Acad. bras. Cienc. 37 (Suppl.), 261-262.

Torti, M. R. \& Boschi, E. E., 1973. Nuevos aportes al conocimiento de los crustaceos decapodos Caridea del genero Campylonotus Bate, 1888. - Physis, B. Aires (A) 32, 65-84.

Totton, A. K. \& Bargman, H. E., 1965. A synopsis of the Siphonophora. British Museum (Nat. Hist.), London, $230 \mathrm{pp}$.

Vanucci, M., 1964. Zoogeografia marinha do Brasil. - Boln Inst. biol. mar. Univ, nac., B. Aires 7, $113-121$.

Vasquez, H., Retamales, P. B. \& Rojas, M. C., 1980. Consideraciones biogeograficas y ecologicas de equinodermos arquibentonicos de Chile central (con excepcion de Crinoidea). - Bolm Inst. oceanogr., S. Paulo 29, 37-39.

Vaz-Ferreira, R., 1965. Ecologia terrestre y marina des los Pinnipedios del Atlantico sudoccidental. - Anaís Acad. bras. Cienc. 37, 279-382.

Wittstock, R. \& Zenk, W., 1983. Some current observations and surface T/S distribution from the Scotia Sea and the Bransfield Strait during early austral summer 1980/81. - Meteor Forsch. Ergebn. (A/B) 24, 77-86.

Wooster, W. S. \& Gilmartin, M., 1961. The Peru-Chile undercurrent. - J. mar. Res. 19, 97-120.

Wüst, G., 1957. Stromgeschwindigkeiten und Strommengen in den Tiefen des Atlantischen Ozeans. - Wiss. Ergebn. dt. atlant. Exped. "Meteor" 6 (1), 261-420. 
Wüst, G. 1965. Water masses and circulation in the western South Atlantic. - Anais Acad. bras. Cienc. 37, 87-91.

Wüst, G. \& Defant, A., 1936. Atlas zur Schichtung und Zirkulation des Atlantischen Ozeans. - Wiss. Ergebn. dt. atlant. Exped. "Meteor", 6.

Zamponi, M. O., 1976. Emendation to family Sideractiidae Danielssen 1890 (Anthozoa: Corallimorpharia) with the creation of Sphincteractis sanmatiensis gen, et sp. nov, - Physis, B. Aires (A) 35, $127-133$.

Zamponi, M. O., 1982. Algunas larvas pelagicas de Anthozoa (Coelenterata). - Neotropica 28, $171-182$.

Zenk, W., 1981. Detection of overflow events in the Shag Rock Passage, Scotia Ridge. - Science, N.Y. 213, 1113-1114.

Zyryanov, V. N. \& Severov, D. N., 1979. Water circulation in the Falkland-Patagonia region and its seasonal variation. - Oceanology 19, 518-522. 